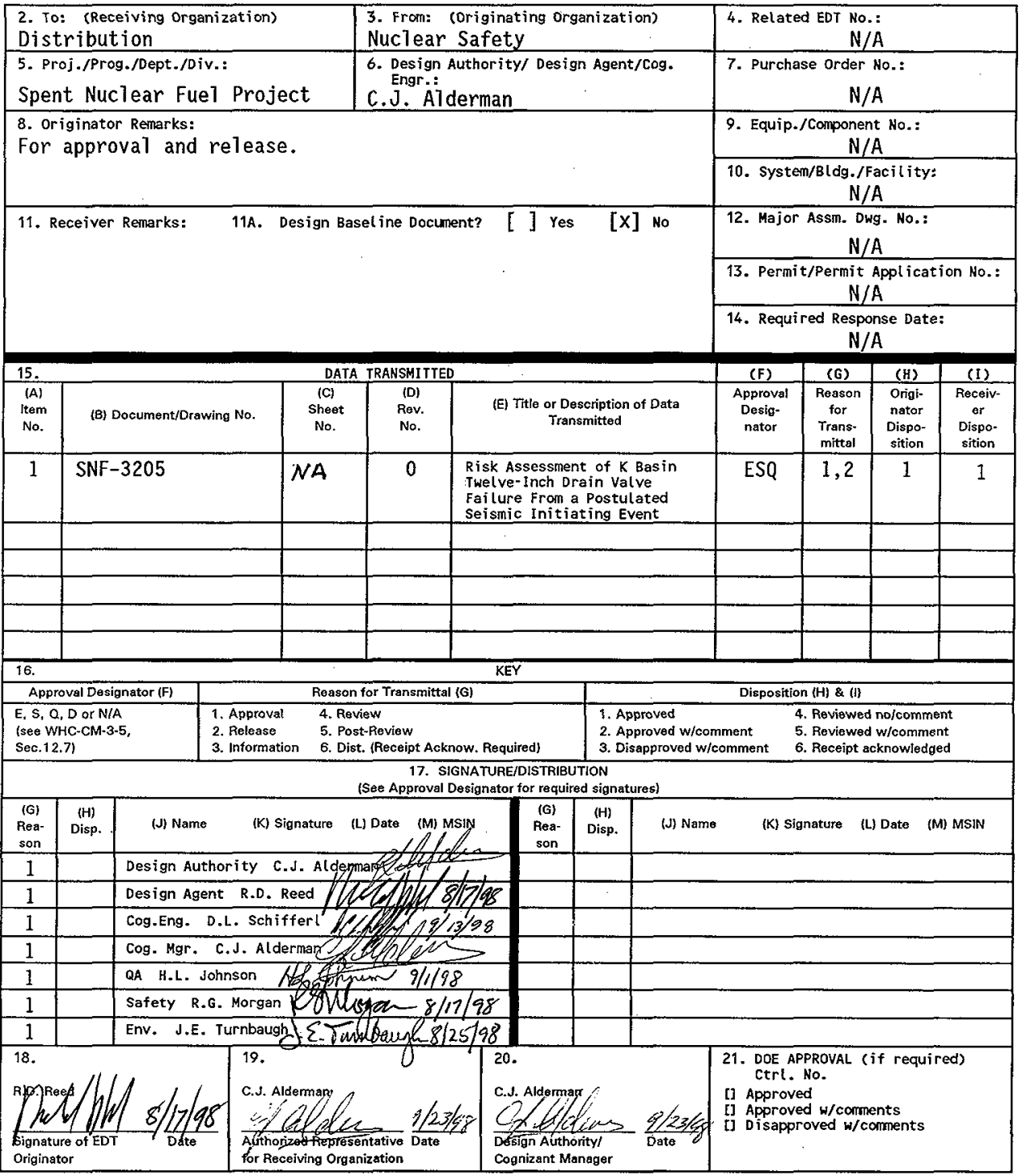

BD-7400-172-2(05/96) GEF097 


\title{
Risk Assessment of K Basin Twelve-Inch Drain Valve Failure From a Postulated Seismic Initiating Event
}

\author{
R.G. Morgan, R.D. Reed*
}

DE\&S Hanford, Inc. (DESH), Richland, WA 99352

U.S. Department of Energy Contract DE-AC06-96RL13200

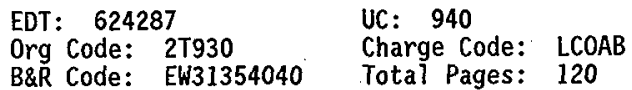

Key Words: Twelve-Inch, Drain Valve, K Basin, Seismic

Abstract: This document identifies the risks of leakage from the $K$ Basins twelve-inch drain valves due to objects potentially being distodged and falling on the valves during seismic events.

* MACTEC Technical Services Company, Richland, Washington

TRADEMARK DISCLAIMER. Reference herein to any specific comercial product, process, or service by trade name, trademark, manufacturer, or otherwise, does not necessarily constitute or imply its endorsement, recommendation, or favoring by the United states Government or any agency thereof or its contractors or subcontractors.

Printed in the United States of America. To obtain copies of this document, contact: Document Control Services, P.O. Box 950, Mailstop H6-08, Richland WA 99352, Phone (509) 372-2420;

Fax (509) 376-4989.

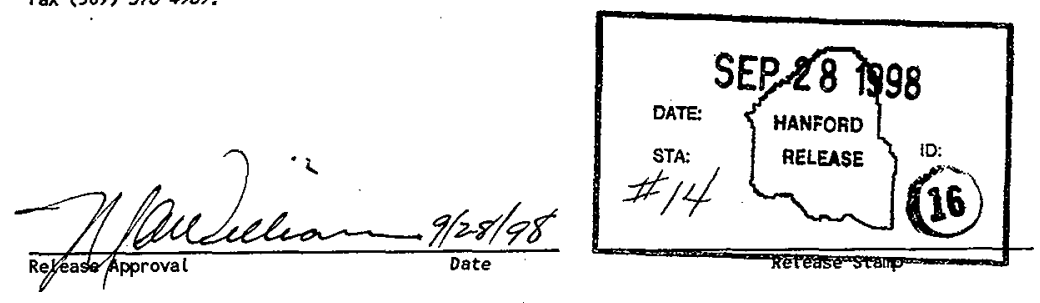


August 12, 1998

Mr. Ron Reed

Fluor Daniel Hanford

Post Office Box 1000 R3-11

Richland, Washington 99352

\section{SUBJECT: DE\&S HANFORD PURCHASE ORDER MRB-SLB-A06272 - LINE ITEM 18 - TRANSMITTAL OF REPORT}

Dear Ron:

Attached please an unbound copy of ARES Report 984519-001; Rev. 2, Risk Assessment of $K$ Basin Twelve-Inch Drain Valve Failure from a Postulated Seismic Initiating Event. All comments received from Michael Golay have been incorporated into this revision.

Thank you for the opportunity to complete this work. If you have any questions, please contact me at 946-3300.

Sincerely,

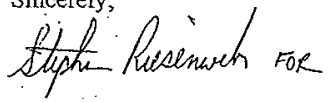

Robert L. Fritz, Vice President and

Manager, Richland Operation

\section{RLF/lci}

Attachments - as stated

cc: Robert Morgan (via fax, w/o attachment)

Ron Butler (via fax, w/o attachment) 


\title{
RISK ASSESSMENT OF K BASIN TWELVE-INCH DRAIN VALVE FAILURE FROM A POSTULATED SEISMIC INITIATING EVENT
}

\author{
prepared for
}

DE\&S Hanford, Inc.

Purchase Order MRB-SLB-A06272

Line Item 18

Report No. 984519-001

Revision 2

SNF-3205, Rev. 0

August 10, 1998

prepared by

\section{ARES CORPORATION}

636 Jadwin Avenue Suite B

Richland, Washington 99352 


\title{
RISK ASSESSMENT OF K BASIN TWELVE-INCH DRAIN VALVE FAILURE FROM A POSTULATED SEISMIC INITIATING EVENT
}

\author{
prepared for
}

DE\&S Hanford, Inc.

Purchase Order MRB-SLB-A06272

Line Item 18

Report No. 984519-001

Revision 2

SNF-3205, Rev. 0

August 10, 1998

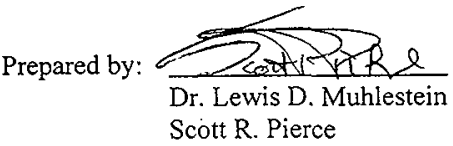

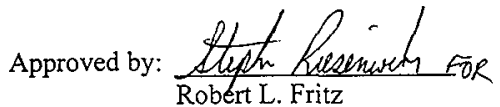

Date:

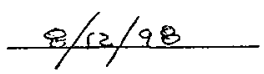




\section{EXECUTIVE SUMMARY AND BRIEFING}

Three twelve-inch drain valves are located along the north wall in the main $\mathrm{K}$ Basin bays. Visual observations suggest that only the valve's bonnet and stem are exposed above the basin concrete floor. If the drain valve bonnet or stem were damaged during a seismic event, the damaged valve could provide a potential leak path that drains the basin and exposes the basin fuel.

The objectives of this analysis are to: 1) evaluate the risk of damaging one or more of the twelveinch drain valves from a seismic initiating event, and 2) determine the associated potential leak rate from a damaged valve. The analysis process is a risk-based uncertainty analysis where each variable is represented using available information and engineering judgement. The uncertainty associated with each variable is represented by a probability distribution, with the uncertainty propagated through the analysis using Monte Carlo convolution techniques. The results are developed as probability distributions and expressed in terms of a corresponding risk curve.

The likelihood of a seismic event causing an object to damage a twelve-inch drain valve is reasonably small (an expected value of $1 \times 10^{-4}$ per year with a 95 percent confidence level). Further, the frequency of drain valve damage as a result of a seismic event is smaller than the frequency of $\mathrm{K}$ Basin concrete damage which may also result from a seismic event.

Combining the expected frequency of the twelve-inch drain valve damage with the likelihood of exceeding a leak rate, provides an expected frequency of exceeding an initial leak rate. For example, there is an expected frequency of $1 \times 10^{-5}$ per year (with a 95 percent confidence) of exceeding an initial leak rate of 400 gallons per minute for one damaged drain valve. With multiple damaged drain valves, the expected frequency of exceeding an initial leak rate is less than $1 \times 10^{-6}$ per year. The analysis determines that the expected frequency of exceeding an initial leak rate is very small for reasonable initial leak rates. 


\section{TABLE OF CONTENTS}

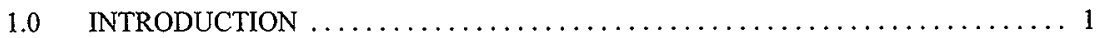

2.0 RISK-BASED UNCERTAINTY ANALYSIS $\ldots \ldots \ldots \ldots \ldots \ldots \ldots \ldots \ldots \ldots \ldots$

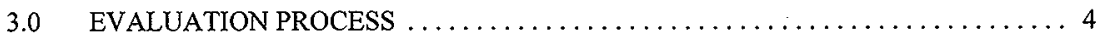

4.0 DESCRIPTION OF K BASINS AND DRAIN VALVE LOCATIONS $\ldots \ldots \ldots \ldots \ldots 8$

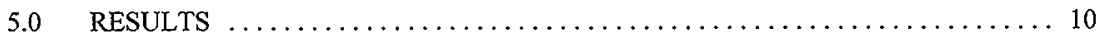

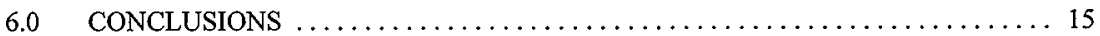

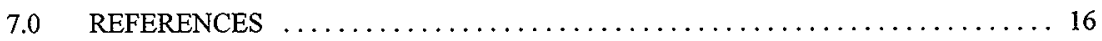

\section{APPENDICES}

Appendix A

Identification of $\mathrm{K}$ Basin Structures Relative To

Twelve-Inch Drain Valve Locations $\ldots \ldots \ldots \ldots \ldots \ldots \ldots \ldots \ldots \ldots \ldots \ldots \ldots \ldots \ldots$

Appendix B

Seismic Initiating Event Frequency

Appendix C

Probability of Objects Striking the Twelve-Inch Drain Valves

Appendix D

K Basin Twelve-Inch Drain Valve Damage States $\ldots \ldots \ldots \ldots \ldots \ldots \ldots \ldots \ldots \ldots \ldots \ldots$

Appendix E

Twelve-Inch Drain Valve Risk Assessment Analysis and Results Appendix F

Validation of Analysis Models 


\section{FIGURES}

Figure 1. Schematic of Risk-Based Uncertainty Analysis. . . . . . . . . . . . . . . . 4

Figure 2. Logic Flow Diagram for the Analysis Process. .................... 5

Figure 3. Root Branch of a Seismic Sequence Event Tree. . . . . . . . . . . . . . . . . 7

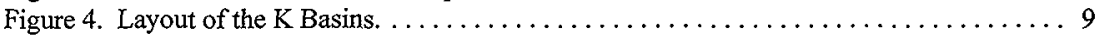

Figure 5. Representation of the Twelve-Inch Drain Valve. . . . . . . . . . . . . . . . 10

Figure 6. Complementary Cumulative Distribution Functions for Frequency of Drain Valve Damage. ........................................ 11

Figure 7. Cumulative Distribution Functions for the Consequences of the Initial Flow Rate.

\section{TABLES}

Table 1. Summary of the Frequency per Year of Valve Damage. $\ldots \ldots \ldots \ldots \ldots \ldots \ldots \ldots$

Table 2. Summary of the Results for the Two Distributions. ................... 14

Table 3. Expected Frequency of Exceeding an Initial Flow Rate for One, Two and Three Damaged Drain Valves. 
RISK ASSESSMENT OF K BASIN TWELVE-INCH DRAIN VALVE FAILURE

Report No. 984519-001, Rev. 2

SNF-3205, Rev. 0

FROM A POSTULATED SEISMIC INITIATING EVENT

\section{ACRONYMS}

CCDF Complementary Cumulative Distribution Function

$\mathrm{CDF}$

Cumulative Distribution Function

CSB

Canister Storage Building

NRC

U.S. Nuclear Regulatory Commission

PDF

Probability Density Function

PGA Peak Ground Acceleration

SNF Spent Nuclear Fuel 


\subsection{INTRODUCTION}

The Spent Nuclear Fuel (SNF) Project will transfer metallic SNF from the Hanford 105 K-East and $105 \mathrm{~K}$-West Basins to safe interim storage in the Canister Storage Building in the 200 Area. The initial basis for design, fabrication, installation, and operation of the fuel removal systems was that the basin leak rates which could result from a postulated accident condition would not be excessive relative to reasonable recovery operations. However, an additional potential $\mathrm{K}$ Basin water leak path is through the $\mathrm{K}$ Basin drain valves. Three twelve-inch drain valves are located in the main basin bays along the north wall. The sumps containing the valves are filled with concrete which covers the drain valve body. Visual observations suggest that only the valve's bonnet and stem are exposed above the basin concrete floor. It was recognized, however, that damage of the drain valve bonnet or stem during a seismic initiating event could provide a potential $\mathrm{K}$ Basin water leak path.

The objectives of this activity are to: 1) evaluate the risk of damaging the three twelve-inch drain valves located along the north wall of the main basin from a seismic initiating event, and 2) determine the associated potential leak rate from a damaged valve.

The analysis process is a risk-based uncertainty analysis where each variable is modeled using available information and engineering judgement. The uncertainty associated with each variable is represented by a probability distribution (probability density function). Uncertainty exists because of the inherent randomness associated with the distribution of values that a variable may assume, and because of a lack of knowledge concerning a variable. Engineering judgement and technical information are used to develop the variable probability density functions, but the bounds of the probability density function are based on physical limitations. The uncertainty, described by probability distributions, is propagated through the analysis by Monte Carlo convolution techniques. The corresponding results are developed as a probability distribution and expressed in terms of the corresponding complementary cumulative distribution function ("risk curve").

A risk assessment using uncertainty analysis is well suited in to evaluating the damage a seismic vent might cause to the drain valves. There is a lack of information relative to precisely how objects might strike the valve if dislodged during a seismic event, where the objects might strike the valve, the impact energy that may be imparted to the valve, the response of the valve to the impact energy, the strain energy that may be required for valve damage, the amount of corrosion the valves may have experienced, and the corresponding valve damage that provides a flow area through the valve for a water leak. Even if the above information was entirely available, an analysis that considered these items would be lengthy to perform and would yield results that were difficult to interpret. 
On the other hand, an uncertainty analysis can provide very good results in the form of a risk curve even with incomplete information. To be effective, however, the uncertainty analysis must be completed at a relatively high level so that the analysis is not encumbered with details. This means identifying the range of contributing events that lead to valve damage. The uncertainty distributions used for each variable must be represented by realistic and physical bounds. The median value of the distribution must be generated using the best available engineering judgement. By using realistic distributions to represent both the randomness of variables and the lack of information, the exact details become less important.

The following sections provide summaries of: 1) background information relative to risk-based uncertainty analysis, 2) a description of the twelve-inch drain valve locations and supporting information relative to the $\mathrm{K}$ Basins, 3 ) the evaluation process, and 4) the results. Technical details and specific analyses required to support the information provided in the main sections of this document are provided in Appendix A (K Basin Structures and Twelve-Inch Drain Valve Location), Appendix B (Seismic Initiating Event), Appendix C (Probability of Objects Striking the Twelve-Inch Drain Valve), Appendix D (Twelve-Inch Drain Valve Damage States), and Appendix E (Analysis and Results). Validation and independent verification of the models are provided in Appendix F.

\subsection{RISK-BASED UNCERTAINTY ANALYSIS}

The conventional concept of risk is defined by the triplet questions (Kaplan and Garrick 1981):

What can go wrong?

How likely is it to happen?

If it does happen, what are the consequences?

What can go wrong is defined by a complete set of events, $\left\{\mathrm{E}_{\mathrm{j}}\right\}$. The likelihood of each event is defined by either the event probability or the event frequency, $P_{j}$ or $f_{j}$. The consequence of the event is defined by $\mathrm{C}_{\mathrm{j}}$. The risk is defined by the complete set of triplets;

$$
R \equiv\left\{\left[E_{j}, P_{j}, C_{j}\right]\right\}
$$

The "risk curve" for the complete set of triplets given in Equation 1 is the complementary cumulative distribution function of the event probabilities (or frequencies) as a function of the event consequences. The risk curve provides the probability (or frequency) of exceeding a specific consequence (exceedance probability or exceedance frequency), and the area under the 
risk curve is the total risk.

The process that will be used to evaluate the risk of drain valve damage is depicted in Figure 1. Uncertainty associated with each variable in the risk assessment will be represented by a probability density function. As noted earlier, engineering judgement and technical information are used to develop the variable probability density functions, but the limits of the probability density function (the edges of the function) are based on physical and realistic information. The uncertainty associated with each variable is propagated through an appropriate risk assessment model using Monte Carlo convolution techniques with a Latin Hypercube sampling process. The Latin Hypercube sampling process provides a better definition of the tails of the probability density functions. The results of the analysis are a probability distribution. The exceedance curve is the complementary cumulative distribution function of the probability density function. The area under the exceedance curve represents the total probability, or expected value.

A major step in the risk assessment is to develop models that quantify the frequency and consequence of drain valve damage. Development of the appropriate models $[Y=f(a, b, c, \ldots)$ in Figure 1] will be discussed later. 


\section{Risk Can Be Evaluated By Uncertainty Analysis}

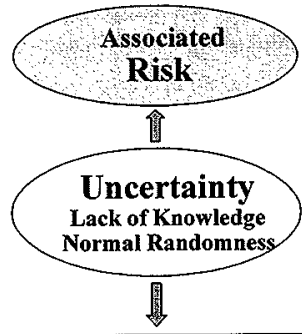

\section{Uncertainty Represented by pdfs for Each Variable}

复

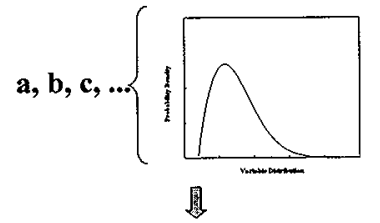

Propagate Uncertainty by Monte Carlo Convolution Techniques
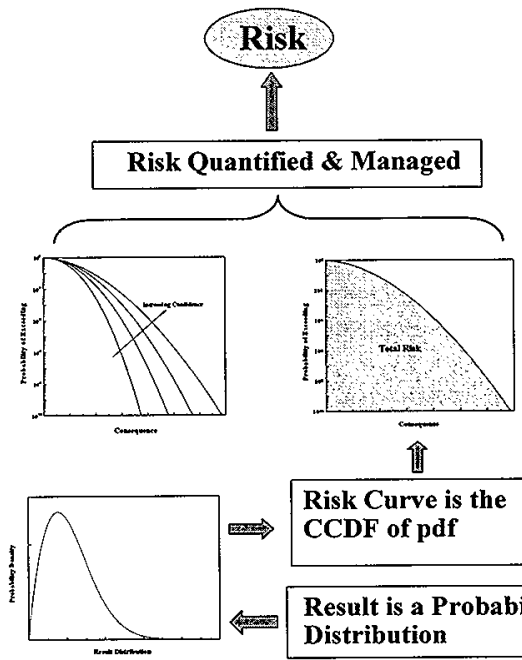
$\Rightarrow$ CCDF of pdf 4

Result is a Probability Distribution $\mathrm{Y}=\mathrm{f}(\mathrm{a}, \mathrm{b}, \mathrm{c}, \ldots . .$.

Figure 1. Schematic of Risk-Based Uncertainty Analysis.

\subsection{EVALUATION PROCESS}

The evaluation process had three principle objectives. As depicted in Figure 2, each objective involved performing several steps. In the following paragraphs, each step is discussed and explained. For this analysis the objectives were; first, to define the set of sequence events that could lead to drain valve damage $\left\{E_{j}\right\}$, from a seismic initiating event (Step 1 in the logic flow diagram of Figure 2); then to quantify the frequency of drain valve damage, $\mathrm{f}$, for each event sequence (Step 2); and finally to determine the potential consequences, $\mathrm{C}_{\mathrm{j}}$, of drain valve damage for each event sequence (Step 3). 


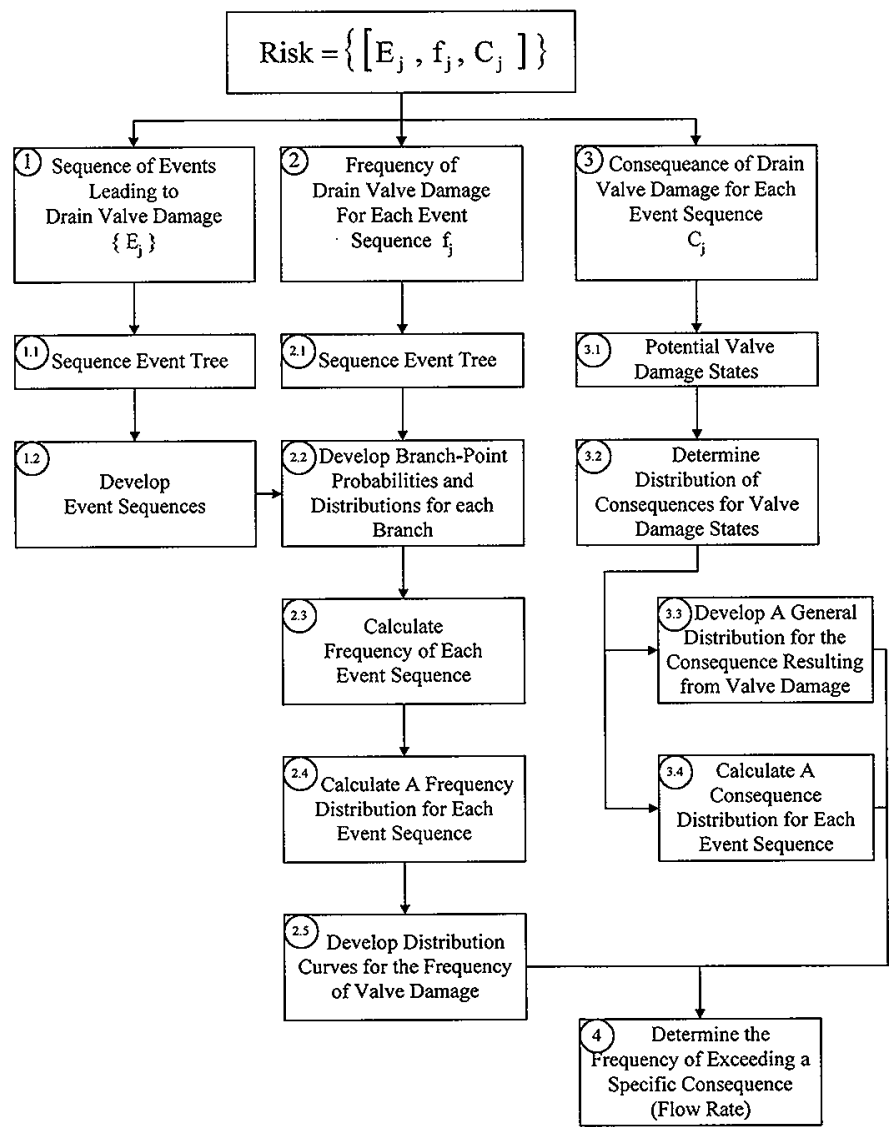

Figure 2. Logic Flow Diagram for the Analysis Process. 


\section{Step 1}

The set of sequence events that could lead to drain valve damage given that a seismic event occurs, $\left\{\mathrm{E}_{\mathrm{j}}\right\}$, is identified using a sequence event tree (Step 1.1). The sequence event tree, developed in Appendix E, identifies logical sequences of events that may occur from the initiating event (a seismic event) to an event where debris may strike the twelve-inch drain valve. The sequence event tree is developed in sufficient detail (Step 1.2) to be able to quantify each sequence event frequency and associated consequence.

\section{Step 2}

The sequence event tree is also used as a tool to quantify the frequency for each sequence event (Step 2.1). An initiating event frequency is determined for the sequence event tree or for each main trunk of the sequence event tree. For this analysis the initiating event which may lead to postulated damage of the $\mathrm{K}$ Basin twelve-inch drain valves is a seismic event. A branch-point probability and probability distribution are developed for each branch in the sequence event tree (Step 2.2). The initiating event frequency and the branch-point probabilities along each branch of the sequence event tree are multiplied to determine the event frequency (Step 2.3) or the frequency distribution for each event sequence (Step 2.4) (see Appendix E for details).

The evaluation of the sequence event frequency considers the likelihood that a seismic event occurs, the likelihood of structural members and debris being dislodged by the seismic event, the likelihood that the dislodged structural members and debris are near the drain valve, and the likelihood that the structural members and debris would hit the drain valve. The frequency of drain valve damage is expressed by the likelihood that specific frequencies will be exceeded. The distribution of sequence event frequencies is evaluated to obtain a 5 th percentile, 50 th percentile, and a 95th percentile exceedance frequency curve (Step 2.5).

Appendix B evaluates the probability that a seismic event will cause a structural failure and lead to an object striking the drain valve. The initiating event frequency is determined by considering a simplified sequence event tree given in Figure 3. The frequency of structural failure, given that an initiating seismic event occurs (the product $f_{i} P_{1}$ in Figure 3 ) is determined by integrating the derivative of the Hanford site seismic hazard curves with the structure fragility curves over all peak ground accelerations (see Appendix B for details). 


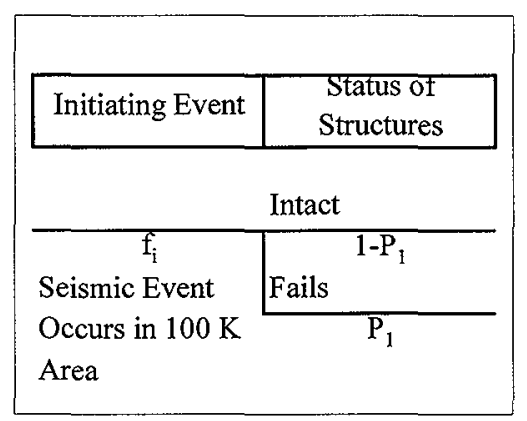

Figure 3. Root Branch of a Seismic Sequence Event Tree.

\section{Step 3}

The consequences of drain valve damage from a seismic initiating event are considered using two different viewpoints. The first viewpoint considers that structural members or debris that may be dislodged from the $\mathrm{K}$ Basin structure by a seismic event. The events of the sequence event tree are followed to where eventually the structural members or debris strike the twelve-inch drain valve. The energy imparted to the drain valve, the response of the valve to the impact energy, and the strain energy required for valve damage is considered. However, such an evaluation does not provide information regarding the corresponding flow area through the valve for a water leak. As noted earlier, only the valve's bonnet and stem are exposed above the basin concrete floor. The remaining parts of the valve are encased in concrete. Consequently, any structural member or debris that may impact the valve will only impact the bonnet or stem. Therefore, it is less likely that the remainder of the valve will be significantly damaged from an impact.

The second viewpoint focuses on an evaluation of the physical description of the twelve-inch drain valve and considers what parts of the drain valve could be damaged. Physical valve damage states were defined (Step 3.1) and an equivalent hydraulic area was determined for each damage state in order to evaluate potential leak rates. A distribution for the equivalent circular hydraulic area was developed by considering the valve damage states and their likelihood of occurrence (Step 3.2) (see Appendix D for details). 
Given the damage states and the equivalent hydraulic area leak area, the initial leak rate is calculated by extrapolating data (Parsons 1998) for the initial leak rate as a function of the equivalent circular area.

The distribution of drain valve leak rates, assuming the valve was damaged, was determined from two perspectives. Each perspective used the same cumulative distribution function that was developed for the equivalent circular area of a damaged drain valve (see Appendix D). The first perspective directly used the cumulative distribution function to develop a distribution for the probability of exceeding an initial leak rate (Step 3.3). This perspective did not consider the individual events of the model. The second perspective propagated the cumulative distribution function through each branch of the sequence event tree, thereby considering the model's individual events (Step 3.4).

The analysis determined: 1) a frequency distribution that the twelve-inch drain valve may be damaged by a seismic event, and 2) given that the twelve-inch drain valve may be damaged, a distribution of the possible leak rate. Consequently, the results are initially provided as two distributions; first, a frequency distribution that identifies the likelihood that the drain valve may be damaged by a seismic event, and, second, given that the drain valve may be damaged, a distribution for the likely leak rate. The event frequency and consequence distributions for potential drain valve damage states were correlated to provide an overall frequency of exceeding a specific consequence (an initial leak rate, see Appendix E, Step 4).

\subsection{DESCRIPTION OF K BASINS AND DRAIN VALVE LOCATIONS}

The sketch of the $\mathrm{K}$ Basins showing the five pits, the fuel storage basin, and the location of the three twelve-inch drain valves located near the north wall of the Basin is provided in Figure 4. Appendix A provides some detailed schematics taken from $\mathrm{K}$ Basin drawings that identify structures that are located near and above the twelve-inch drain valves. Also, provided in Appendix A is a list of these structures, including descriptions and weights of each.

A sketch of the $\mathrm{K}$ Basin twelve-inch drain valve is shown in Figure 5. This figure shows the internal parts of the valve, and the approximate depth to which the valve is immersed in concrete. 


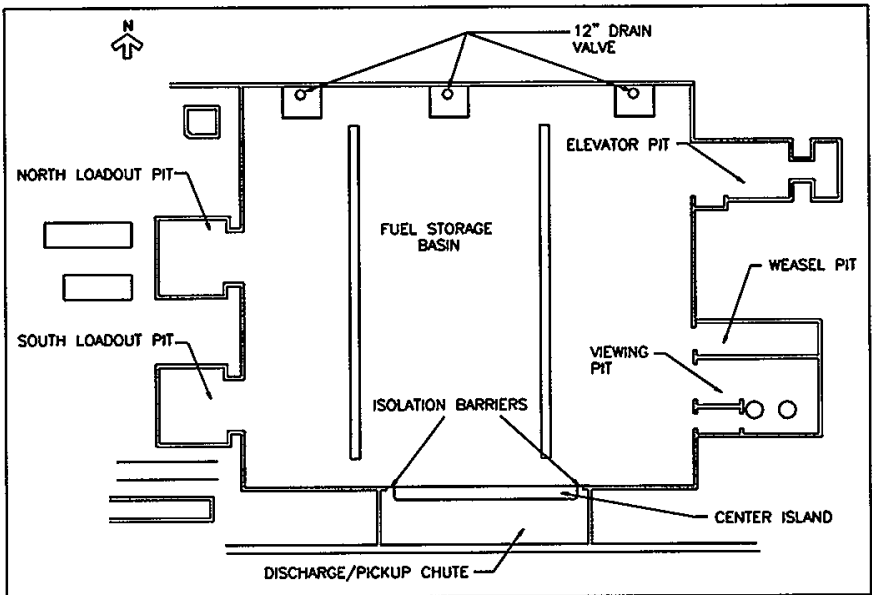

Figure 4. Layout of the $K$ Basins. 


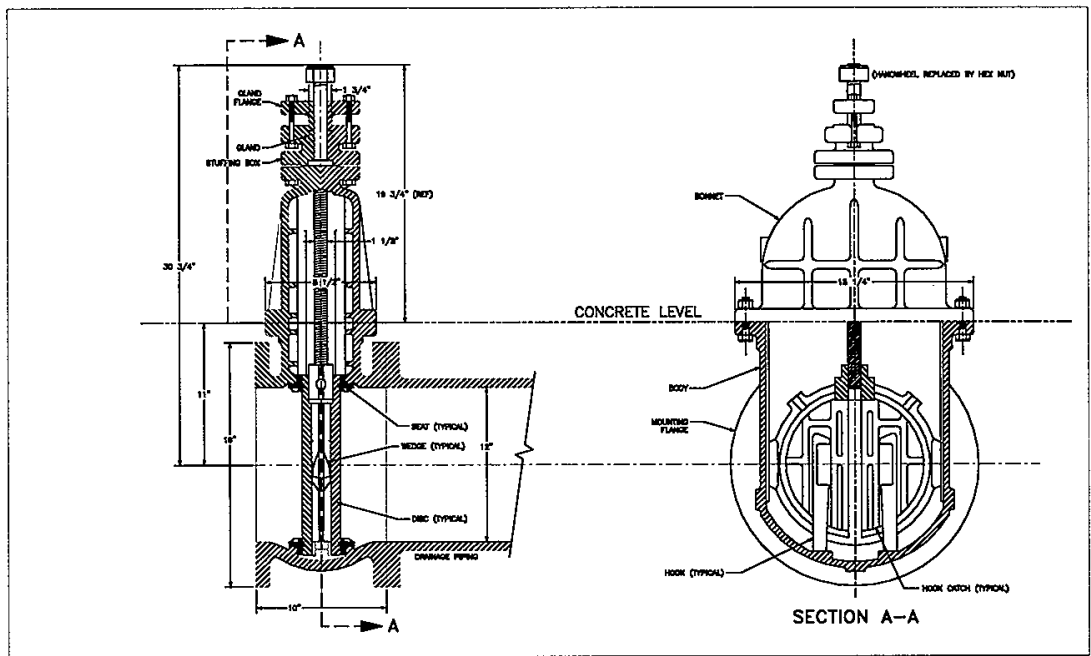

Figure 5. Representation of the Twelve-Inch Drain Valve.

\subsection{RESULTS}

The sequence event trees were quantified in Appendix $E$ by representing each of the branch-point probabilities by a lognormal probability density function. The parameters used to define each lognormal probability density functions are provided in Appendix E. The solution to the sequence event tree provides a frequency distribution representing whether a seismic event will damage a twelve-inch valve, and the corresponding consequences (initial leak rate) which could occur if the valve were damaged.

Each of the event sequences in the sequence event tree in Appendix E describes a different path that could lead to drain valve damage. Combining all the paths, the frequency of valve damage can be considered as a distribution of the probability of exceeding a frequency of valve damage. As discussed in Appendix E, this distribution can be characterized by 5 th, 50 th, and 95 th percentiles for the frequency of valve damage as presented in Figure 6 . The event sequences with the largest frequencies are those events involving the canister racks, the grating, and the 
combination of grating and super structure, respectively.

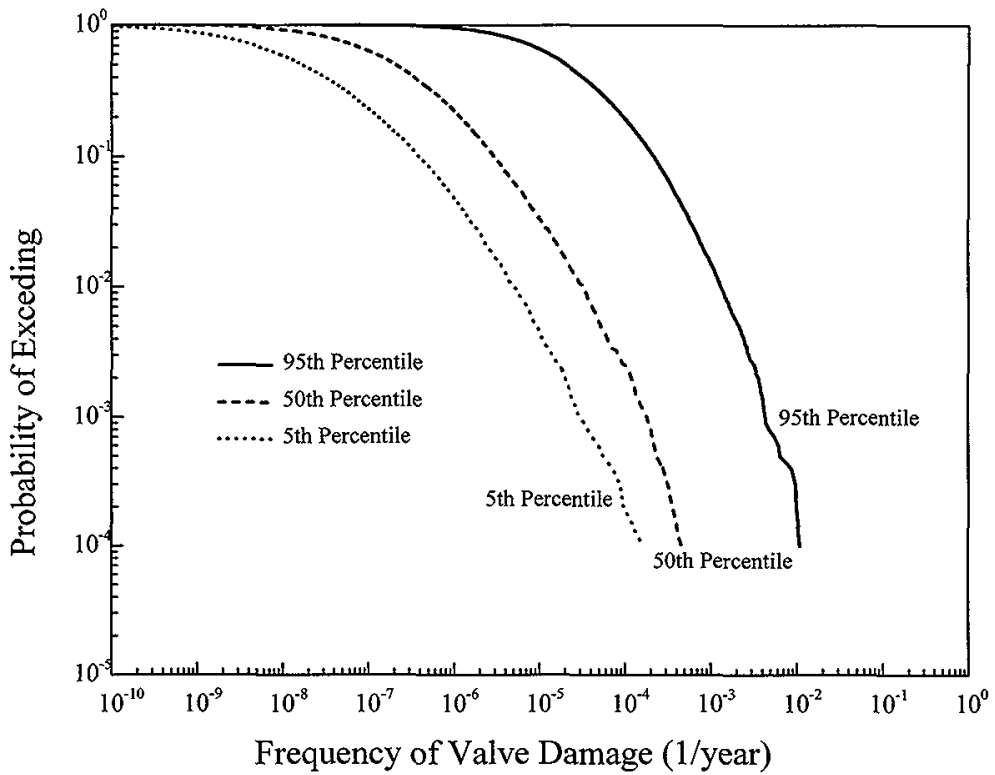

Figure 6. Complementary Cumulative Distribution Functions for Frequency of Drain Valve Damage.

The results of Figure 6 can be summarized as seen in Table 1. The left-hand column of percentiles (50th, 80th, 90th and 95th) represents the probability that the frequency of valve damage is less than the value stated in the table for a specific confidence level identified by the row of percentiles (5th, 50th and 95th). For example, the expected frequency of valve failure is $1 \times 10^{-4}$ at a probability of 0.8 and a confidence level of 95 percent. Likewise, there is a probability of 0.5 that the frequency of valve damage is less than $2 \times 10^{-5}$ per year at the same confidence level. 
Table 1. Summary of the Frequency per Year of Valve Damage.

\begin{tabular}{|c|c|c|c|}
\hline \multirow{2}{*}{$\begin{array}{c}\text { Probability in terms } \\
\text { of Percentile }\end{array}$} & \multicolumn{3}{|c|}{ Distribution for the Frequency per Year of Valve Damage } \\
\cline { 2 - 4 } & 5 th Percentile & 50 th Percentile & 95 th Percentile \\
\hline 50 th & $2 \times 10^{-8}$ & $2 \times 10^{-7}$ & $2 \times 10^{-5}$ \\
\hline 80 th & $1 \times 10^{-7}$ & $1 \times 10^{-6}$ & $1 \times 10^{-4}$ \\
\hline 90 th & $4 \times 10^{-7}$ & $3 \times 10^{-6}$ & $2 \times 10^{-4}$ \\
\hline 95 th & $9 \times 10^{-7}$ & $7 \times 10^{-6}$ & $4 \times 10^{-4}$ \\
\hline Expected Value & $3 \times 10^{-7}$ & $2 \times 10^{-6}$ & $1 \times 10^{-4}$ \\
\hline
\end{tabular}

The results of consequence (initial leak rates) were also developed. These results were expressed as cumulative distribution functions for the initial leak rate. The cumulative distribution function provides the likelihood (or probability) that the initial leak rate will be less than a specified value (the probability of not exceeding). Figure 7 provides these results as the probability of not exceeding an initial leak rate. The results were determined using two perspectives. The smooth curve in Figure 7 assumes that any potential valve damage has the same distribution for the initial leak rate. The discrete data points in Figure 7 are from the second perspective where the event frequencies and corresponding consequences were rank ordered and the frequencies were cumulative summed (see Appendix E, Kaplan and Garrick 1981). Both curves in Figure 7 are nearly identical thereby inferring the chosen methodology does not bias the results. 


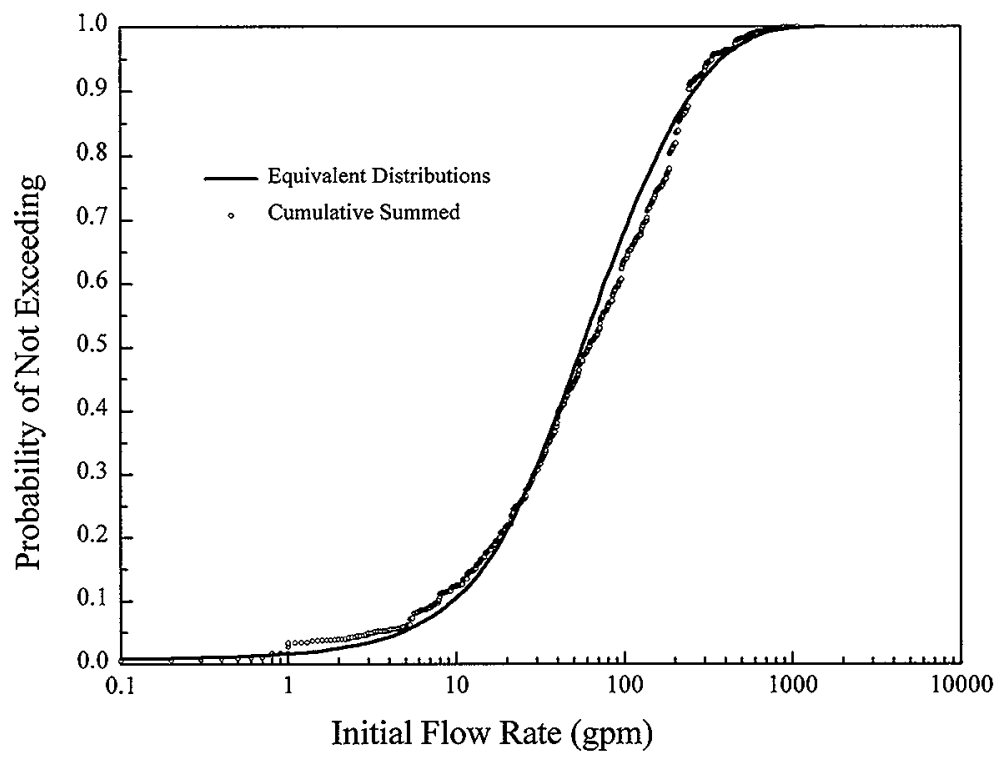

Figure 7. Cumulative Distribution Functions for the Consequences of the Initial Flow Rate.

The results in Figure 7 are summarized in Table 2 for both distributions; the likelihood that the drain valve may be damaged by a seismic event, and given that the drain valve may be damaged, the likely leak rate. Table 2 provides the median value, expected value, and the 95 th percentile for the distribution that represents the likelihood that the drain valve may be damaged by a seismic event (in terms of the 5th, 50th, and 95 th percentiles). Table 2 also provides the median value, expected value, and the 95th percentile of the initial leak rate given that the drain valve is damaged. For example, the expected value of the 50 th percentile of the valve damage frequency is $2 \times 10^{-6}$ per year. The expected value of the initial flow rate is $107 \mathrm{gpm}$. Table 2 also provides the 95 th percentile for the valve damage frequency and the initial flow rate. This value is 
interpreted, for example, that there is a probability of 0.95 that the 50 th percentile of the valve damage frequency is less than $7 \times 10^{-6}$ per year; and there is a probability of 0.95 that the initial flow rate is less than $390 \mathrm{gpm}$.

Table 2. Summary of the Results for the Two Distributions.

\begin{tabular}{|l|c|c|c||c|}
\hline \multirow{2}{*}{} & \multicolumn{3}{|c|}{$\begin{array}{l}\text { Likelihood That The Drain Valve May } \\
\text { Be Damaged By A Seismic Event }\end{array}$} & \multirow{2}{*}{$\begin{array}{c}\text { Given That The Drain Valve } \\
\text { May Be Damaged, } \\
\text { the Likely Flow Rate (gpm) is: }\end{array}$} \\
\cline { 2 - 4 } & \multicolumn{2}{|c|}{ Frequency of Valve Damage per Year } & 95 th & \\
\cline { 2 - 4 } & 5 th & 50 th & $2 \times 10^{-5}$ & 56 \\
\hline Median & $2 \times 10^{-8}$ & $2 \times 10^{-7}$ & 107 \\
\hline $\begin{array}{l}\text { Expected Value } \\
\text { or Average }\end{array}$ & $3 \times 10^{-7}$ & $2 \times 10^{-6}$ & $1 \times 10^{-4}$ & 107 \\
\hline 95 th & $9 \times 10^{-7}$ & $7 \times 10^{-6}$ & $4 \times 10^{-4}$ & 390 \\
\hline
\end{tabular}

From the results in Table 2, one concludes that for a single twelve-inch drain valve, the likelihood that the drain valve may be damaged by a seismic event is reasonably small, an expected value of $2 \times 10^{-6}$ per year, and certainly less than $7 \times 10^{-6}$ per year. Given that a twelve-inch drain valve is damaged, the corresponding consequences, in terms of an initial flow rate, are also reasonably small; an expected value of $107 \mathrm{gpm}$, and certainly less than $400 \mathrm{gpm}$.

One may combine the separate results for the frequency per year of drain valve damage in Figure 6 and the data provided in Figure 7 for the likelihood of an initial leak rate. This is accomplished by combining the expected frequency of valve damage with each probability of exceeding an initial leak rate. The results are the expected frequency per year of exceeding an initial leak rate in gallons per minute (see Appendix $\mathrm{E}$ for details).

Three twelve-inch drain valves are in the main basin bays along the north wall. These valves could fail in various combinations yielding differing consequences. It is possible that only one valve could be damaged during a seismic event. It is also possible that two valves or even three valves could be damaged by the same seismic event. Using the methodology presented in Appendix $\mathrm{D}$, the $5 \mathrm{th}, 50 \mathrm{th}$, and 95 th percentile of the expected frequency of exceeding an initial flow rate for the damage of one, two and three twelve-inch drain valves are presented in Table 3. 


\section{Table 3. Expected Frequency of Exceeding an Initial Flow Rate for One, Two and Three Damaged Drain Valves.}

\begin{tabular}{|c|c|c|c|c|}
\hline $\begin{array}{c}\text { Number of Drain Valves } \\
\text { Damaged }\end{array}$ & \multicolumn{3}{|c|}{95 th Percentile of the Expected Frequency } & $\begin{array}{c}\text { Initial Flow Rate of } \\
(\mathrm{gpm})\end{array}$ \\
\hline & 5 th & 50 th & 95 th & \\
\hline \multirow{3}{*}{1} & $6 \times 10^{-7}$ & $3 \times 10^{-6}$ & $2 \times 10^{-4}$ & Flow Rate $\geq 50$ \\
\hline & $3 \times 10^{-7}$ & $2 \times 10^{-6}$ & $9 \times 10^{-5}$ & Flow Rate $\geq 100$ \\
\hline & $2 \times 10^{-7}$ & $9 \times 10^{-7}$ & $3 \times 10^{-5}$ & Flow Rate $\geq 200$ \\
\hline & $9 \times 10^{-8}$ & $6 \times 10^{-7}$ & $2 \times 10^{-5}$ & Flow Rate $\geq 300$ \\
\hline & $3 \times 10^{-8}$ & $3 \times 10^{-7}$ & $2 \times 10^{-5}$ & Flow Rate $\geq 400$ \\
\hline & $6 \times 10^{-9}$ & $3 \times 10^{-8}$ & $2 \times 10^{-6}$ & Flow Rate $\geq 800$ \\
\hline 2 & $<1 \times 10^{-6}$ & $<1 \times 10^{-6}$ & $<1 \times 10^{-6}$ & All Flow Rates \\
\hline 3 & $<1 \times 10^{-6}$ & $<1 \times 10^{-6}$ & $<1 \times 10^{-6}$ & All Flow Rates \\
\hline
\end{tabular}

\subsection{CONCLUSIONS}

Combining the expected frequency of the twelve-inch drain valve damage with the likelihood of exceeding an initial leak rate, provides an expected frequency of exceeding an initial leak rate. For example, at the 50th confidence level, the frequency of exceeding an initial leak rate of 800 gallons per minute for one damaged drain valve is $3 \times 10^{-8}$ per year. With multiple damaged drain valves the expected frequency of exceeding an initial leak rate decreases rapidly as the product of small numbers, while the initial leak rate increases as the sum of the individual drain valve leak rates. Consequently, there is an expected frequency of less than $1 \times 10^{-6}$ per year that the flow rate will be appreciable for two or three drain valves damaged. In the limit there is a very small expected frequency that the initial leak rate would exceed 1980 gallons per minute (the very conservative initial leak rate shown in Appendix D). 


\subsection{REFERENCES}

Parsons 1998, K-Basins Drain Valve Leak Rate Analysis, Parsons Infrastructure and Technology Group, Inc., Richland, WA.

Cloud, R. L., 1980, Seismic Performance of Piping In Past Earthquakes, Robert L. Cloud Associates, Inc., presented at the Specialty Conference on Civil Engineering and Nuclear Power, Knoxville, TN.

Crane 1960, Valves and Fittings, Catalog No. 60, Crane Company, Chicago, IL.

Crane 1988, Flow of Fluids, Crane Technical Paper No. 410, Crane Company, Chicago, IL.

Crane 1997, Dimensional Data Report, CVNO Report No. DD-071, Rev. 0, Crane Nuclear Operations, Bolingbrook, IL.

Frier, W. A., 1998, System Description - Structures Systems, HNF-1904, Rev. 0, Duke Engineering and Services Hanford, Richland, WA.

Ha, N. D., 1996, 105-KE /KW Irradiated Fuel Storage Basin Seismic Qualifications, WHC-SD-N031-SA-002, Rev. 0-A, ICF Kaiser, Richland, WA.

Hanford 1997, Guidelines for Assessing the Seismic Adequacy of Existing Performance Category Equipment at the Hanford Site, HNF-SD-GN-DGS-30006, Rev. 2.

Hyde, L. L., 1996, Structural Evaluation of K Basin Fuel Canister Storage Racks, WHC-SD-SNF-DA-006, Rev. 0, ICF Kaiser Engineers, Hanford, Richland, WA

Kanjilal, S. K., 1997, Seismic Qualification of $105 \mathrm{~K}$ Basin Superstructure Using 0.12g Earthquake Ground Acceleration, HNF-SD-SNF-SA-004, Rev. 0, Fluor Daniel Northwest, Richland, WA.

Kaplan, S. and Garrick, J. B., On The Quantitative Definition of Risk, Risk Analysis, Vol. 1, No. 1, pp. 11-27.

Kennedy, R. P., et al., 1980, Probabilistic Seismic Study of an Existing Nuclear Power Plant, Nuclear Engineering and Design, Vol. 59. 
Lindeburg, M.R., 1997, Mechanical Engineering Reference Manual, Professional Publications, Belmont, CA.

National Academy of Sciences, 1973, The Great Alaska Earthquake of 1964, National Academy of Sciences, Washington, D.C.

NRC 1985., Handbook of Nuclear Power Plant Seismic Fragilities, NUREG/CR-3558, U.S. Nuclear Regulatory Commission, Washington, D.C.

Roberson, J. A., and Crowe, C. T., 1980, Engineering Fluid Mechanics, Houghton Mifflin Co., Boston, MA.

Schifferl, D. L., 1998, Summary of Phase 1 Task Completion 105 D Basin Floor Drain Valves, HNF-2222, Rev. 0, Duke Engineering and Services Hanford, Richland, WA.

Tallman, A. M., 1996, Probabilistic Seismic Hazard Analysis, DOE Hanford Site, Washington, WHC-SD-W236A-TI-002, Rev. 1, Westinghouse Hanford Company, Richland, WA.

Winkel, B. V., 1991, 105-KE / 105-KW Irradiated Fuel Storage Basins Seismic Qualification, WHC-SD-NR-SA-024, Rev. 0, Westinghouse Hanford Company, Richland, WA. 
RISK ASSESSMENT OF K BASIN TwELVE-INCH DRAIN VALVE FAILURE

From A PoSTULATED SEISMIC INITIATING EVENT
Report No. 984519-001, Rev. 2

SNF-3205, Rev. 0 August 10, 1998

\section{Appendix A}

Identification of K Basin Structures Relative

To the Twelve-Inch Drain Valve Locations 


\section{A.1 INTRODUCTION}

During a seismic event, some objects in and over the $\mathrm{K}$ Basins may fall and impact the twelveinch drain valves located along the basins' north wall. This appendix describes those objects and their proximity to the valves.

\section{A.2 DISCUSSION}

Objects that could impact the valves are located both above and beside the valves. Based on a review of $\mathrm{K}$ Basin drawings and a visual inspection of the basins, the objects were catalogued and grouped according to the object's proximity to the valves. Four groups were defined:

Group 1: Objects on the floor of the basin such as the canister storage racks.

Group 2: Objects located between the basin floor and the water level. Examples include the recirculation and skimmer piping.

Group 3: Objects at or near the height of the grating. Such objects included the monorails and the grating panels.

Group 4: Objects located within the roof structure. This included structural beams and trusses.

Table A-1 provides examples of items the analysis considered. Figure A-1 through A-5 show typical locations of the items and their proximity to the valves. Both the table and the figures show typical items and typical locations; the exact arrangement above and around each valve varied between the three valves and between the two basins. For example, the recirculation piping system is below the water in the K-West Basin and above the water in the K-East Basin. The table and figures were developed from Winkel (1991), Hyde (1996), Frier (1998), and a review of $\mathrm{K}$ Basin drawings.

After dividing the items of Table A-1 into the above groups, the analysis determined what generic events might lead to valve damage. The analysis then determined the frequency with which each event might occur. Treating each group of events separately, the analysis determined the overall frequency with which the valves might be damaged. Since each group used generic events rather than all possible events, each generalized event represents a distribution of possible outcomes. 
RISK ASSESSMENT OF K BASIN TWELVE-INCH DRAIN VALVE FAILURE

Report No. 984519-001, Rev. 2

From A POSTULATED SEISMIC INITIATING EVENT

Table A-1. Examples of Objects That Might Fall Onto or Might Impact the 12-Inch Valves.

\begin{tabular}{|l|c|}
\hline \multicolumn{1}{|c|}{ Item } & $\begin{array}{c}\text { Approx. } \\
\text { Weight (lbs.) }\end{array}$ \\
\hline Monorail Hoist & 350 \\
\hline Monorail Load & 2,200 \\
\hline Floor Grating (section with approximate dimensions of 14 feet by 5 feet) & 1,000 \\
\hline Skimmer Piping (6 inch schedule 40 pipe, approximately 20 feet in length) & 400 \\
\hline Recirculation Piping (8 inch schedule 40 pipe, approximately 20 feet in length) & 600 \\
\hline Storage Rack & 500 \\
\hline Counter Weight & 1,200 \\
\hline Skimmer Assembly & 350 \\
\hline Monorail Beam (S-Shaped Beam, approximately 28 feet in length) & 500 \\
\hline Support Pipe (5 inch schedule 40 pipe, approximately 14 feet in length) & 200 \\
\hline Beam (W-Shaped Beam, approximately 28 feet in length) & 600 \\
\hline Truscan Bar Joist (14 feet in length) & 300 \\
\hline Truss & 1,100 \\
\hline Roof Panel (14 feet by 5 feet section of concrete, metal and asbestos) & 2,000 \\
\hline
\end{tabular}


RISK ASSESSMENT OF K BASIN TWELVE-INCH DRAIN VALVE FAILURE From A Postulated SEISMiC INITIATING EVENT
Report No. 984519-001, Rev. 2

SNF-3205, Rev. 0

August 10, 1998

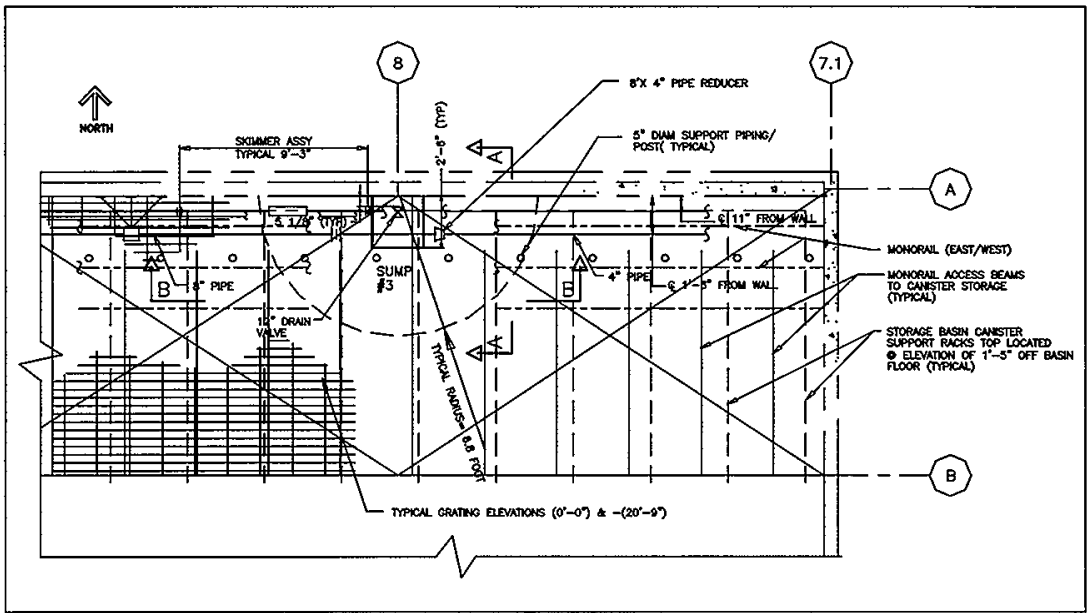

Figure A-1. Typical Valve Location as Seen from Above. 


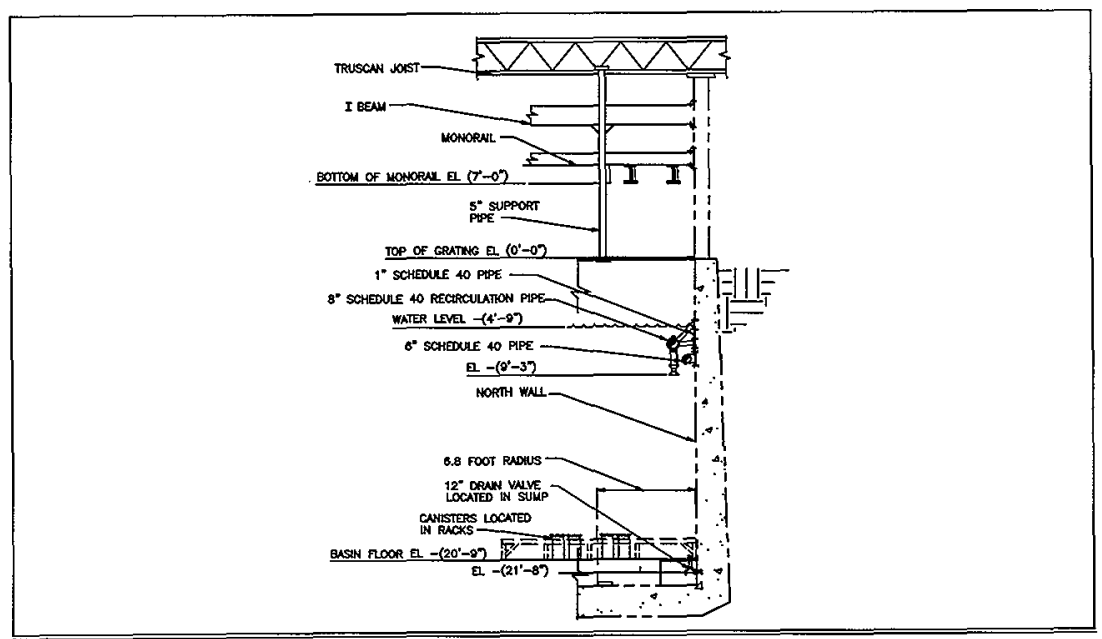

Figure A-2. Typical Valve Location as Seen From the Side. 


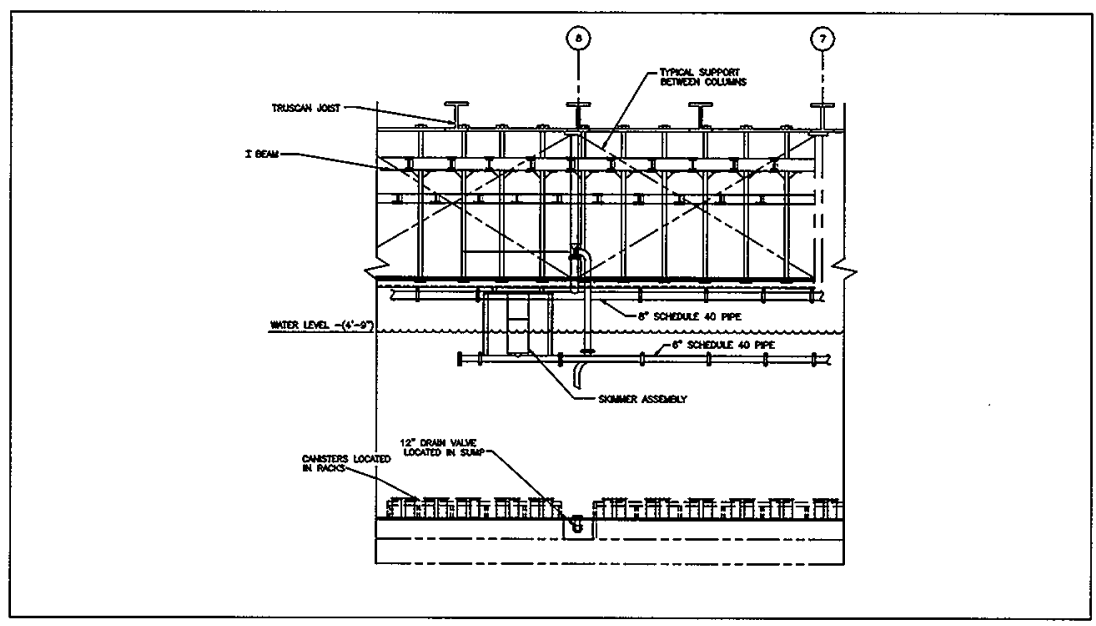

Figure A-3. Typical Valve Location as Seen From the Basin. 


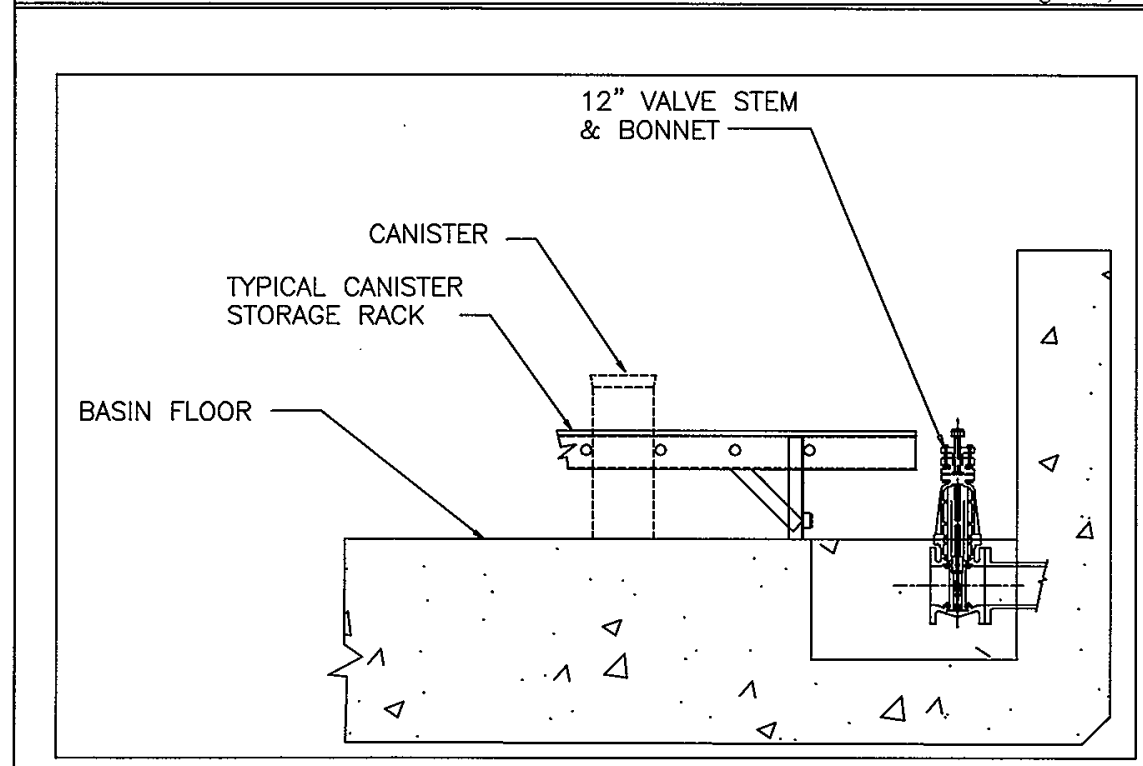

Figure A-4. Typical Locations of Valve and Canister Storage Racks as Seen from the Side. 


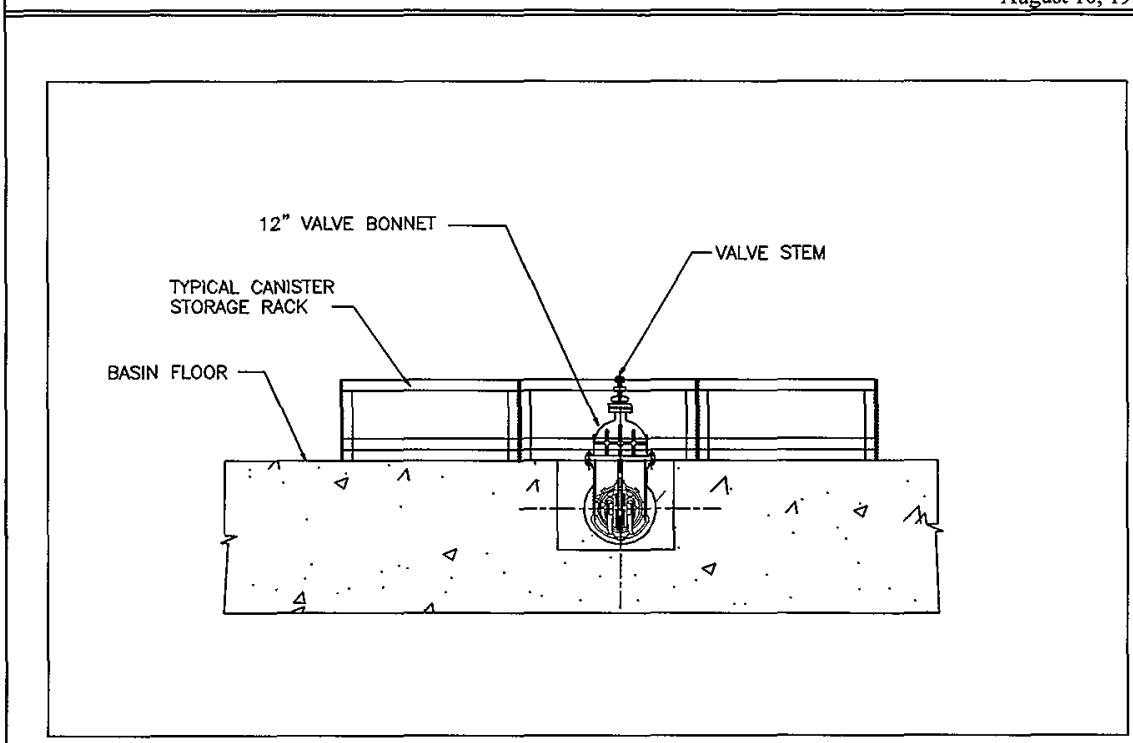

Figure A-5. Typical Locations of Valve and Canister Storage Racks as Seen from the Basin (Canisters not Shown). 
RISK ASSESSMENT OF K BASIN TWELVE-INCH DRAIN VALVE FAILURE

FROM A POSTULATED SEISMIC INITIATING EVENT
Report No. 984519-001, Rev. 2 SNF-3205, Rev. 0 August 10, 1998

\section{Appendix B \\ Seismic Initiating Event}




\section{B.1 INTRODUCTION}

For this evaluation the initiating event leading to postulated damage of the $\mathrm{K}$ Basin twelve-inch drain valves is a seismic event. This appendix evaluates the probability of structural failure given that a seismic event occurs for the $\mathrm{K}$ Basin super structures, the $\mathrm{K}$ Basin submerged piping systems (skimmer piping system and the recirculation piping system), and $\mathrm{K} B$ Basin concrete structures. First, consider the root branch of the sequence event tree (refer to Figure B-1) where the initiating frequency is $f_{i}$ and the probability of structural failure is $P_{1}$. The frequency of structural failure, given an initiating event, is given by the product $f_{j} P_{1}$.

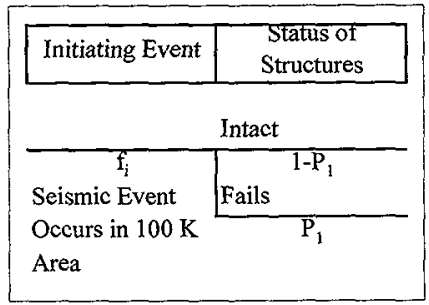

Figure B-1. Root Branch of a Seismic Sequence Event Tree.

The seismic hazard curves provide the frequency per year of exceeding a peak ground acceleration given that a seismic event occurs. That is, the seismic hazard curves are exceedance curves for the peak ground acceleration. Therefore, the seismic hazard curves do not provide the frequency of a seismic event nor the frequency of structural failure, rather the frequency of exceeding a peak ground acceleration should a seismic event occur. To obtain the frequency of structural failure (the product $f_{i} P_{1}$ in Figure B-1), given a seismic event occurs, the process pictorially represented in Figure B-2 is used which combines the seismic hazard curves and the fragility curves over all values of the peak ground acceleration (Kennedy 1980). Each contribution presented in Figure B-2 is discussed below. 
Seismic Hazard Curve

Frequency of Exceeding

a Peak Ground Acceleration

Given a Seismic Event Occurs.

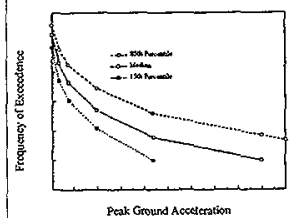

Fragility Curve

Probability of Structural

Failure as a Function

of the PGA.

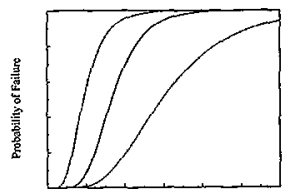

Peak Ground Acesteretion

\section{Frequency of Failure}

Conditional Frequency

of Structural Failure

Given a Seismic Event.

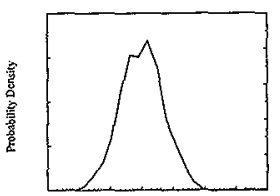

Faihus Froquency (1/yeas)

$$
\int_{\text {PGA }}\left\lfloor\begin{array}{c}
\text { Derivative of the } \\
\text { Seismic Hazard Curve }
\end{array}\right] *(\text { Fragility Curve })=\text { Fr }\left[\begin{array}{cc}
\text { Structural } & \text { Seismic } \\
\text { Failure } & \text { Event }
\end{array}\right\rfloor
$$

Figure B-2. Pictorial Representation of the Analysis Process.

\section{B.2 EVALUATION OF THE CONDITIONAL FREQUENCY OF STRUCTURAL FAILURE}

For a seismic event, the seismic hazard curves represent the frequency per year of exceeding a peak ground acceleration (PGA) given that a seismic event occurs. That is, the seismic hazard curves are the complementary cumulative distribution function of the probability density function that represents the distribution of potential values of the PGA given that a seismic event occurs. The seismic hazard curves are developed using uncertainty analysis and express the uncertainty associated with the seismic activity rate, form of attenuation, seismic spectral content, dampening effects, etc. Note that for the seismic hazard curves to be expressed in terms of an exceedance frequency the probability density function has been normalized to the number of seismic events per year rather than normalized to unity.

Let $\phi$ (a) represent the complementary cumulative distribution function of the peak ground acceleration, or the seismic hazard curve. The probability that the peak ground acceleration is between $a$ and $a+d a$ is given by;

$$
-\frac{\mathrm{d} \phi(\mathrm{a})}{\mathrm{da}}=\mathrm{g}(\mathrm{a})
$$


which is the probability density function of the distribution of the peak ground acceleration, $g(a)$.

The fragility curve of a structure, $F(a)$, characterizes the ability of the structure to resist a seismic event. The fragility curve expresses the probability of structural failure as a function of the peak ground acceleration. The fragility curve of a structure also has uncertainty which is represented by a distribution of the failure probability about a median value, and a family of curves distributed about the median value.

The integral of the derivative of the seismic hazard curve and the fragility curve represents the conditional probability of structural failure given a seismic event occurs. Mathematically the integral is expressed by;

$$
\theta=\int_{\text {all } \mathbf{a}}\left[-\frac{d \phi(a)}{d a}\right] F(a) d a
$$

If the uncertainty in the seismic hazard curve and the fragility curve are considered, then the conditional probability of structural failure given a seismic event occurs is a distribution of values given by;

$$
\theta_{i j}=\int_{\text {all } a}\left[-\frac{d \phi_{i}(a)}{d a}\right] F_{j}(a) d a
$$

where the uncertainty in the seismic hazard curve and the fragility curve is represented by a family of curves noted by the indices $i$ and $j$. For example, the indices could be used to identify seismic hazard curves for the 5,50 and 95 percentiles.

The seismic hazard curves for the Hanford $100 \mathrm{~K}$ Area have been determined (Tallman 1996) and are provided in Figure B-3. The uncertainty in the seismic hazard curves is expressed by the curves for the median (50th percentile) and the 5 th and 95 th percentiles.

The seismic hazard curves for the Hanford $100 \mathrm{~K}$ Area in Figure B-3 are reproduced in Figure B4 along with a set of normalized lognormal probability density functions (given by the solid curves) that were created to represent the data for the seismic hazard curves. The normalized lognormal probability density functions are used to facilitate the analysis using Equation B-3. 


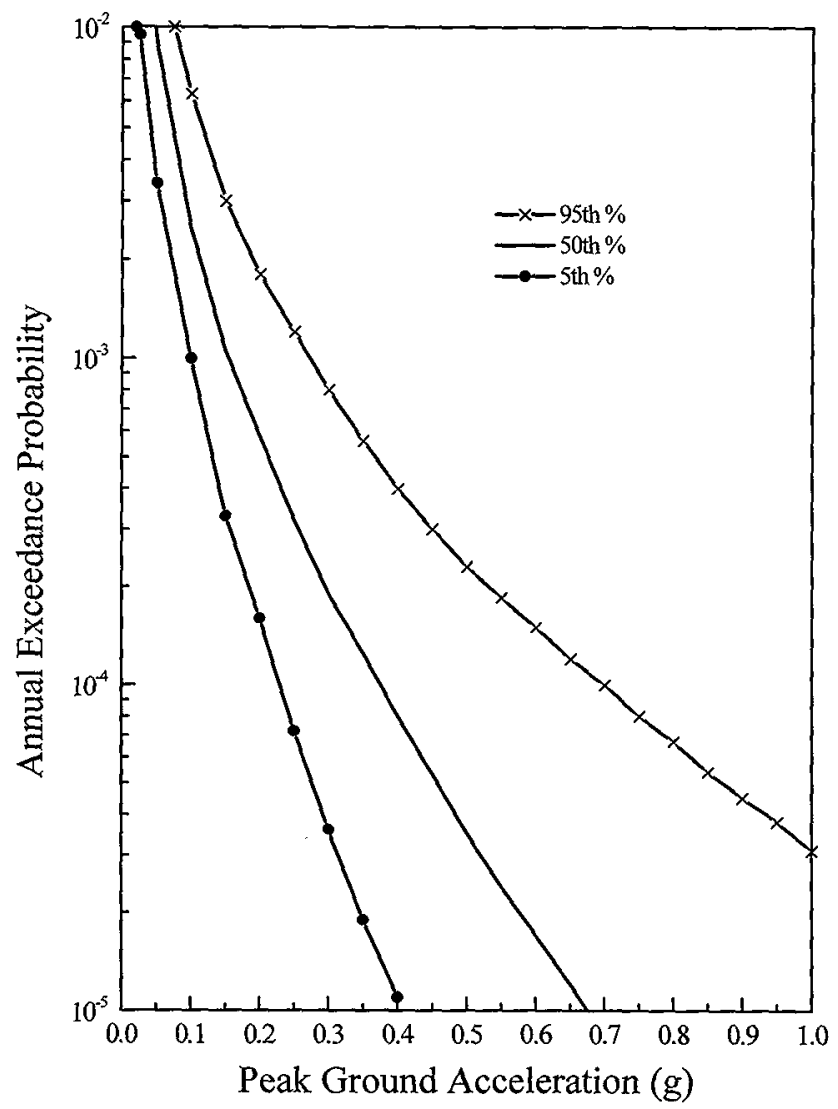

Figure B-3. Seismic Hazard Curves for the Hanford Site $100 \mathrm{~K}$ Are Shown on a Semi-Log Scale. 


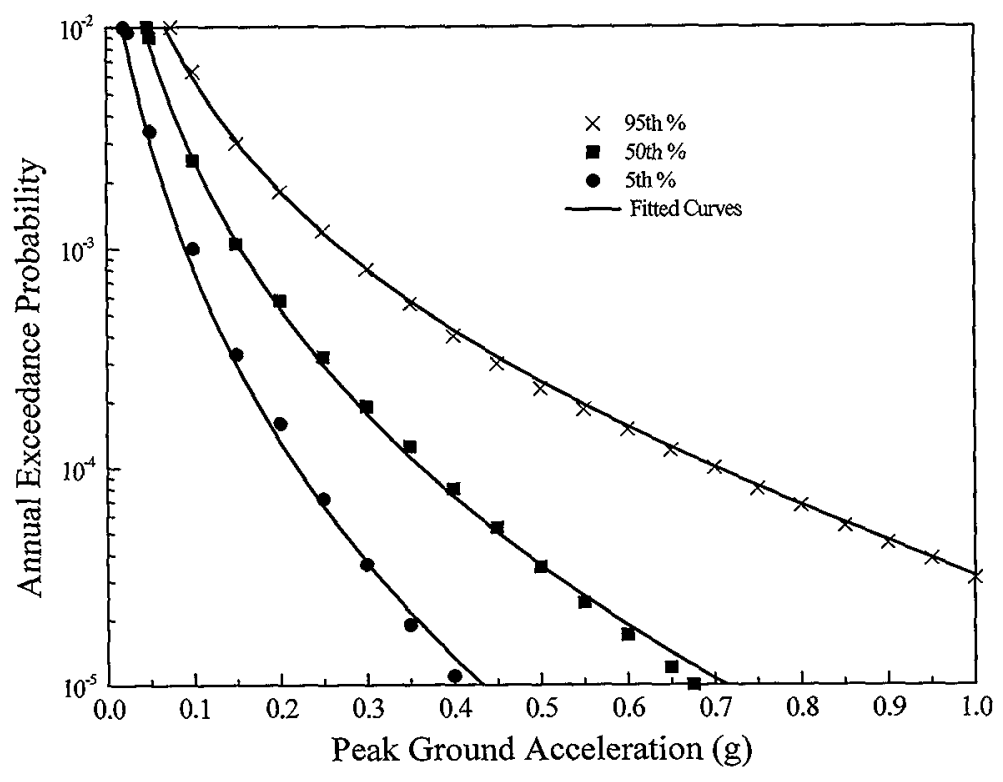

Figure B-4, Seismic Hazard Curves for the Hanford $100 \mathrm{~K}$ Area and the Associated Normalized Lognormal Probability Density Functions That Were Used to Represent the Data.

A fragility curve is expressed in terms of the structures median peak ground acceleration capacity $(\AA)$ and two random variables that represent the inherent variability about the median ground acceleration capacity and the uncertainty in the median value. It is usually assumed that the random variables are lognormally distributed with logarithmic standard deviation defined by $\beta_{\mathrm{R}}$ and $\beta_{\mathrm{U}}$ (Kennedy 1980). Thus, $\beta_{\mathrm{R}}$ represents the inherent randomness about the median peak ground acceleration, and $\beta_{U}$ represents the uncertainty in the median value. The values of $\beta_{R}$ and $\beta_{U}$ are determined by considering various safety factors of a structure. 


\section{B.3 EVALUATION OF THE CONDITIONAL FREQUENCY OF STRUCTURAL FAILURE FOR SUPER STRUCTURE}

For the $\mathrm{K}$ Basins, the median peak ground acceleration for the super structure is taken as $0.12 \mathrm{~g}$ (Kanjilal 1997) which is assumed to be the peak ground acceleration for the $\mathrm{K}$ Basin super structure design basis earthquake. While there is not sufficient information to determine $\beta_{R}$ and $\beta_{\mathrm{U}}$, there is sufficient information to consider some possible values (Kanjilal 1997). It is assumed that the $\mathrm{K}$ Basin super structure is not very resilient to a seismic event (as suggested by the low peak ground acceleration) such that the inherent randomness about the median peak ground acceleration would be quite small. Therefore, a value of $\beta_{R}=0.28$ was selected. On the other hand, the uncertainty in the median value of the peak ground acceleration should be reasonably large. Therefore a value of $\beta_{U}=0.40$ was selected. These values of $\beta_{R}$ and $\beta_{U}$ are reasonable and are typical of values used for structures which are not very resilient to a seismic event. They are also representative of the range of values suggested by the U.S. Nuclear Regulatory Commission (NRC) for developing fragility curves (NRC 1985).

However, it should be noted that because of the steep slope of the seismic hazard curves in Figure B-3 near a peak ground acceleration of $0.12 \mathrm{~g}$, the slope of the seismic hazard curves dominate the integral in Equation B-3. Thus the structural failure frequency is not very sensitive to the uncertainty associated with the fragility curves, and reasonable variations in the fragility curves will be dominated by the slope of the seismic hazard curves. Thus, the chosen values of $\beta_{\mathrm{R}}$ and $\beta_{\mathrm{U}}$ are reasonable and could vary by as much as 50 percent and not significantly change the value of the integral in Equation B-3. The intent is to obtain a reasonable fragility curve that would represent some of the known features of the $\mathrm{K}$ Basin structures. Using the values of $\AA=$ $0.12 \mathrm{~g}, \beta_{\mathrm{R}}=0.28$, and $\beta_{\mathrm{U}}=0.40$ produces the fragility curves presented in Figure B-5. 


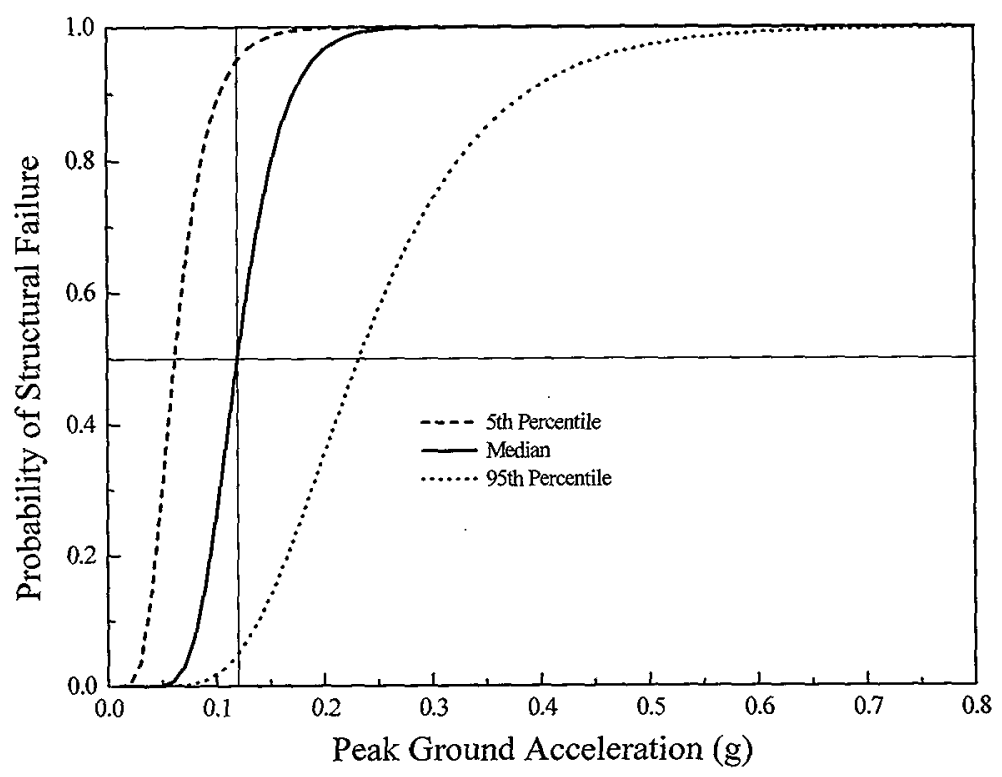

Figure B-5. Possible Fragility Curves for the K Basin Super Structure.

Using Equation B-3, the family of curves represented by the seismic hazard curves (Figure B-4) and the fragility curves shown in Figure B-5, the conditional probability of structural failure given that a seismic event occurs is calculated for the $\mathrm{K}$ Basin super structure. The complementary cumulative distribution function of the conditional probability provides the probability of exceeding a frequency of structural failure given that a seismic event occurs. The results are presented in Figure B-6 which provides the probability of exceeding a structural failure frequency (1/year). 


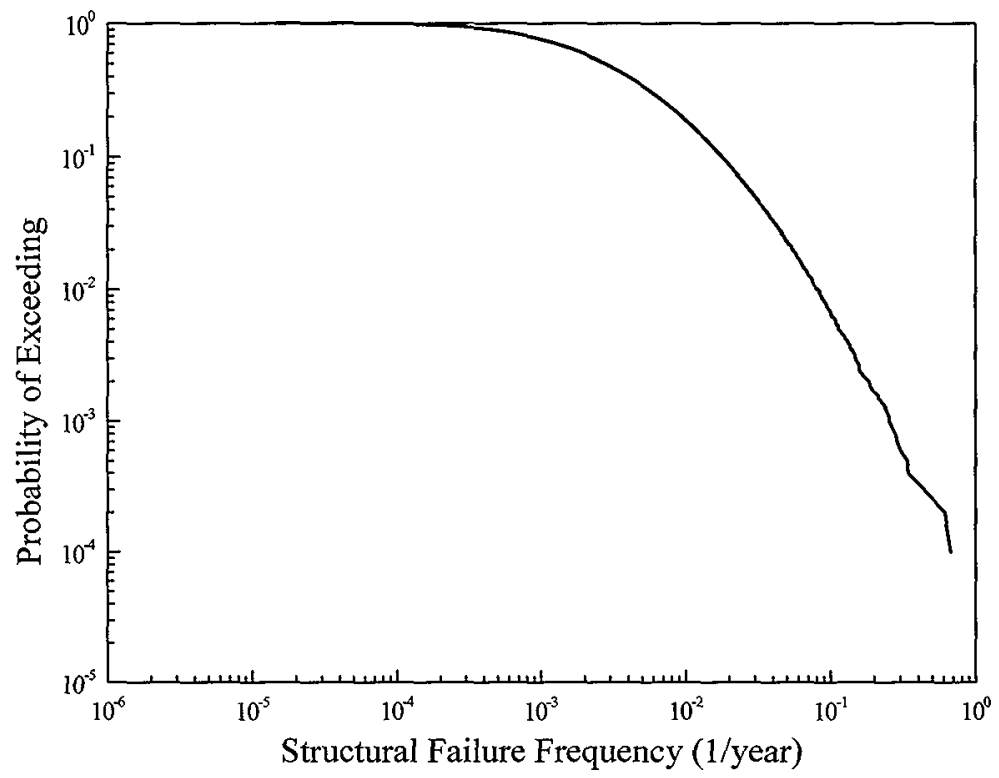

Figure B-6. Probability of Exceeding a Frequency of Structural Failure of the K Basin Super Structure Given that a Seismic Event Occurs.

\section{B.4 EVALUATION OF THE CONDITIONAL FREQUENCY OF STRUCTURAL FAILURE FOR BASIN CONCRETE STRUCTURE}

For the $\mathrm{K}$ Basin concrete structure the median peak ground acceleration is taken as $0.20 \mathrm{~g}$ (SAR 1998) which is the $K$ Basin design basis earthquake. The same values of $\beta_{R}$ and $\beta_{v}$ used for the super structure were used for the basin concrete structure. That is, $\beta_{R}=0.28$ and $\beta_{U}=0.40$. These values were selected because it was assumed that the $K$ Basin concrete structure is not very resilient to a seismic event such that the inherent randomness about the median peak ground acceleration would be quite small. On the other hand, the uncertainty in the median value of the 
peak ground acceleration should be reasonably large. Again, these values of $\beta_{\mathrm{R}}$ and $\beta_{\mathrm{U}}$ are reasonable and are typical of values used for structures which are not very resilient to a seismic event. Using the values of $\AA=0.20 \mathrm{~g}, \beta_{R}=0.28$, and $\beta_{U}=0.40$ the fragility curves presented in Figure B-7 were developed.

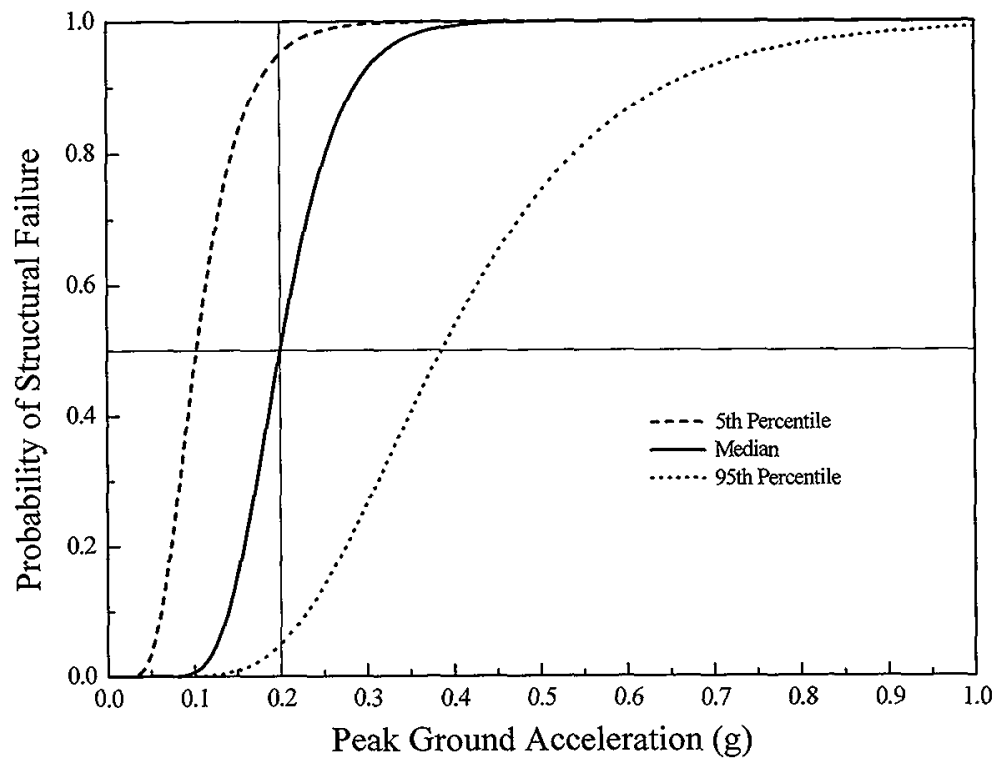

Figure B-7. Possible Fragility Curves for the K Basin Concrete Structure.

Using Equation B-3, the family of curves represented by the seismic hazard curves, (Figure B-4) and the fragility curves shown in Figure B-7, the conditional probability of structural failure of the concrete structure given that a seismic event occurs is calculated. The complementary cumulative distribution function of the conditional probability provides the probability of 
exceeding a frequency of structural failure given that a seismic event occurs. The results are presented in Figure B-8 which provides the probability of exceeding a structural failure frequency (1/year).

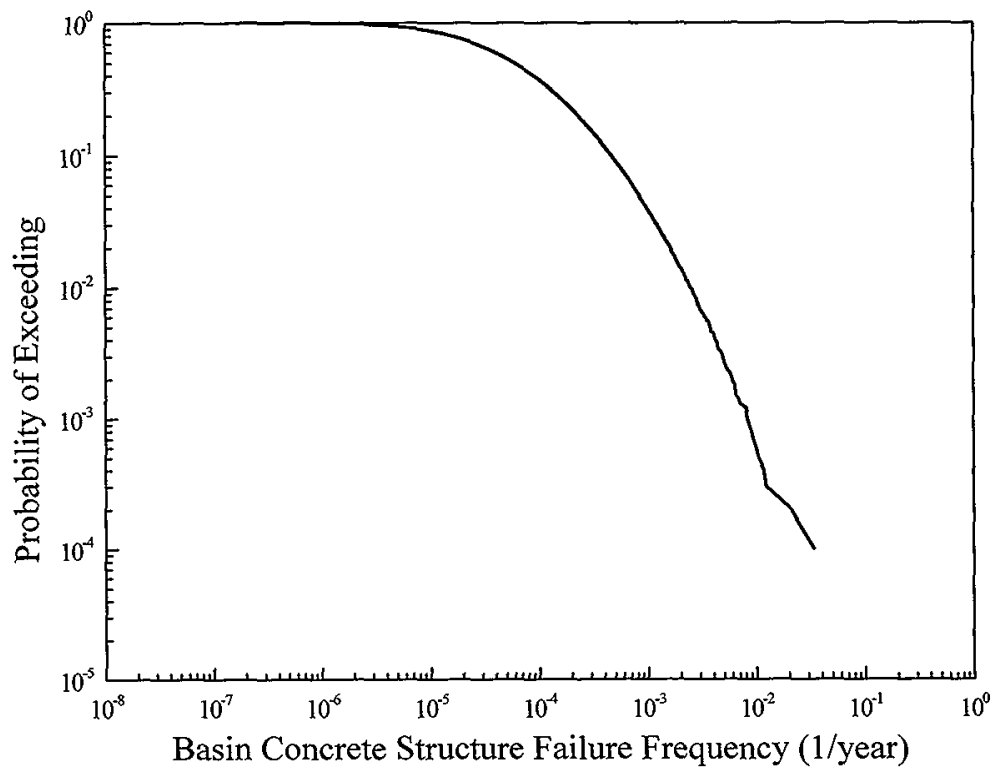

Figure B-8. Probability of Exceeding a Frequency of Structural Failure of the K Basin Concrete Structure Given that a Seismic Event Occurs.

\section{B.5 EVALUATION OF THE CONDITIONAL FREQUENCY OF PIPING SYSTEM FAILURE}

The piping systems located in the $\mathrm{K}$ Basins near the location of the twelve-inch drain valves consist of the skimmer piping and the recirculation piping. Experience has demonstrated that piping systems are more resilient during a seismic event than the structures that support them. 
Therefore, the frequency of structural failure is developed for the $\mathrm{K}$ Basin piping systems. First, however, recent experience discussed by Mr. Robert L. Cloud (Cloud 1980) is reviewed relative to piping system response in several recent earthquakes. The earthquakes include Imperial Vailey (1979), Miyagi-Ken-Oki (1978), Managua (1972), San Fernando (1971), Alaska (1964), Kern County (1952), Long Beach (1933). The observations by Mr. Cloud are summarized in the following quotations.

"... piping systems correctly designed for normal service are relatively impervious to earthquake damage. The basic concept of controlled flexibility built into power piping renders these systems even more resilient than the buildings from which they are supported."

An oil fired $60 \mathrm{MW}$ steam plant located on the Kern River near Bakersfield, California, and designed and built in $1947-1948$ experienced a seismic event with peak ground acceleration of $0.25 \mathrm{G}$. It was reported that there;

"... was no damage at all to piping systems. This is a clear example of the almost complete seismic protection that is provided by even the most rudimentary seismic design procedures (by today's standards)."

Three industrial facilities, the ENALUF $50 \mathrm{MW}$ and two $20 \mathrm{MW}$ Power Plants in Managua, Nicaragua, were subject to a peak ground accelerations on the order of $0.6 \mathrm{~g}$. Mr. Cloud reports;

"... with unknown and probably no seismic design applied, the piping sustained accelerations on the order of $0.6 \mathrm{~g}$ ground motion with no failure."

Finally, quoting from the National Academy of Sciences evaluation of the Alaska Earthquake (National Academy of Sciences 1973);

"The overall damage to piping systems was surprisingly low. Many instances were reported where piping systems remained intact, despite the significant structural and nonstructural damage suffered by the building."

The peak ground acceleration reported by Mr. Cloud for piping systems that were not damaged ranged from $0.2 \mathrm{~g}$ up to $0.6 \mathrm{~g}$ (i.e., $0.2 \mathrm{~g}, 0.25 \mathrm{~g}, 0.34 \mathrm{~g}, 0.39 \mathrm{~g}$ and $0.6 \mathrm{~g}$ ). Note that due to the amplification factor, the piping systems actually experienced accelerations up to $6 \mathrm{~g}$ and were not damaged. 
The NRC (NRC 1985) has developed parameters for a master fragility curve for piping systems $\left(\beta_{R}=0.18\right.$ and $\left.\beta_{U}=0.33\right)$. A median peak ground acceleration capacity of $\AA=0.36 \mathrm{~g}$ was used along with the values of $\beta_{R}$ and $\beta_{U}$ to construct the fragility curves for $K$ Basins piping systems. This value of $\AA$ is within the range of peak ground accelerations reported for which piping systems survived a seismic event and is three times the median peak ground acceleration of the design basis earthquake for $\mathrm{K}$ Basins super structure. Using these parameters, the fragility curves for $\mathrm{K}$ Basins piping is provided in Figure B-9.

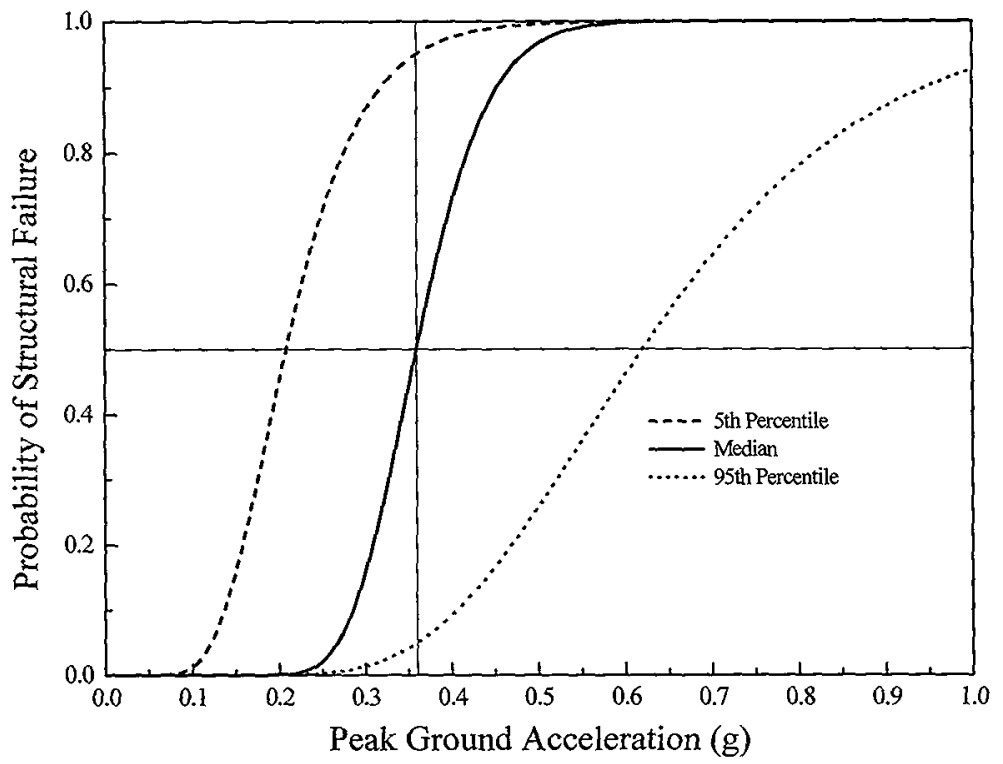

Figure B-9. Possible Fragility Curves for the K Basin Piping Systems.

Using Equation B-3, the family of curves represented by the seismic hazard curves, (Figure B-4) and the fragility curves shown in Figure B-9, the conditional probability of piping system failure 
given that a seismic event occurs is calculated. The complementary cumulative distribution function of the conditional probability provides the probability of exceeding a frequency of structural failure given that a seismic event occurs. The results are presented in Figure B-10, which provides the probability of exceeding a structural failure frequency $(1 /$ year $)$.

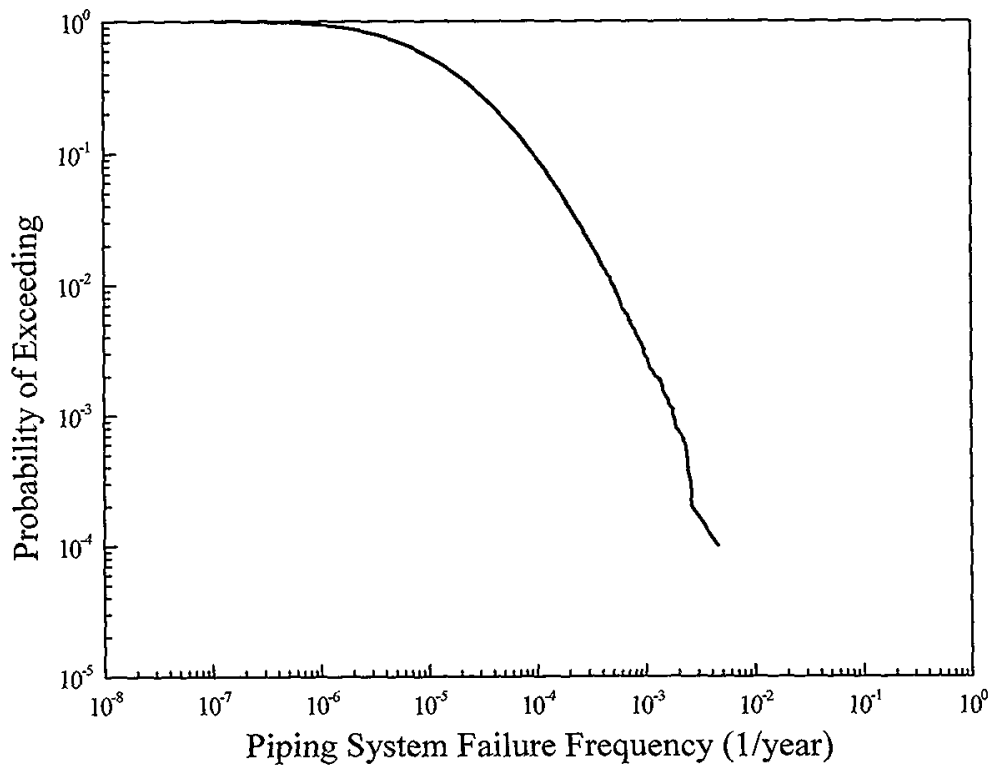

Figure B-10. Risk Curve for the Frequency of Structural Failure of the K Basin Piping Systems Given that a Seismic Event Occurs.

For this analysis, the frequency of structural failure for the $\mathrm{K}$ Basin super structure is the distribution provided in Figure B-6. For the $\mathrm{K}$ Basin concrete structure the distribution provided in Figure B-8 is used. For K Basin piping systems, the distribution provided in Figure B-10 is used. 


\section{B.6 EVALUATION OF THE SEISMIC RESPONSE OF THE CANISTER RACKS}

The $\mathrm{K}$ Basin canister racks are situated at the bottom of the $\mathrm{K}$ Basin in north-south rows as shown in Figures A-4 and A-5. The canister racks are free standing on the bottom of the K Basin, supported by four legs, with only friction at the floor to resist lateral movement. The canister racks directly in front of the twelve-inch valves are less wide than the adjacent racks to allow for the valves, but are reported to be fairly close to the valves (within an inch). As can be seen in Figure A-4, the top of the canister rack is the same height as the junction of the twelveinch valve stem and bonnet. Any lateral motion of the canister racks could potentially impact the upper bonnet and stem of the valve. Hyde (Hyde 1996) notes that the canister racks are structurally adequate and will maintain their physical configuration in a seismic event.

Because the canister racks lie at the bottom of the $\mathrm{K}$ Basin, the racks will experience the same acceleration (both horizontally and vertically) from a seismic event as the bottom of the $\mathrm{K}$ Basin without any appreciable amplification. Consequently, the canister racks will move with the same motion (acceleration) as the bottom of the basin which contains the twelve-inch drain valve and the drain line. Thus, when the canister racks and the twelve-inch drain valve are moving with the same motion, the racks will not impact the drain valve. Only when the horizontal acceleration of the canister racks exceeds the static friction force of the racks will the racks begin to slip or slide and possibly impact the valve.

Consider the vertical and horizontal forces exerted on the canister racks,

$$
\begin{aligned}
& \pm m a_{x}=F_{x}=F_{f} \\
& \pm m a_{y}=F_{y}=F_{B}-m g+N \\
& F_{f}=\mu_{s} N
\end{aligned}
$$

where $m$ is the mass of the canister racks, $a_{x}$ and $a_{y}$ are the oscillatory seismic accelerations, $g$ is the acceleration constant, $F_{f}$ is the static friction force, $F_{B}$ is the buoyant force, $N$ is the normal force, and $\mu_{\mathrm{s}}$ is the coefficient of static friction.

Therefore,

$$
\begin{aligned}
& N= \pm m a_{y}+m g-F_{B} \\
& \pm m a_{x}=\mu_{s} N=\mu_{s}\left( \pm m a_{y}+m g-F_{B}\right)
\end{aligned}
$$


Representing the horizontal acceleration $\left( \pm \mathrm{a}_{x}\right)$ as $\mathrm{bg}$, an acceleration factor times the gravitational constant, $g$, the lateral motion of the racks can be expressed as;

$$
\begin{aligned}
& m b g=\mu_{s}\left( \pm m a_{y}+m g-F_{B}\right) \text { or } \\
& b=\mu_{s}\left[1-\frac{F_{B}}{m g} \pm \frac{a_{y}}{g}\right]
\end{aligned}
$$

The canister racks will begin to move when;

$$
\begin{aligned}
& b \geq \mu_{s}\left[I-\frac{F_{B}}{m g} \pm \frac{a_{y}}{g}\right] . \\
& b \geq f \mu_{s}
\end{aligned}
$$

where

$$
f=1-\frac{F_{B}}{m g} \pm \frac{a_{y}}{g} .
$$

The factor $f$ is decreased by the buoyant force and is either increased or decreased depending on the oscillatory motion of the vertical ground acceleration. When $a_{y}$ is positive, $f$ is smaller, and when $a_{y}$ is negative $f$ is larger.

Hyde (1996) surveyed the available information relative to the coefficient of static friction for steel on concrete. Although the available information is not extensive, Hyde identified a range for the coefficient of static friction from 0.2 to 0.6 with a reasonable value near 0.35 . In many structural reliability analyses, a value of 0.3 is used for the coefficient of static friction. For this analysis a range of the coefficient of static friction from 0.2 to 0.6 is used with a median value of 0.35 . The range accounts for the variability in the buoyant forces and the oscillating vertical ground acceleration. The values for the acceleration factor are ranged from 0.05 to 0.4 with a median value of 0.2 assuming that there is little amplification between the bottom of the $\mathrm{K}$ Basin and the ground motion.

The coefficient of static friction and the acceleration factor were varied using a Monte Carlo approach with a Latin Hypercube sampling process to evaluate the results of Equation B-7. The probability of exceeding a negative value for the expression $b-f \mu_{s}$ (mathematically, $\operatorname{Pr}\left[\left(b-f \mu_{s}\right)\right.$ 
$\geq 0]$ ) was determined from the resulting distribution with a point value of 0.05 . That is, for these ranges of acceleration $(0.05 \mathrm{~g}$ to $0.4 \mathrm{~g})$ and coefficient of static friction $(0.2$ to 0.6$)$ the point value for the probability of the canister racks starting to slip is 0.05 . Thus, this point value is used as the probability that the canister racks will begin to slip and impact the twelve-inch drain valve for a reasonable range of acceleration. The seismic hazard curves are used to provide a distribution for the frequency of exceeding a peak ground acceleration of $0.35 \mathrm{~g}$. This information is used to evaluate the sequence event tree for the impact of the canister storage racks on the $\mathrm{K}$ Basin twelve-inch drain valve.

approach with a Latin Hypercube sampling process to evaluate the results of Equation B-7. The probability of exceeding a negative value for the expression $b-f \mu_{s}$ (mathematically, $\operatorname{Pr}\left[\left(b-f \mu_{s}\right)\right.$ 


\section{Appendix C}

Probability of Objects Striking the Twelve Inch Drain Valves 


\section{C.1 INTRODUCTION}

A variety of objects could be dislodged and fall as a result of a seismic event. Some objects would fall vertically and land on the basin floor directly below their original positions. In most cases, however, the seismic event would impart both a horizontal and vertical velocity to the object as it begins to fall. The object would then follow a trajectory that carries it away from its initial horizontal position. To determine the probability of a falling object hitting the valve, this horizontal movement was quantified.

In the following sections, a zone of convergence is defined for each valve. Objects that may fall and strike the valve must start from within this region. Objects whose initial positions are outside this region will be assumed to be too far from the valve to impact it.

\section{C.2 TRAJECTORY OF FALLING OBJECTS}

An object with an initial horizontal velocity may follow many different trajectories when falling. The specific trajectory an object follows is determined by the buoyancy and drag forces that act on the object. In the absence of these forces, falling objects follow parabolic trajectories as predicted by Newton's Second Law. Specifically, the horizontal distance R traveled by an object with initial horizontal velocity $\mathrm{V}_{0}$ is,

$$
R=V_{0} \sqrt{\frac{2 H}{g}}
$$

where $\mathrm{H}$ is the vertical distance an object falls and $\mathrm{g}$ is the gravitational constant (Lindeburg, 1997). Consistent with Equation C-1, Figure C-1 indicates the parabolic path an object would follow if its initial velocity is $5 \mathrm{ft} / \mathrm{s}$ and the object is allowed to fall a distance of 30 feet. 


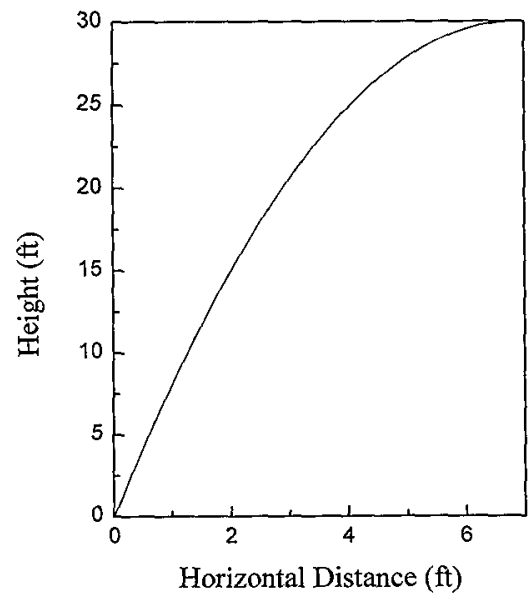

Figure C-1. Parabolic Trajectory of Object Unaffected by Buoyancy or Drag.

Equation C-1 and Figure C-1 describe the motion of an object that is unaffected by buoyancy forces. Most objects that could fall into the $\mathrm{K}$. Basins have densities which are much greater than the density of the basin water. The buoyancy force that would act upon these objects is, therefore, very small in comparison to the gravitational force the objects would experience. For this reason, the effects of buoyancy will be ignored in discussing the trajectories of objects falling through the basin water.

Equation C-1 and Figure C-1 also describe the motion of an object unaffected by viscous force. In the case of the $\mathrm{K}$ Basins, an object may experience considerable drag force as it falls through the basin water. This force generally acts in a direction opposite to the object's direction of motion. In the vertical component of the object's direction, the drag force slows the rate of acceleration; however the object's velocity continues to increase under the gravitational force until the object reaches its terminal velocity. In the horizontal direction, the drag force slows the object's motion, continually reducing the object's horizontal velocity. Because the vertical velocity increases while the horizontal velocity decreases, the drag force causes an object to arc 
downward, thereby deviating from the parabolic trajectory predicted by Equation $\mathrm{C}-1$. This effect is shown in Figure $\mathrm{C}-2$ for several trajectories with increasing drag forces.

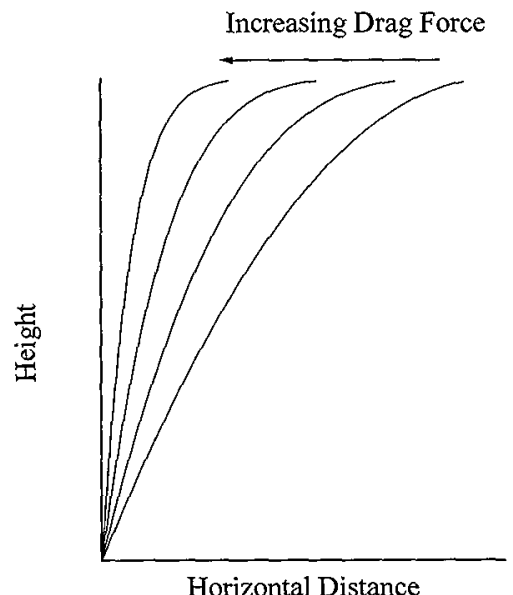

Figure C-2. Drag Force Effects on Trajectory.

As shown in Figure C-2, drag forces cause an object to travel shorter.horizontal distances than the object would have traveled in the absence of the drag force. With this slowing of the horizontal motion, neglecting drag forces overestimates the horizontal distance an object will travel when falling.

\section{C.3 ZONE OF CONVERGENCE}

If an object with an initial horizontal velocity $\left(\mathrm{V}_{0}\right)$ is dropped, Equation $\mathrm{C}-1$ defines the maximum horizontal distance the object will travel. As shown by Figure C-2, this is true even when the effects of drag forces are considered. When Equation C-1 is applied to objects in the vicinity of the $\mathrm{K}$ Basin twelve-inch drain valves, falling objects located at horizontal distances greater than $\mathrm{R}$ will not reach the valve. Therefore, such objects are not capable of damaging the 
valve during a seismic event.

When the curve produced from Equation C-1 is rotated about a vertical axis that passes through the valve, a cone is generated. The region of space within this cone will include all objects that have the potential of falling and striking the valve. More importantly, any objects outside this zone of convergence cannot directly impact the valve and can be ignored. A pictorial representation of the zone of convergence is shown in Figure C-3. Objects that may fall within the cone are assumed to start at some initial radius $R_{o}$. For a given height, a seismic event is assumed incapable of displacing objects greater distances than $R_{m}$.

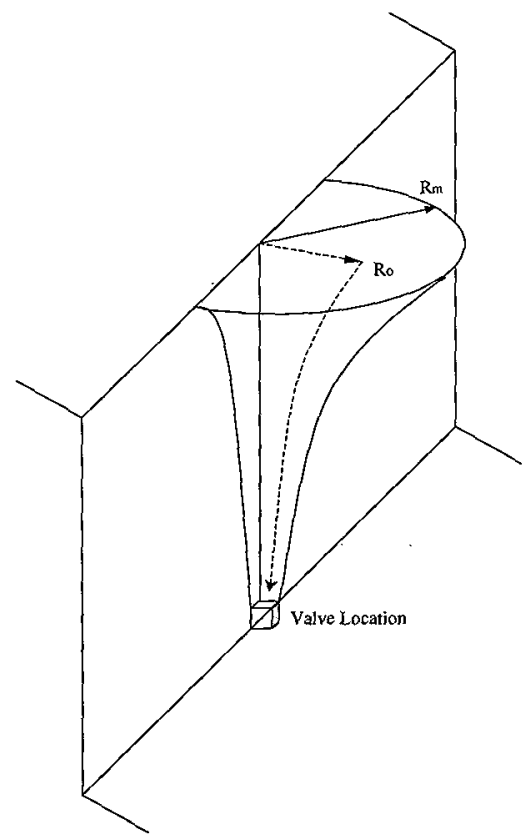

Figure C-3. Zone of Convergence. 
To determine the probability of striking the three twelve-inch drain valves, a cone was developed and located over each valve. The height of the cone corresponded to the height of the basin ceiling (as measured from the valve). Using Equation C-1, the outer radius of the cone was determined from the maximum initial horizontal velocity a seismic event might impart to the object. Figure C-4 shows the zone influence for a typical valve.

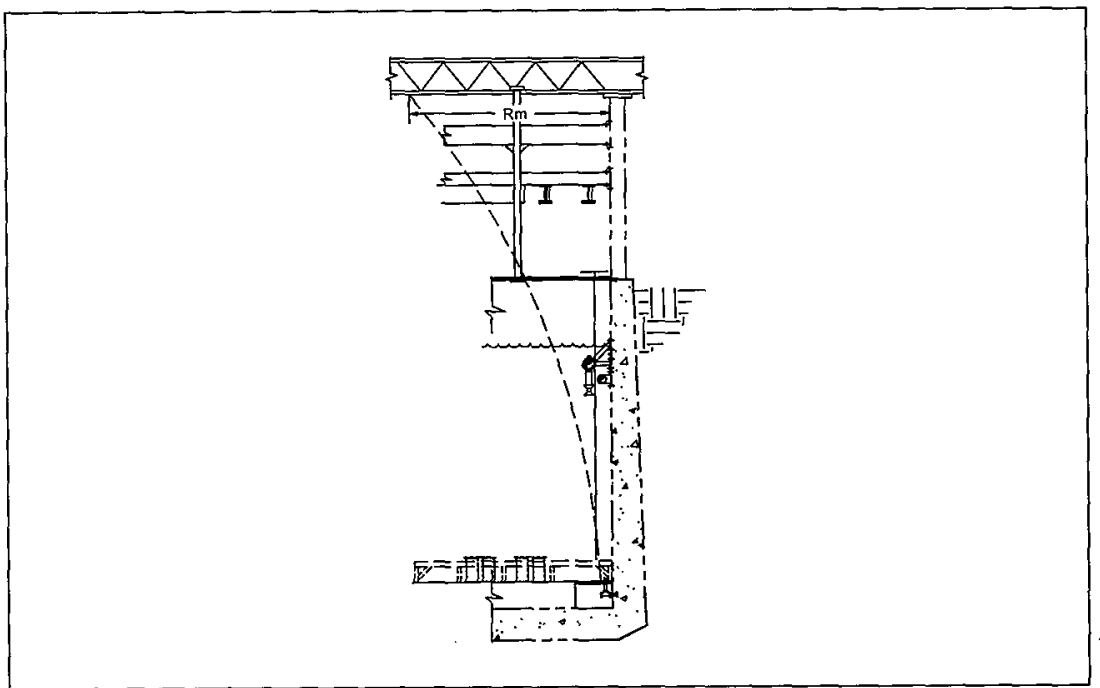

Figure C-4. Zone of Convergence for a Typical Valve

Because all three valves are located near the basin wall, objects that would fall outside the basin perimeter were ignored. Objects with trajectories that caused the objects to strike the wall directly above the valve were assumed to fall vertically down the wall, striking the valve. 


\section{C.4 MODELING THE ZONE OF CONVERGENCE}

The zone of convergence was modeled using a Monte Carlo simulation technique. Since the geometry surrounding the valves is nearly the same, the simulation was run for only one of the three valves. After defining the cone and centering it over the valve, 20,000 objects were simulated and dropped into the zone of convergence. The objects dropped varied in size, initial position and initial velocity. The trajectories of the 20,000 objects were then determined and each object's final resting position calculated. Objects that struck the wall were assumed to then fall straight downward from the point of contact with the wall. Based on each object's final resting position, the size of the object and the size of the valve, the number of objects that hit the valve was calculated. From this, the probability of a single object striking the valve was developed.

As previously discussed, the height of the cone corresponded to the distance from the valve to the basin ceiling. Since a variety of objects were simulated, the vertical distance that each object fell was randomly varied from 25 feet to 35 feet. This is consistent with the valve protruding approximately 1.5 feet above the basin floor, the depth of the basin below the grating being approximately 21 feet, and the height of the ceiling over the basin being approximately 15 feet.

The outer radius of the cone was determined from the maximum initial velocity an object may have. Using a trajectory similar to that of Figure $\mathrm{C}-1$, described the maximum trajectory an object may have due to a seismic event. For an object that falls 30 feet, the maximum horizontal displacement was determined to be approximately 6.8 feet. Using Equation C-1, this distance corresponds to a maximum initial velocity of $5 \mathrm{ft} / \mathrm{s}$ (Hanford 1997). The Monte Carlo simulation was conducted once using this value for the maximum initial velocity. The simulation was also conducted using other initial velocities which equated to maximum radii of $3.4 \mathrm{ft}$ and $13.6 \mathrm{ft}$. These additional simulations served to quantify the effect that the cone's radius had on the calculated probability and to acknowledge that some uncertainty exists in the assumed maximum velocity.

The valve was modeled as an elliptically shaped object with a horizontal cross-section of 8 by 18 inches. The size of objects dropped into the zone of convergence was varied from objects 1 inch in diameter to objects with a horizontal cross section of twice the cone's maximum radius. Since most objects that may fall will not be round in shape but will be rectangular, cylindrical or asymmetric, the modeling allowed each object to assume a unique shape. In addition, the modeling included randomness to account for potential rotation that the object might experience either from the initial drop or from falling through the basin water. 


\section{C.5 PROBABILITY THAT AN OBJECT WITHIN THE ZONE OF CONVERGENCE WILL STRIKE THE VALVE}

The Monte Carlo simulation was performed for several cone radii. Each radius corresponded to a different maximum initiating velocity. The results of each run were then normalized to obtain the probability of a single object hitting the valve. To verify that 20,000 objects were representative for the range of possible sizes, positions and velocities, the simulation was repeated for 30,000 and 40,000 objects. Since the results varied by less than 5 percent, the use of 20,000 objects was assumed adequate.

The results of various simulations are presented in Figure $\mathrm{C}-5$. These results assume an object falls into the cone. The results do not factor in the probability of an object being dislodged, nor do they factor in the probability that the damage to the valve (i.e., leaking) will occur within the cone (see Appendix $\mathrm{E}$ for a discussion of how these probabilities were factored into the analysis).

As seen in Figure C-5, the probability is approximately 0.05 that an item within the cone will strike the valve if the item falls. As the maximum initial velocity (maximum cone radius) is decreased, the likelihood of hitting the valve increases. For larger initial velocities, the likelihood decreases. While Hanford (1997) defines the maximum velocity as $5 \mathrm{ft} / \mathrm{s}$ (i.e., a maximum radius of $6.8 \mathrm{ft}$ ), this analysis used a range of initial velocities. As discussed in Appendix $E$, the range of initial velocities (maximum cone radii) was modeled as a lognormal distribution with a median probability value of 0.05 . 


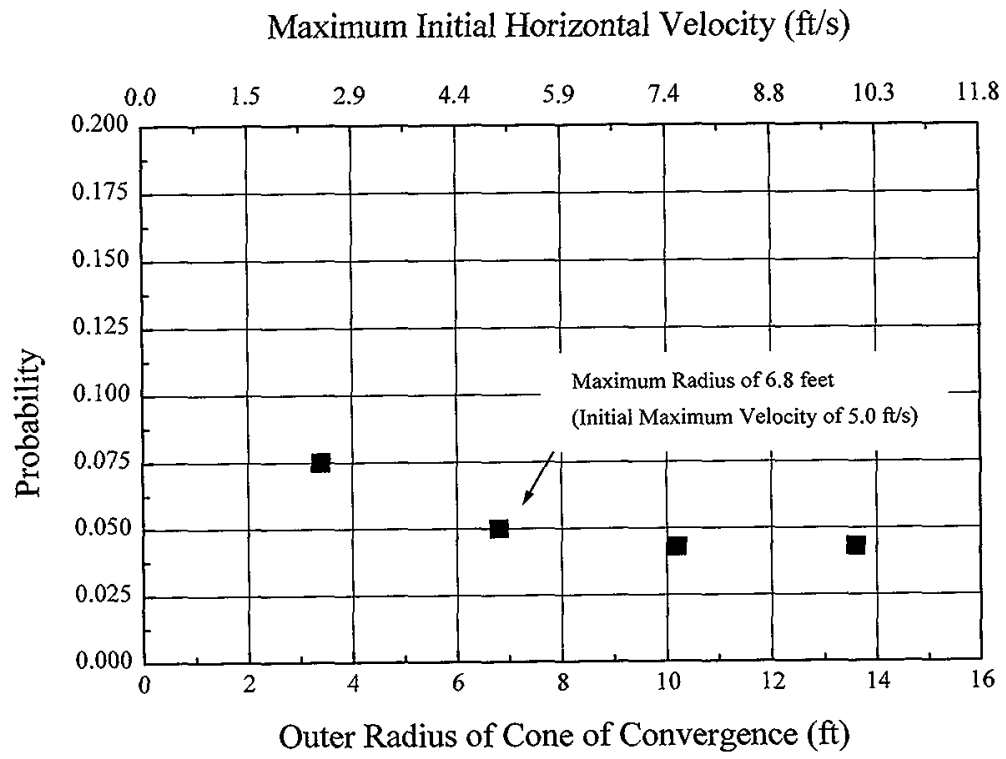

Figure C-5. Object's Probability of Hitting the Valve Assuming it is Dropped into the Zone of Convergence. 
RISK AsSESSMENT OF K BASIN TWELVE-INCH DRAIN VALVE FaILURE

From A POSTULATED SEISMIC INITIATING EVENT
Report No. 984519-001, Rev. 2 SNF-3205, Rev. 0 August 10, 1998

\section{Appendix D}

K Basin Twelve-Inch Drain Valve Damage States 


\section{D.1 INTRODUCTION}

The likelihood of an object striking the drain valve was developed in Appendix C. If one is to determine the likelihood that a given initial flow rate will occur through a damaged drain valve, one must first determine the extent of damage produced by an object striking the valve. Two methods are discussed for developing this range of valve damage. The first will be discussed briefly; the second will be explored in detail as the second method was employed in this report. However, before discussing the two approaches, a brief summary is provided of the valve's mechanical design.

\section{D.2 VALVE DESCRIPTION}

The $\mathrm{K}$ Basin twelve-inch drain valves are described in the vendor literature as flanged, 25-pound, iron body, double-disc, gate valves with non-rising stems manufactured by the Crane Company (Crane 1960, 1988, 1997). The gate valve when fully opened has a 12-inch diameter port through the valve body. The discs that constitute the two gates have upstream and downstream perimeter seats sealing to the valve body seats when the valve is closed. The assembly that closes the gate consists of a disk nut, a brass stem, two hooks, wedges, and two cast iron discs. When the valve is closed, the hooks engage the bottom of the body and force the wedges between the discs. This force drives the discs outward against the seats thereby sealing the flow of water past each gate. With the valve closed, the discs not only prevent the flow of water through the valve and isolate the bonnet cavity from both the upstream and downstream piping.

The bonnet is attached to the valve body with a gasket. On top of the bonnet is a stuffing box which is also attached with a gasket. The stuffing box provides a packing seal where the valve stem leaves the valve. This packing prevents leaks from occurring between the bonnet cavity and the exterior environment. Critical components of the bonnet and the gate assembly are shown in Figure D-1. 


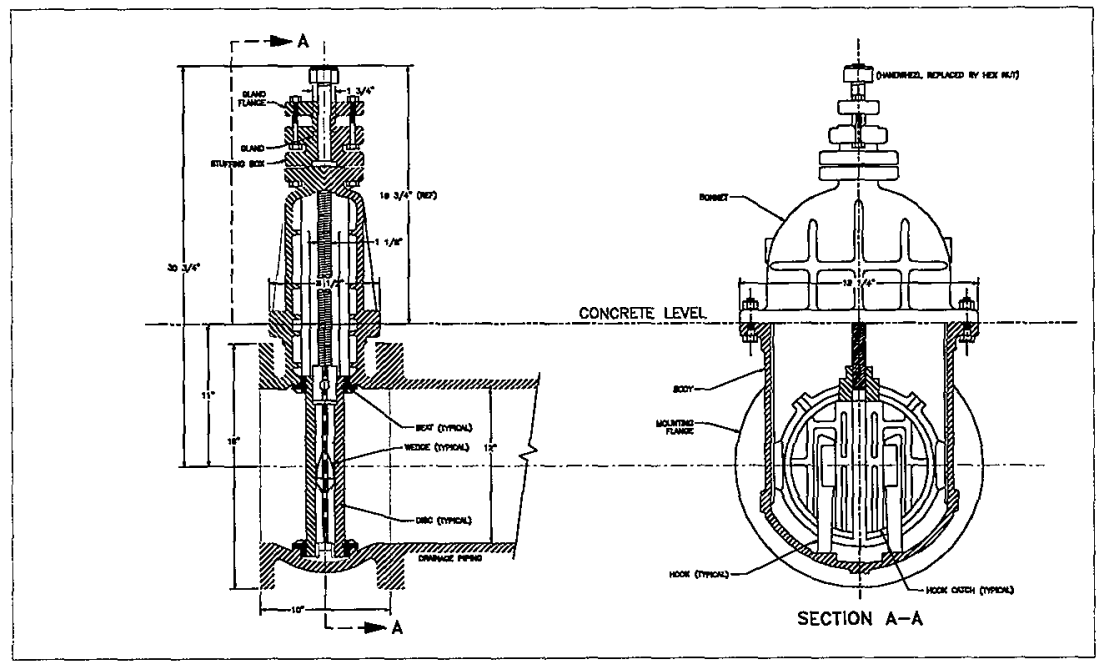

Figure D-1. Cross-Section of the K Basin Twelve-Inch Drain Valve.

\section{D.3 TWO APPROACHES OF ASSESSING DRAIN VALVE DAMAGE}

Given that a falling object strikes the twelve-inch drain valve, the amount of damage that may result needs to be estimated. Once the amount of damage is determined, the amount of leakage through the damaged valve can be ascertained. Therefore, one objective of this report is to quantify the range of potential flow rates through a drain valve damaged by a falling object. Two approaches can be followed to determine this range of initial flow rates. In one approach, the impact dynamics of every item that could strike the drain valve would be analyzed to determine the extent of valve damage and the ensuing leak rates. In the other approach, a range of possible initial flow rates could be developed based on the potential extent of valve damage. In the first approach, each object drop is considered as a series of events that leads to a specific amount of damage and, hence, to a specific leak rate occurring from the valve. The latter approach considers a more global situation and does not consider the individual consequences of the items dropped. 
The first approach is probably the most obvious. For every object that could fall and strike a drain valve, one would calculate the structural damage that the impact would produce and the resulting leakage that could occur. One must take care to consider all objects that might fall onto the valve, the many possible angles of impact, the differing impact velocities and the various contact areas at impact that may result. Nonetheless, this exhaustive approach would yield the complete range of leak rates that can occur from a damaged valve.

This exhaustive approach is problematic because of the many calculations that would have to be performed. Many objects of differing shapes and masses may fall onto the valve and each object can assume many differ orientations at impact. Furthermore, the valve's many internal components require differing calculations depending upon the specifics of each impact. As shown in Schifferl (1998), the strain resulting from a vertical strike of the valve's stem is calculated differently than the bending moment stresses that occur if the falling object strikes the bonnet. Unfortunately, these calculations would not always yield an indication of potential leakage from the valve. Schifferl (1998) presents six calculations that predict the amount of force necessary to damage various valve components. Only one of the calculations (damage of the valve discs) is a damage state that leads directly to leakage of water through the valve. The other calculations involve components that only indirectly lead to leakage. For example, only one of the six Schifferl calculations determines the force necessary to fail the stuffing box bolts. Such a failure does not explicitly lead to leakage, as a failed bolt does not provide a path for flow past the valve discs. Since several components may fail together to cause a leak, the calculation of forces required to cause the failure is not always straightforward. Combining this difficulty with the many permutations of masses, sizes, shapes, and impact orientations that must be considered, the amount of analytical work required for this approach could grow beyond that which could be completed in a reasonable period of time.

The second approach overcomes the problem of exhaustive calculations required by the first approach by considering the uncertainty in the initial flow rates that physically can occur. With this method, a more global situation is considered and the consequences of an individual impact need not be considered. Rather, the approach bounds the set of possible outcomes (i.e., what flow rates could physically occur). While it is true that falling objects can damage the valve in many different ways, the resulting initial flow rates are limited. By understanding how the valve may fail, one can ascertain the more likely leak rates that may occur. With these likely leak rates and the bounding rates (no flow and the maximum flow the connecting piping will allow), an uncertainty distribution of initial flow rates can be developed that provides the likelihood of a specific initial flow rate occurring should the valve be damaged. 


\section{D.4 VALVE DAMAGE STATES}

Nine damage states were postulated in which the valve would likely fail. These damage states represent the end state of failure; i.e., the resulting initial flow rate that would likely occur. The damage states were developed by considering how the valve might leak if damaged. For example, even though the valve stem and bonnet might be damaged, the valve would not leak unless the disks or their seats were also damaged. Because leaking only can occur if a few critical components (such as the disks or seats) are damaged, the damage states focused on these critical components.

To develop these nine damage states, the authors reviewed the manufacturer drawings and material lists. After identifying what components were critical in preventing the valve from leaking, the authors reviewed the information with the SNF Project management, technical and operational personnel. Based upon their experience and discussions with valve manufacturers, the authors refined the expected damage states. Table D-1 presents the finalized damage states that, based on engineering judgement and experience, represent the nine most probable damage states. 
Table D-1. Deseription of Valve Damage States.

\begin{tabular}{|c|c|}
\hline Number & Description of the damage postulated to occur to the twelve-inch gate valve \\
\hline 1 & No significant damage to either the valve stem or the bonnet. \\
\hline 2 & $\begin{array}{l}\text { Significant damage to the bonnet, but the valve internals are intact with no leakage from the } \\
\text { bonnet through the seats to the downstream piping. }\end{array}$ \\
\hline 3 & $\begin{array}{l}\text { The packing in the stuffing box is damaged which disrupts the seating surfaces between the } \\
\text { valve disk and body. The packing damage causes a leak path into the bonnet. The limiting } \\
\text { leak rate is determined by the resistance to flow between the stem and the bonnet housing. } \\
\text { This assumes that the upstream packing leak and downstream seat leaks are much larger } \\
\text { than the limiting leak rate at stem/bonnet housing. }\end{array}$ \\
\hline 4 & $\begin{array}{l}\text { The valve bonnet is damaged such that the area of inflow into the bonnet exceeds the } \\
\text { limiting flow resistance of one disk seat on the downstream side which is damaged such that } \\
\text { the entire width of the disk seat for the top half }\left(180^{\circ}\right) \text { of the valve is swept away. }\end{array}$ \\
\hline 5 & $\begin{array}{l}\text { The valve bonnet is damaged such that the area of inflow into the bonnet exceeds the } \\
\text { limiting flow resistance of one body seat on the downstream side which is damaged such } \\
\text { that the entire width of the body seat for the top half }\left(180^{\circ}\right) \text { of the valve is swept away. }\end{array}$ \\
\hline 6 & $\begin{array}{l}\text { The valve bonnet has been damaged such that the area of inflow into the bonnet exceeds the } \\
\text { limiting flow resistance of one body and one disk seat on the downstream side which is } \\
\text { damaged such that the combined dimensions provide a leak path. }\end{array}$ \\
\hline 7 & $\begin{array}{l}\text { The valve bonnet has been damaged such that the area of inflow into the bonnet exceeds the } \\
\text { limiting flow resistance of the following described damage area. Torque on the stem causes } \\
\text { the disk, downstream body and disk seats in the area of the disk nut to break. This removes } \\
\text { a } 45^{\circ} \text { section of disk and seats. }\end{array}$ \\
\hline 8 & $\begin{array}{l}\text { The valve bonnet has been damaged such that the area of inflow into the bonnet exceeds the } \\
\text { limiting flow resistance of the following described damage area. Impact on the valve stem } \\
\text { causes a downward impact on the double disk. The downstream disk cracks and breaks, } \\
\text { with the upper } 180^{\circ} \text { of the disk and disk seat breaking into small enough pieces to be swept } \\
\text { away into the drain piping. The body seats are still intact and there is no damage to the } \\
\text { upstream disk/seats. }\end{array}$ \\
\hline 9 & $\begin{array}{l}\text { The valve bonnet has been damaged such that the area of inflow into the bonnet is the } \\
\text { limiting flow resistance. This assumes that all yalve internal components are completely } \\
\text { removed. This is the worst case scenario from the (Parsons 1998) analysis. Equivalent area } \\
\text { and leak rate are taken from the worst case. }\end{array}$ \\
\hline
\end{tabular}




\section{D.5 FLOW RATES CORRESPONDING TO THE VALVE DAMAGE STATES}

Each potential valve damage state considered the removal of key internal pieces of the valve. The cross-sectional areas of the removed pieces were modeled as equivalent circular areas so that conventional fluid flow equations derived for circular pipe flow could be used (Roberson 1980). In this methodology the non-circular leak path is converted to an equivalent hydraulic radius $\left(R_{h}\right)$ or equivalent circular area $\left(A_{c}\right)$, from which the initial flow (leak rate) is calculated. This analysis is required because the non-circular leak path areas have a larger shear stress boundary (wetted perimeter) which reduces the leak rate.

From the calculated equivalent hydraulic area for each damage state, the results of Parsons (1998) were interpolated to determine each damage state's initial leak rate. This document (Parsons 1998) developed the leak rate that would occur if the valve bonnet was entirely severed and the valve's internal components (discs, stem, wedges, hooks, etc.) were removed from the valve body. The analysis modeled the damaged valve as well as the piping configuration that leads from the basin to a collection box. The piping beyond the collection box was not modeled as the analysis assumed that the collection box would effectively drain faster than it would fill (i.e., pressure losses downstream of the collection box would not influence the flow upstream of the collection box). The analysis determined $1980 \mathrm{gpm}$ would initially flow through the damaged twelve-inch valve. The analysis considered this flow rate to be the maximum bounding leakage rate as it assumes free flow through the valve. The results of the analysis (Parsons 1998) are provided in Figure D-2 as a function of the equivalent hydraulic area through the twelve-inch gate valve. The results indicate that the leak rate varies linearly with the equivalent flow area through the valve. 


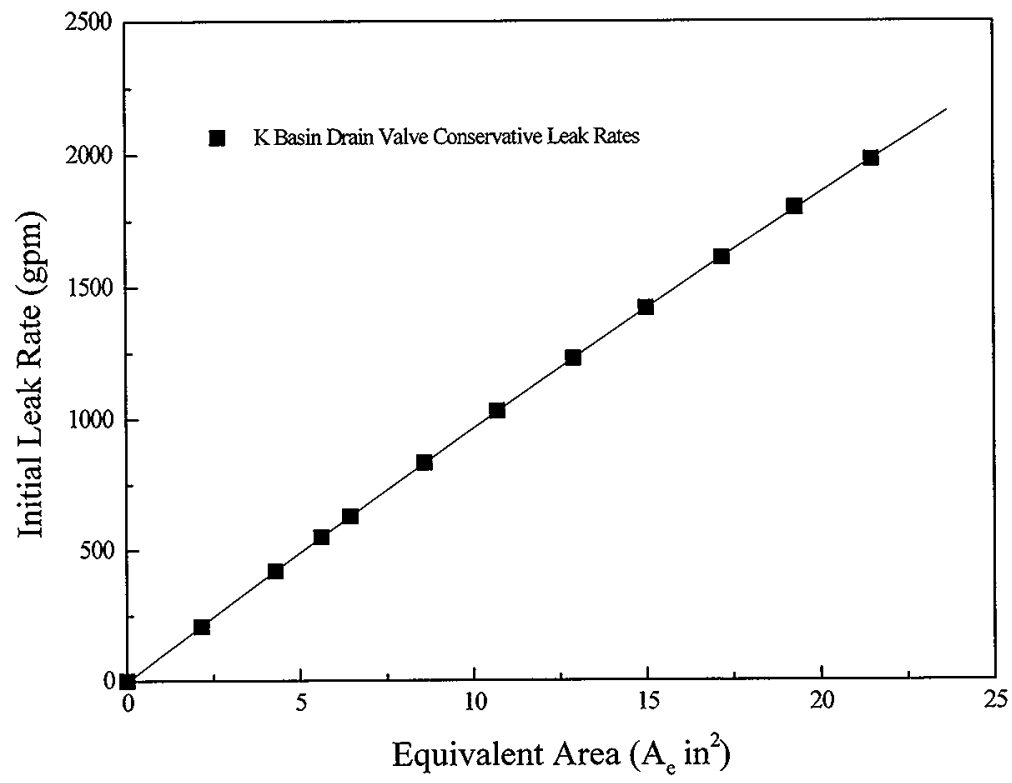

Figure D-2. Initial Leak Rate vs. Equivalent Area.

Table D-2 provides the hydraulic radius and the equivalent area for each damage state. Table D2 also provides the initial flow rate as interpolated from Figure D-2. Two problems exist with such extrapolations. First, some of the lesser damage states resulted in leak rates small enough for the flow to be near laminar. Parsons (1998) assumed the leaking flow was always turbulent. Therefore, at the lower flow rates, the extrapolated data underestimates the frictional loss through the damaged valve. This in turn results in an overestimation of the leak rate at these lesser damage states. The second problem with extrapolating results from Parsons (1998) is the pipe will be empty when the damage first occurs. At the lower leak rates, the pipe may never completely fill with liquid after the valve becomes damaged. In this region of leak rates, the extrapolated leak rates will underestimate the actual leak rate. While it is unlikely that these two 
problems will completely cancel each other, the fact that one overestimates the flow and the other underestimates the flow implies that their combined effect will be an overall small error.

Table D-2. Damage States and Associated Leak Rates.

\begin{tabular}{|c|c|c|c|}
\hline $\begin{array}{c}\text { State } \\
\text { No. }\end{array}$ & $\begin{array}{c}\text { Hydraulic Radius } \\
\text { (inch) }\end{array}$ & $\begin{array}{c}\text { Equivalent Area } \\
\text { (inch }^{2} \text { ) }\end{array}$ & $\begin{array}{c}\text { Leak } \\
\text { Rate (gpm) }\end{array}$ \\
\hline 1 & 0.00 & 0.00 & 0 \\
\hline 2 & 0.00 & 0.00 & 0 \\
\hline 3 & 0.06 & 0.05 & 3 \\
\hline 4 & 0.08 & 0.08 & 7 \\
\hline 5 & 0.12 & 0.19 & 22 \\
\hline 6 & 0.20 & 0.50 & 58 \\
\hline 7 & 0.58 & 4.19 & 421 \\
\hline 8 & 0.68 & 5.73 & 564 \\
\hline 9 & 1.31 & 21.48 & 1980 \\
\hline
\end{tabular}

Figure D-3 provides the graph of the initial leak rate as a function of the equivalent hydraulic area for the valve damage states identified in Table D-2 (solid circles). Figure D-3 also shows the leak rate data (Parsons 1998) from Figure D-2 (solid line). 


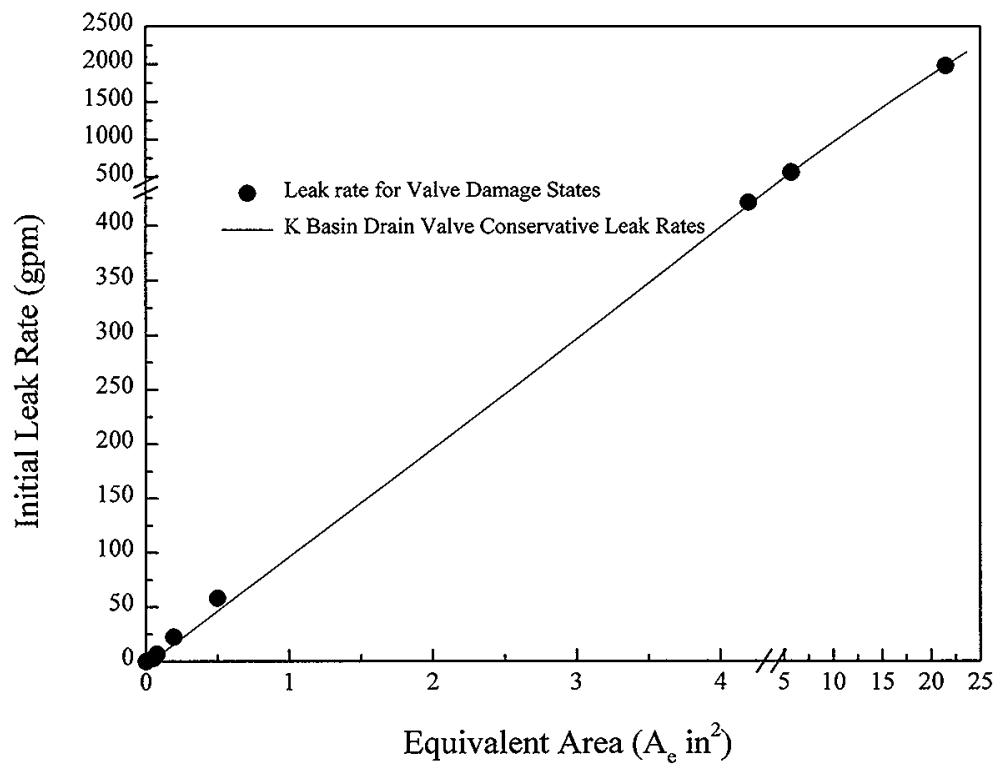

Figure D-3. Initial Leak Rates and Equivalent Area for the Nine Postulated Damage States.

\section{D.6 VALVE DAMAGE STATE PROBABILITY DISTRIBUTION}

Based on the potential valve damage states developed and defined in Table D-1, a cumulative distribution function was determined that represents the likelihood of not exceeding a specific equivalent circular hydraulic area. This determination was based on, first, a logical thought process, and, second, a mathematical evaluation. In addition, a sensitivity evaluation was developed. 
There are two important points that must be emphasized. Six of the valve damage states (4 through 9) consider the valve bonnet to be severely damaged. Even though the damaged bonnet offers little flow resistance, the internal valve parts (such as the disks) prevent a large amount of leakage from occurring. Also, the valve body is completely encased in the drain sump concrete with just the valve bonnet and stem protruding above the concrete. Therefore, any object that may strike the valve may damage the bonnet and stem, even to the extent of destroying the bonnet. However, the rest of the valve may not be damaged, and, in fact, the internal gates and seats may still remain intact.

Consider first the logical thought process. A cumulative distribution provides the probability of not exceeding a specific value, or the likelihood that the parameter is less than a specified value. The physical bounds of the cumulative distribution function for the equivalent circular hydraulic area are: 1) there is a probability of zero that the equivalent circular hydraulic area is less than or equal to zero, and 2) there is a probability approaching one that the equivalent circular hydraulic area is less than 22 square inches which represents the maximum leakage area associated with the total throat area of the valve (Damage State 9). Because of the extreme nature of Damage State 8 , there is a high probability that the equivalent circular hydraulic area is less than 6 square inches (the equivalent circular area of Damage State 8). Furthermore, given the case of either Damage States 3 and 4 occurring, there is a low probability that the equivalent circular hydraulic area is less than 0.1 square inches (the equivalent circular hydraulic area of these damage states). Finally, based on the physical description of the valve damage states, there is a reasonable probability $(0.4$ to 0.6$)$ that the equivalent circular hydraulic area is less than the equivalent circular hydraulic area associated with Damage State 6. These considerations are summarized in Table D-3. 
Table D-3. Summary of the Considerations for the Equivalent Circular Area Cumulative Distribution Function.

\begin{tabular}{|c|c|}
\hline Probability & Equivalent Circular Area $\left(\mathrm{in}^{2}\right)$ \\
\hline 0 & $\mathrm{~A}_{\mathrm{e}}<0$ \\
\hline Approaching 0 & $\mathrm{A}_{\mathrm{e}}<0.05$ \\
\hline Low & $\mathrm{A}_{\mathrm{e}}<0.2$ \\
\hline $0.4-0.6$ & $\mathrm{~A}_{\mathrm{e}}<0.5$ \\
\hline High & $\mathrm{A}_{\mathrm{e}}<6$ \\
\hline Approaching 1 & $\mathrm{A}_{\mathrm{e}}<22$ \\
\hline
\end{tabular}

Next, consider the more mathematical evaluation. The results for the equivalent circular hydraulic area in Table D-2 were fit to several probability density functions (lognormal, Gamma, Beta, and Weibull) using two commercially available probability density function fitting routines. As the equivalent circular hydraulic area spans several decades $\left(0.05\right.$ to $\left.22 \mathrm{in}^{2}\right)$, a lognormal probability density provides the best representation of the data. Also, because of the wide range of values for the equivalent circular hydraulic area, not many probability density functions can represent the full range of the data. Thus, after fitting the data for the equivalent circular hydraulic area in Table D-2 to a lognormal probability density function, the parameters of the distribution function were slightly varied to better represent the full range of the data (i.e., $\mathrm{P}=0$ for $\mathrm{A}_{e}=0$ and $\mathrm{P}$ approaching 1 for $\mathrm{A}_{\mathrm{e}}=22$ ).

The results from Table D-3 and the best representation for the fitted probability density function are shown in Figure D-4. The data set from Table D-3 is represented by the solid squares in Figure D-4 with reasonable error bars. The solid curve in Figure D-4 represents the adjusted fitted function which best represents the data set for the valve damage states. The first and second variations shown by the other curves in Figure D- 4 represent other lognormal probability density functions that were used for sensitivity studies. Figure D- 5 provides an expanded view of the information in Figure D-4 for small equivalent circular hydraulic areas.

The adjusted fitted function (solid curve) in Figures D-4 and D-5 provides the best fit to all of the data, and in particular the best fit for the data for low equivalent circular hydraulic area. The first variation shown in Figures D-4 and D-5 provides a reasonable fit to the data for larger equivalent 
RisK ASSESSMENT OF K Basin TWELVE-INCh DRAIN VALVE FaILURE From A POSTULATED SEISMIC INITIATING EVENT

Report No. 984519-001, Rev. 2

circular hydraulic area (around 4 to $6 \mathrm{in}^{2}$ ). The second variation shown in Figures D-4 and D-5 does not provide a reasonable fit to any of the data except for the minimum and upper bound, but is used for sensitivity studies.

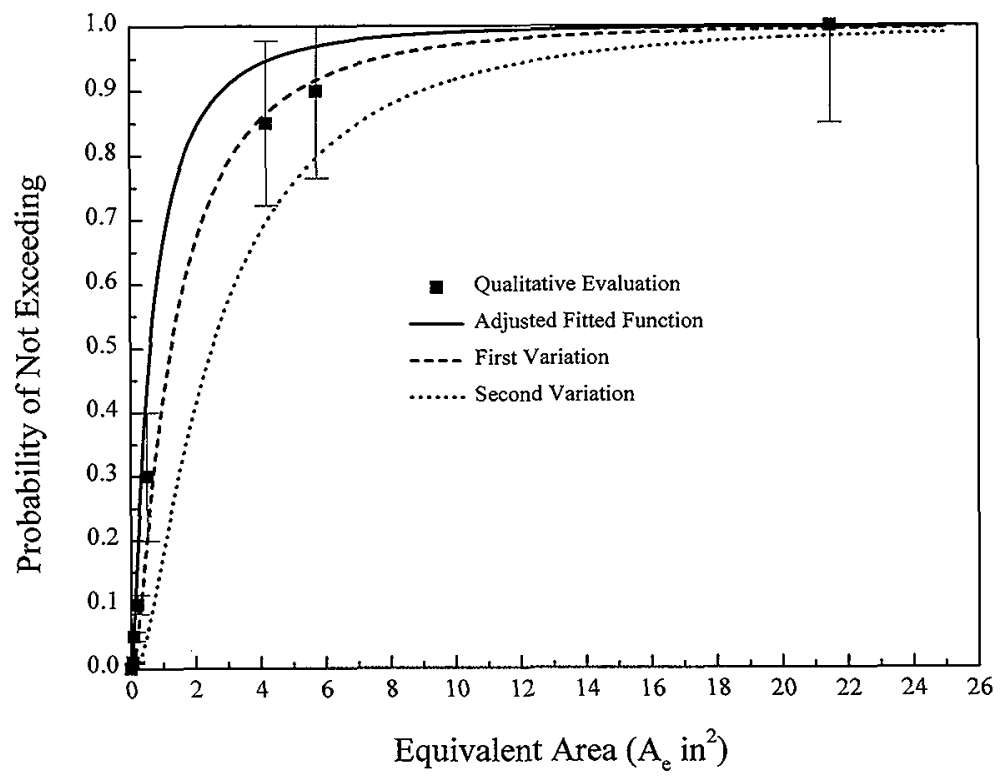

Figure D-4. Possible Cumulative Distribution Function for the Equivalent Circular Hydraulic Area for the Twelve-Inch Drain Valves. 


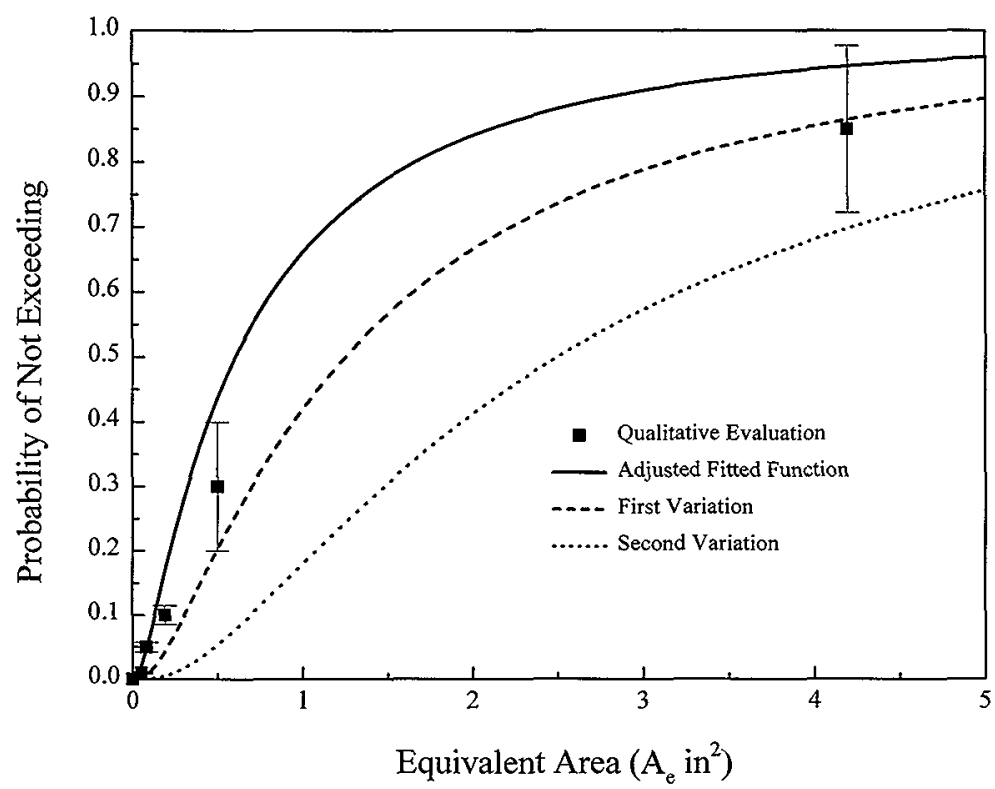

Figure D-5. Expanded View of the Possible Cumulative Distribution Function for the Equivalent Circular Hydraulic Area for Twelve-Inch Drain Valve.

The cumulative distribution functions shown in Figure D-4 for the equivalent circular hydraulic area are used to develop the probability of exceeding an initial leak rate. The cumulative distribution for the initial leak rate is obtained by extrapolating the data presented by Parsons (1998) for each equivalent circular hydraulic area provided in the cumulative distributions in Figure D-4 to determine a corresponding value for the initial leak rate. The set of corresponding values for the initial leak rate provides a cumulative distribution for the initial leak rate. The probability of exceeding an initial leak rate is then just the complementary cumulative distribution function. 
RISK ASSESSMENT OF K BASIN TWELVE-INCH DRAIN VALVE FaILURE

From A POSTULATED SEISMIC INITIATING EVENT

Report No. 984519-001, Rev. 2

SNF-3205, Rev. 0

August 10, 1998

Appendix E

Twelve-Inch Drain Valve Risk Assessment Analysis and Results

Pere




\section{E.1 INTRODUCTION}

This appendix provides the analysis of: 1) the frequency that the twelve-inch drain valve may be damage by a seismic event, 2) the distribution of the possible initial flow rate that can result from damage, and 3) a combination of these which represents the frequency of exceeding a specific initial flow rate. Thus, the results are provided as three distributions;

First, the likelihood that the drain valve may be damaged by a seismic event.

\section{Second,}

the likely initial flow rate given that the drain valve has been damaged.

Third, the frequency of exceeding a specific initial flow rate.

The evaluation process that develops these three distributions is presented in Figure 2 of the main document. This process is briefly discussed as follows.

The frequency of drain valve damage is determined from a sequence event tree that identifies the set of events that may lead to drain valve damage. This evaluation considers the likelihood that a seismic event occurs, the likelihood of structural members and debris being dislodged by the seismic event, the likelihood that the dislodged structural members and debris are near the drain valve, and the likelihood that the structural members and debris would hit the drain valve.

The distribution for the drain valve leak rate, given that the valve may be damaged, is determined from two perspectives. Both perspectives use the cumulative distribution function of equivalent circular hydraulic area that was developed in Appendix D. This distribution was developed by extrapolating initial flow rates from data presented in Parsons (1998).

In the first perspective, the cumulative distribution function for the equivalent circular hydraulic area is used directly to develop a distribution for the probability of exceeding an initial flow rate. In this perspective it is assumed that any valve damage has the same potential distribution of possible hydraulic areas.

In the second perspective, the consequence for each event that may lead to drain valve damage in the event tree is represented by the distribution function of the equivalent circular hydraulic area developed in Appendix D. In this perspective, it is also assumed that the distribution for potential valve damage is the same for each event that may lead to valve damage. However, the event frequencies and consequences for those events that may lead to drain valve damage are 
correlated to provide an overall perspective of the results.

Uncertainty analysis is used to quantify the branch-point probabilities, where the branch-point probabilities are represented by probability density functions which are bounded by physical and realistic bounds and the median value is determined by best engineering judgement. For example, branch-point probabilities are physically bounded from zero to one. A lognormal probability density function is used to represent probabilities that range over decades (e.g., 0.1 , 0.01 , or 0.001 ) with bounding limits established between a reasonably small number (e.g., $1 \times 10^{-6}$ ) and one. The median value is identified based on engineering judgement using the combined knowledge of several experts. In an uncertainty Monte Carlo analysis random branchpoint probabilities are selected from the probability distribution between the reasonably small number and one. For example, the random selection of branch-point probability values from a lognormal probability density function that is bounded from $1 \times 10^{-6}$ to 1 with a median value of 0.01 provides values that range from $1 \times 10^{-6}$ to 1 with the 50 th percentile near 0.01 .

\section{E.2 SEQUENCE EVENT TREES FOR A SEISMIC INITIATING EVENT}

A seismic event in the $100 \mathrm{~K}$ Area is considered the initiating event. Figure A-2, Figure A-3, and Figure $A-4$ are schematics that identify those structures that lie near or above the twelve-inch drain valves in the $K$ Basins. These structures consist of the canister racks, recirculation pipe, skimmer system, grating, monorails, I-Beams, joists, etc. Potential events that may occur as a result of a seismic event are the canister racks could strike the valve from lateral motion, the piping systems could become dislodged and fall directly on the drain valves or be rotated and strike the drain valve, the grating may fail and fall, and pieces of the super structure above the grating may become dislodged and fall. The analysis did not explicitly consider a complete collapse of the $\mathrm{K}$ Basin super structure, but rather considered that pieces of the super structure could become dislodged as a result of the seismic event.

The dislodged structures that fall may lie inside or outside of the zone of convergence around the drain valve. If the dislodged structures fall outside of the zone of convergence, they will most likely not impact the drain valve. However, dislodged structures that lie outside of the zone of convergence may impact other structures (e.g., the grating could impact the submerged piping) which may, in turn, lie inside the zone of convergence. Combinations of events may also occur, such as pieces of the super structure impacting the grating causing the grating to fail with both the pieces of super structure and grating falling and hitting the valve. For dislodged objects that fall inside the zone of convergence around the drain valve, they may or may not hit the drain valve. 
Figure E-1 provides a sketch of the structures that are near and/or lie above the twelve-inch drain valve based on the figures in Appendix $A$. Based on the possible events discussed above, a sequence event tree was developed to represent potential sequences that may be associated with drain valve damage. The sequence event tree is shown in Figure E-2. It should be emphasized that there may be other combinations of sequences that could be imagined, and, thus, the sequence event tree in Figure E-2 is not all inclusive. However, the sequence event tree does identify the most significant and representative events. What is important is that the sequence event tree provides a reasonable representation of the event sequences for which realistic branchpoint probability distributions are developed.

Pieces of Super Structure I $\quad$ I $\quad I \quad I$

Grating

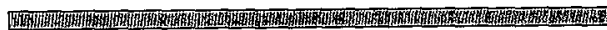

Submerged Piping \& Systems

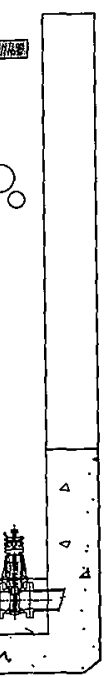

Figure E-1. Sketch of the Structures Near and/or Above the

Twelve-Inch Drain Valve (see Figures in Appendix A). 
The major end states of the sequence event tree in Figure E-2 are briefly discussed in groups in the following paragraphs. The groups are identified by the boxes shown on the right side of Figure E-2 (e.g., Impact of Racks). For each group of end states there are several end states for which there would be no impact to the drain valve and one end state for which the drain valve would be impacted. The end states for which the drain valve would be impacted are listed in Figure E-2 as "damage state" and those event sequences leading to a damage state are discussed below.

\section{- Impact of Racks (Sequence Event 3)}

Assuming that a seismic event occurs, the first major end state is where the acceleration of the canisters from the seismic motion is larger than the static friction force. The canister racks may impact the drain valve leading to a damage state.

- Impact of Piping (Sequence Event 6)

The occurrence of a seismic event could lead to failure of the recirculation pipe or the skimmer system. The falling piping and/or associated debris may lie within the convergence zone around the drain valve. If so, the falling piping and/or associated debris may strike the drain valve leading to a damage state.

- Impact of Grating (Sequence Events 9 and 12)

The occurrence of a seismic event could lead to failure of the grating. The failed grating and/or debris may (leading to Sequence Event 12), or may not (leading to Sequence Event 9) impact the piping systems. In the events leading to Sequence Event 12, the failed grating does not fail the piping systems. For both sequences, the failed grating and/or debris may lie within the convergence zone around the drain valve, and, if so, may strike the drain valve leading to a damage state (Sequence Events 9 and 12).

\section{- Impact of Piping and Grating (Sequence Event 15)}

This sequence event considers that the failed grating fails the piping systems and that both the failed grating and failed piping lie within the convergence zone and could strike the valve leading to a damage state. 


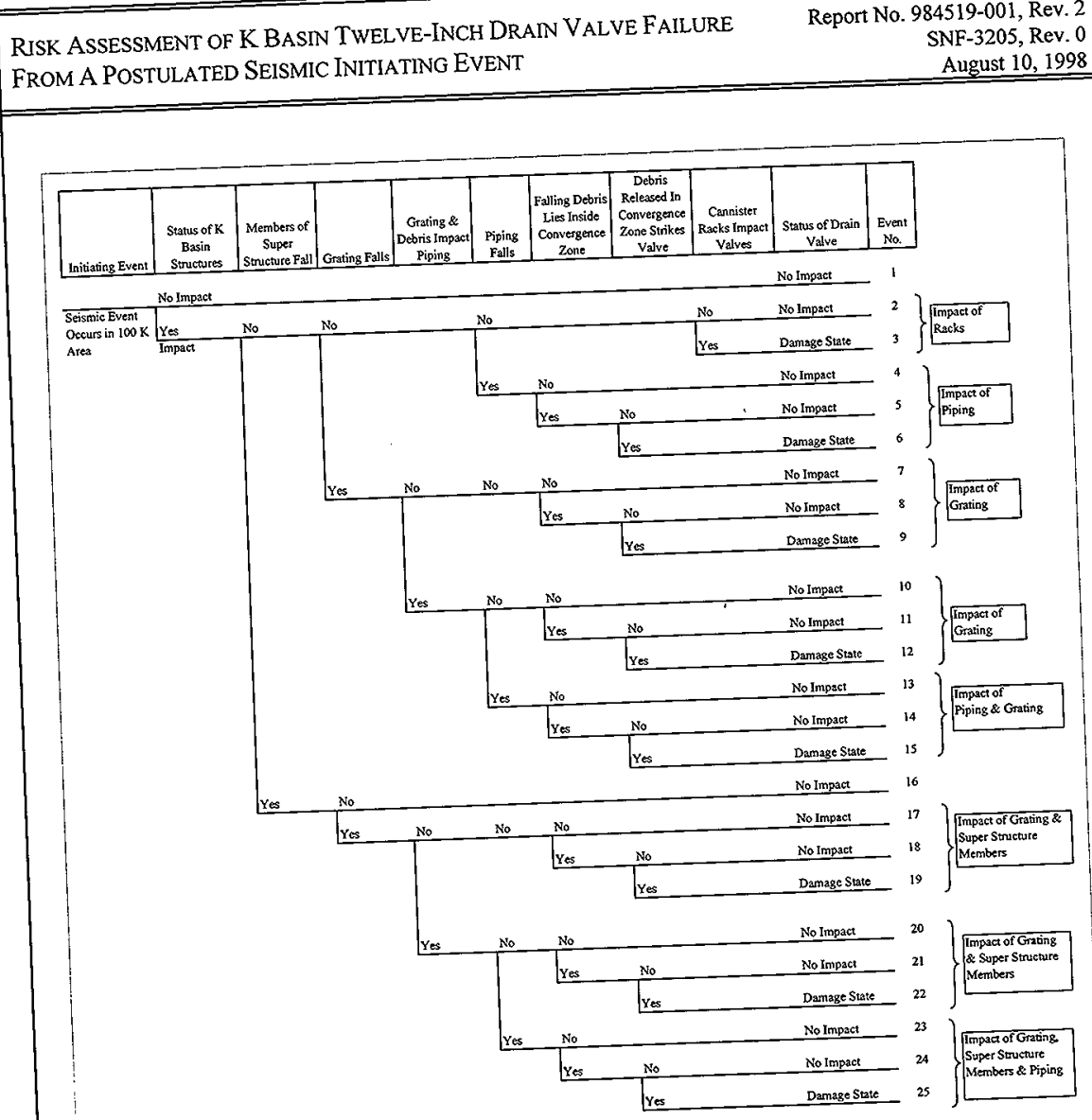

Figure E-2. Sequence Event Tree for Potential Drain Valve Damage
Given a Seismic Initiating Event. 
- Impact of Grating and Super Structure Members (Sequence Events 19 and 22)

The occurrence of a seismic event could lead to failure of members of the super structure. The falling super structure members would have to fail the grating in order to be able to strike the drain valve. The failed super structure members, grating and/or debris may (leading to Sequence Event 22), or may not (leading to Sequence Event 19) impact the piping systems. In the events leading to Sequence Event 22 the failed grating does not fail the piping systems. For both sequences, the failed super structure, grating and/or debris may lie within the convergence zone around the drain valve, and, if so, may strike the drain valve leading to a damage state (Sequence Events 19 and 22).

\section{Impact of Grating, Super structure Members and Piping (Sequence Event 25)}

This sequence event considers that the failed super structure members and failed grating fails the piping system. The sequence assumes that the failed super structure members, grating and piping all lie within the convergence zone and could strike the valve leading to a damage state.

Figure $\mathrm{E}-3$ is a sequence event tree that considers potential damage to the $\mathrm{K}$. Basin concrete structure. Since the body of the twelve-inch drain valve and the corresponding drain line are encased in concrete (reinforced concrete for the drain line), it is very unlikely that damaged concrete around the drain valve will damage the valve. Consequently Event Sequence 28 is not considered further. The important event in Figure E-3 is for potential damage of the K Basin concrete structure (Event Sequence 27) for which the structure failure frequency is given in Appendix B.

\begin{tabular}{|c|c|c|c|c|c|c|}
\hline Initiating Event & $\begin{array}{c}\text { Status of K Basin } \\
\text { Structures }\end{array}$ & $\begin{array}{c}\text { Failed Concrete } \\
\begin{array}{c}\text { Structure Fails Drain } \\
\text { Valve }\end{array}\end{array}$ & $\begin{array}{c}\text { Status of Drain } \\
\text { Valve }\end{array}$ & $\begin{array}{l}\text { Status of } \\
\text { Concrete } \\
\text { Structure }\end{array}$ & Event No. & \\
\hline & No Impact & & No Impact & No Impact & 26 & \\
\hline $\begin{array}{l}\text { Seismic Event } \\
\text { Occurs in } 100 \mathrm{~K}\end{array}$ & Yes & No & No Impact & Damage State & $27\}$ & $\begin{array}{l}\text { Impact to Basin } \\
\text { Concrete }\end{array}$ \\
\hline Area & $\begin{array}{l}\text { Basin Concrete } \\
\text { Structure Impacted }\end{array}$ & Yes & Damage State & & $28^{J}$ & Structure \\
\hline
\end{tabular}

Figure E-3. Sequence Event Tree for Potential Damage to the K Basin Concrete Structure. 
Two examples of possible events that are not explicitly considered in the sequence event tree are now discussed. The event tree did not consider specifically objects that might hit the canister racks and cause the racks to impact the drain valves. For such an event to occur, the falling object must strike the canister racks in a direction that imparts momentum to the canister racks toward the drain valves. Few objects would have the correct trajectory to strike the canister racks and impart momentum in a direction toward the drain valves. If an object had the correct trajectory, the canister racks would likely absorb part of the collision energy in the form of deformation. No collision is truly elastic, therefore, only a fraction of the falling object's kinetic energy would be transmitted into movement of the canister rack or racks. When one considers the loss of energy in the impact and the combined mass movement after impact, only large objects or small objects with large velocities would be able to transfer appreciable momentum to the canister racks. The force transferred to the canister racks would have to be large enough to overcome the frictional force that would resist any lateral movement of the canister racks. Given the weight of a canister rack (particularly, a canister rack loaded with fuel canisters), this force would have to be substantial. For an object to deliver a substantial force in the horizontal direction, the object would need to have a substantial horizontal velocity at the time of impact. As discussed in Appendix $\mathrm{C}$, however, most objects would lose much of their horizontal velocity to the effect of drag forces. Thus, most objects would be incapable of generating the necessary momentum to impart enough horizontal momentum to the canister racks to overcome the frictional force holding the rakes in place. Combining this unlikelihood with the unlikelihood of the same object having a trajectory in the correct direction relative to the canister racks and drain valves, such events were not explicitly considered in the sequence event tree.

Events involving objects that partially remain attached to structural members also were not explicitly considered in the sequence event tree. One could postulate that a pipe might break at one end, pivoting into the $\mathrm{K}$. Basin toward a drain valve. If the length of the pipe and the pivot height were correct, one could postulate that the object's free end could strike a drain valve or canister rack without the object following the parabolic path discussed in Appendix C. An object striking a canister rack and imparting momentum to the canister rack was discussed in the paragraph above. It is unlikely that an object would have the correct length, the correct height of pivot, and the correct horizontal pivoting position to allow such an event to occur. Therefore, the sequence event tree did not explicitly consider events involving objects that partially remain attached to structural members and rotate foward the drain valves. 


\section{E.3 PROBABILITY DISTRIBUTIONS USED TO REPRESENT THE SEQUENCE EVENT TREE BRANCH-POINT PROBABILITIES}

The parameters used to define the lognormal probability density functions for the branch-point probabilities are listed in Table E-1. The initial point value is given in the column marked "Value" and represents the best engineering judgement of this branch-point probability. The point value was also used as the median value for the cumulative distribution function. In Table $\mathrm{E}-1$, the lognormal mean value is written as $\ln (\mu)$ and the lognormal standard deviation is given as $\ln (\sigma)$. The bounds of the lognormal probability density functions are listed as Min and Max.

In defining probability density functions, it is often easier to consider either cumulative distribution functions or complementary cumulative distribution functions. A probability density function ( $\mathrm{pdf}$ ), given by $\mathrm{g}(\mathrm{x})$, is related to a cumulative distribution function, $\mathrm{F}(\mathrm{x})$, and a complementary cumulative distribution function, $\mathrm{G}(\mathrm{x})$, by the following relationships.

$$
\begin{aligned}
& F(x)=\int_{0}^{x} g(z) d z \\
& G(x)=\int_{x}^{\infty} g(z) d z \\
& g(x)=\frac{d F(x)}{d x}=-\frac{d G(x)}{d x}, G(x)=1-F(x)
\end{aligned}
$$

The distributions for the initiating event frequencies for the super structure, piping and basin concrete structure given a seismic event occurs were developed in Appendix B. They were shown as complementary cumulative distribution functions but are easily converted to either cumulative distribution functions or probability density functions using the relationships given in Equation E-1. The parameters used to define the probability density functions for the initiating event frequencies for the super structure (Number 1), piping (Number 2) and basin concrete structure (Number 3) are listed in Table E-1. Also developed in Appendix B was the distribution for the initiating event frequency for the start of movement of the canister racks as a result of the seismic event (Number 4) and the distribution for the branch-point probability that the canister racks will impact the drain valve (Number 11). The parameter used to define these probability density functions are also listed in Table $E-1$.

The distribution for debris that lies in the zone of convergence and strikes the drain valve was developed in Appendix C. Table E-1 lists the parameters that define this probability density 
function (Number 5). The distributions for the branch-point probabilities for the failed piping debris (Number 6 ) and the failed grating debris (Number 7) lying in the zone of convergence were developed by considering the ratio of the grating or piping cross-sectional area to the corresponding area of three zones of convergence (one for each of the three twelve-inch valves lying along the north wall).

\section{Table E-1. Parameters Used to Define the branch-Point Probability Distributions for the Twelve-Inch Drain Valve Sequence Event Trees.}

\begin{tabular}{|c|l|r|r|r|r|r|}
\hline No. & Branch-Point Probability Description & Value & $\ln (\mathrm{mu})$ & $\ln ($ sigma $)$ & \multicolumn{1}{c|}{ Min } & Max \\
\hline 1 & Initiating Event Frequency for Super Structures & $2.80 \mathrm{E}-03$ & -5.88 & 1.45 & $1.00 \mathrm{E}-06$ & 1 \\
\hline 2 & Initiating Event Frequency for Piping & $1.20 \mathrm{E}-05$ & -11.33 & 1.6 & $1.00 \mathrm{E}-08$ & 1 \\
\hline 3 & Initiating Event Frequency for Concrete Structure & $6.00 \mathrm{E}-05$ & -9.72 & 1.6 & $1.00 \mathrm{E}-08$ & 1 \\
\hline 4 & Initiating Event Frequency for Rack Movement & $1.90 \mathrm{E}-04$ & -8.57 & 1.2 & $1.00 \mathrm{E}-07$ & 1 \\
\hline 5 & Debris Released in Convergence Zone Strike Valve & $5.00 \mathrm{E}-02$ & -3.00 & 0.5 & $1.00 \mathrm{E}-06$ & 1 \\
\hline 6 & Failed Piping Debris Lies in Convergence Zone & $3.20 \mathrm{E}-01$ & -1.12 & 1.2 & $1.00 \mathrm{E}-06$ & 1 \\
\hline 7 & Failed Grating Debris Lies in Convergence Zone & $2.50 \mathrm{E}-01$ & -1.38 & 1.2 & $1.00 \mathrm{E}-06$ & 1 \\
\hline 8 & Failed Grating Damages Piping & $1.00 \mathrm{E}-01$ & -2.3 & 1.2 & $1.00 \mathrm{E}-06$ & 1 \\
\hline 9 & Grating \& Debris Impact Piping & $1.00 \mathrm{E}-02$ & -4.6 & 1.2 & $1.00 \mathrm{E}-06$ & 1 \\
\hline 10 & Failed Super Structure Members Fail Grating & $5.00 \mathrm{E}-01$ & -0.693 & 1.0 & $1.00 \mathrm{E}-06$ & 1 \\
\hline 11 & Canister Racks Impact Valves & $4.70 \mathrm{E}-02$ & -3.057 & 1.1 & $1.00 \mathrm{E}-06$ & 1 \\
\hline
\end{tabular}

The distribution for the branch-point probability for failed grating damaging the piping (Number 8) was developed by considering the ratio of the piping cross-sectional area to the area of one complete section of grating along the north side of the basin. A similar consideration was used to develop the distribution for the combination of the grating and super structure debris damaging the piping (Number 9 ).

The grating is hung by pipes from I-beams and joists (see Figures A-2 and A-3 of Appendix A). As such, during a seismic event the grating will behave like a physical pendulum under the amplified acceleration of the peak ground acceleration. This pendulum motion will be a major factor in dislodging the grating from its supports. However, if the grating is not dislodged from its supports due to the pendulum motion, there is a possibility that other super structure members that may be dislodged will be caught by the grating. In the sequence event tree of Figure E-2 this possibility is considered, however, the branch-point probability is taken as a distribution about 0.5 (Number 10 ). That is, the possibility that the grating will not fail when the super structures 
fail is considered in the sequence event tree, but the probability is not assumed to be very small.

\section{E.4 RESULTS FROM THE SOLUTION OF THE SEQUENCE EVENT TREES}

The branch-point probability density functions (Table E-1) in the two sequence event trees (Figures E-2 and E-3) were randomly varied using a Monte Carlo approach with a Latin Hypercube sampling method for 10,000 iterations. The distribution of event frequency for each of the sequence events leading to a valve damage state were recorded along with the possible consequences (equivalent circular hydraulic area and calculated initial flow rates). The sequence events that lead to a valve damage state are Sequence Events $3,6,9,12,15,19,22$, and 25 as shown in Figure E-2. The sequence event that leads to possible basin concrete damage is Sequence Event 27.

The results for the event frequencies and the event consequences were prepared as complementary cumulative distribution functions. The results for the event frequencies for each event sequence that lead to a valve damage state are presented in Figure E-4 as the probability of exceeding a frequency (1/year) of valve damage. Note that Figure E-4 provides the probability of exceeding a frequency of valve damage, but does not provide the extent of the damage should the valve be damaged. Also provided in Figure E-4 for comparison is the probability of exceeding a frequency of $\mathrm{K}$ Basin concrete structure damage due to a seismic event (Event Sequence 27). Again note that the probability of exceeding a frequency of K Basin concrete structure damage does not provide the extent of the damage should a seismic event occur. Therefore, since all of the curves in Figure E-4 are the probability of exceeding the frequency of either valve damage or concrete structure damage they can be directly compared. As expected, the frequency curve for concrete structure damage is at least equal to or slightly larger than the other frequency curves. That is, the probability of exceeding the frequency of concrete damage essentially bounds the probability of exceeding the frequency of valve damage given that a seismic event occurs. 


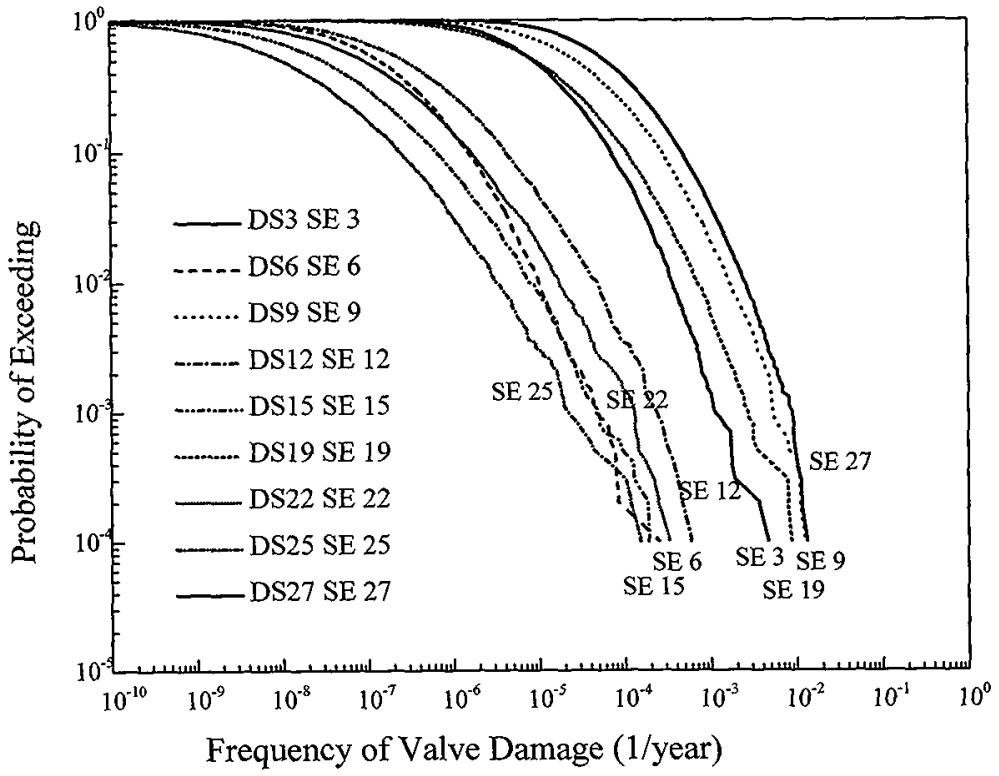

Figure E-4. Complementary Cumulative Distribution Functions for the Frequency of Drain Valve Damage and Basin Concrete Damage.

Note that Event Sequences 3, 9, and 19 have the largest distribution of event frequencies. Event Sequence 3 is related to an impact to the drain valve from the canister racks. Event Sequence 9 is related to an impact to the drain valve from the grating, and Event Sequence 19 is related to an impact to the drain valve from the grating and pieces of the super structure.

The event sequences in the sequence event tree describe different paths or sequences that may lead to drain valve damage. Therefore, the frequency of valve damage for the event sequences in 
Figure E-4 can be considered as a distribution for each value of the exceedance probability for which the 5th, 50th, and 95 th percentiles of the distribution can be determined. The results for the 5th, 50th, and 95th percentiles of the distribution for the frequency of valve damage are presented in Figure E-5.

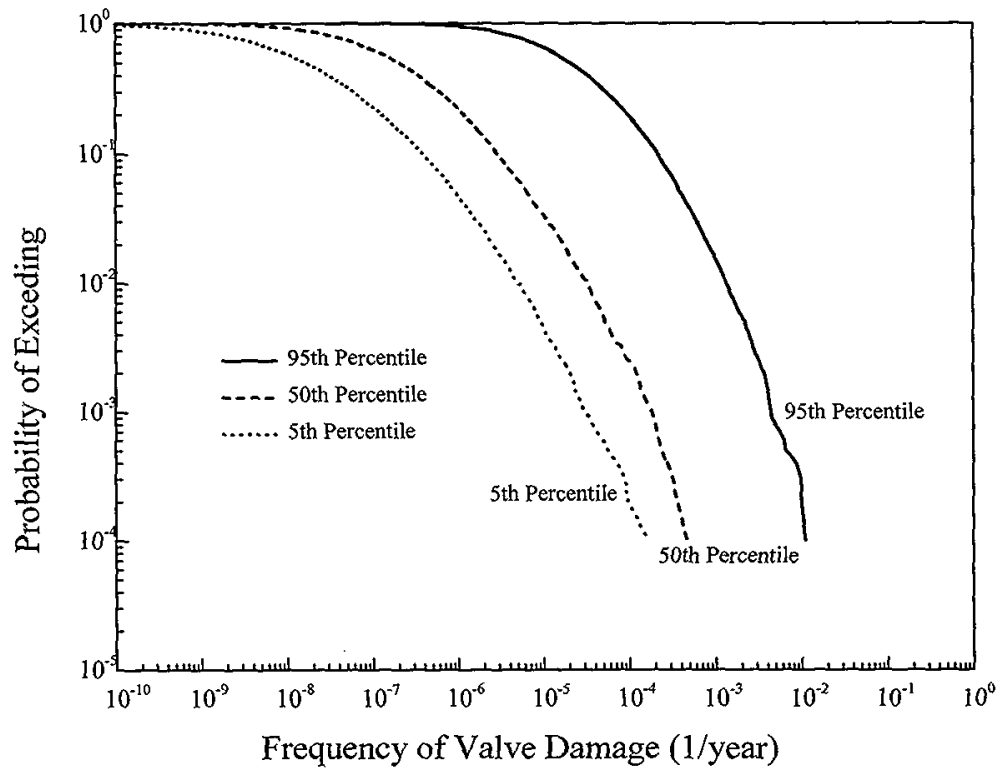

Figure E-5. Complementary Cumulative Distribution Function for the 5th, 50th, and 95th Percentiles of the Distribution for the Frequency of Drain Valve Damage.

The results of Figure E-4 and Figure E-5 are summarized in Table E-2 for each sequence event that leads to a valve damage state. In Table E-2 the percentiles (50th, 80th, 90th, and 95th) are 
presented which represent the probability that the frequency of valve damage is less than the value stated in the table for a specific sequence event. For example, for Sequence Event 3, there is a probability of 0.5 that the frequency of valve damage is less than $9 \times 10^{-6}$ per year. Similarly, for Sequence Event 3 there is a probability of 0.95 that the frequency of valve damage is less than $1 \times 10^{-4}$ per year. The expected value (EV) of the frequency of valve damage is also provided in Table E-2. The expected value is the mean valve for each sequence event. Table E-3 provides similar information for the distribution for the frequency of valve damage for the event sequences.

Table E-2. Summary of the Frequency per Year of Valve Damage for the Sequence Events.

\begin{tabular}{|c|c|c|c|c|c|c|c|c|}
\hline Percentile & SE 3 & SE 6 & SE 9 & SE 12 & SE 15 & SE 19 & SE 22 & SE 25 \\
\hline 50th & $9 \times 10^{-6}$ & $1 \times 10^{-7}$ & $3 \times 10^{-5}$ & $3 \times 10^{-7}$ & $3 \times 10^{-8}$ & $9 \times 10^{-6}$ & $9 \times 10^{-8}$ & $1 \times 10^{-8}$ \\
\hline 80 th & $4 \times 10^{-5}$ & $7 \times 10^{-7}$ & $1 \times 10^{-4}$ & $2 \times 10^{-6}$ & $2 \times 10^{-7}$ & $5 \times 10^{-5}$ & $6 \times 10^{-7}$ & $8 \times 10^{-8}$ \\
\hline 90 th & $7 \times 10^{-5}$ & $2 \times 10^{-6}$ & $3 \times 10^{-4}$ & $4 \times 10^{-6}$ & $7 \times 10^{-7}$ & $1 \times 10^{-4}$ & $2 \times 10^{-6}$ & $2 \times 10^{-7}$ \\
\hline 95 th & $1 \times 10^{-4}$ & $3 \times 10^{-6}$ & $5 \times 10^{-4}$ & $9 \times 10^{-6}$ & $2 \times 10^{-6}$ & $2 \times 10^{-4}$ & $4 \times 10^{-6}$ & $6 \times 10^{-7}$ \\
\hline EV & $3 \times 10^{-5}$ & $8 \times 10^{-7}$ & $1 \times 10^{-4}$ & $2 \times 10^{-6}$ & $4 \times 10^{-7}$ & $5 \times 10^{-5}$ & $1 \times 10^{-6}$ & $2 \times 10^{-7}$ \\
\hline
\end{tabular}

Table E-3. Summary of the Combined Distribution for the Frequency per Year of Valve Damage.

\begin{tabular}{|c|c|c|c|}
\hline \multirow{2}{*}{ Percentile } & \multicolumn{3}{|c|}{ Distribution for the Frequency per Year of Valve Damage } \\
\cline { 2 - 4 } & 5 th Percentile & 50 th Percentile & 95 th Percentile \\
\hline 50 th & $2 \times 10^{-8}$ & $2 \times 10^{-7}$ & $2 \times 10^{-5}$ \\
\hline 80 th & $1 \times 10^{-7}$ & $1 \times 10^{-6}$ & $1 \times 10^{-4}$ \\
\hline 90 th & $4 \times 10^{-7}$ & $3 \times 10^{-6}$ & $2 \times 10^{-4}$ \\
\hline 95 th & $9 \times 10^{-7}$ & $7 \times 10^{-6}$ & $4 \times 10^{-4}$ \\
\hline EV & $3 \times 10^{-7}$ & $2 \times 10^{-6}$ & $1 \times 10^{-4}$ \\
\hline
\end{tabular}


As noted earlier, the distribution for the drain valve leak rate, given that the valve may be damaged, is determined from two perspectives. First, the cumulative distribution function for the equivalent circular hydraulic area is used directly to develop a distribution for the probability of exceeding an initial flow rate. Second, the consequence for each event in the sequence event tree is represented by the distribution function for the equivalent circular hydraulic area. Both perspectives assume that the distribution for potential valve damage is the same for each event leading to valve damage. However, the event frequencies and consequences for those events that may lead to drain valve damage are correlated to provide an overall perspective of the results. The consequences are rank ordered from smallest to largest and the event frequencies are summed in a reverse order (complementary cumulative distribution) to provided either the frequency or probability of exceeding a consequence (Kaplan and Garrick 1981). Again, it is emphasized that the cumulative distribution function for the initial flow rate is calculated by extrapolating the Parson (1998) data using the distribution of equivalent circular hydraulic area.

The results from both consequence perspectives are presented in Figure E- 6 as cumulative distribution functions for the initial flow rate. The cumulative distribution functions provide the likelihood (or probability) that the initial flow rate will be less than a specified value (the probability of not exceeding). The smooth curve in Figure E- 6 is from the perspective that any potential valve damage has the same distribution for the equivalent circular hydraulic area or, correspondingly, for the initial flow rate. The discrete data points in Figure E-6 are from the second perspective where the event frequencies and corresponding consequences were rank ordered and the frequencies were cumulatively summed. Both curves in Figure E-6 are nearly identical.

Figure $\mathrm{E}-7$ is the probability density function for the consequences of an initial flow rate that corresponds to the smooth curve cumulative distribution function presented in Figure E- 6 . The median value of the initial flow rate is $56 \mathrm{gpm}$, while the average value of the initial flow rate is $107 \mathrm{gpm}$ (rounded to $110 \mathrm{gpm}$ ). 
RISK ASSESSMENT OF K BASIN TWELVE-INCH DRAIN VALVE FAILURE FROM A POSTULATED SEISMIC INITIATING EVENT

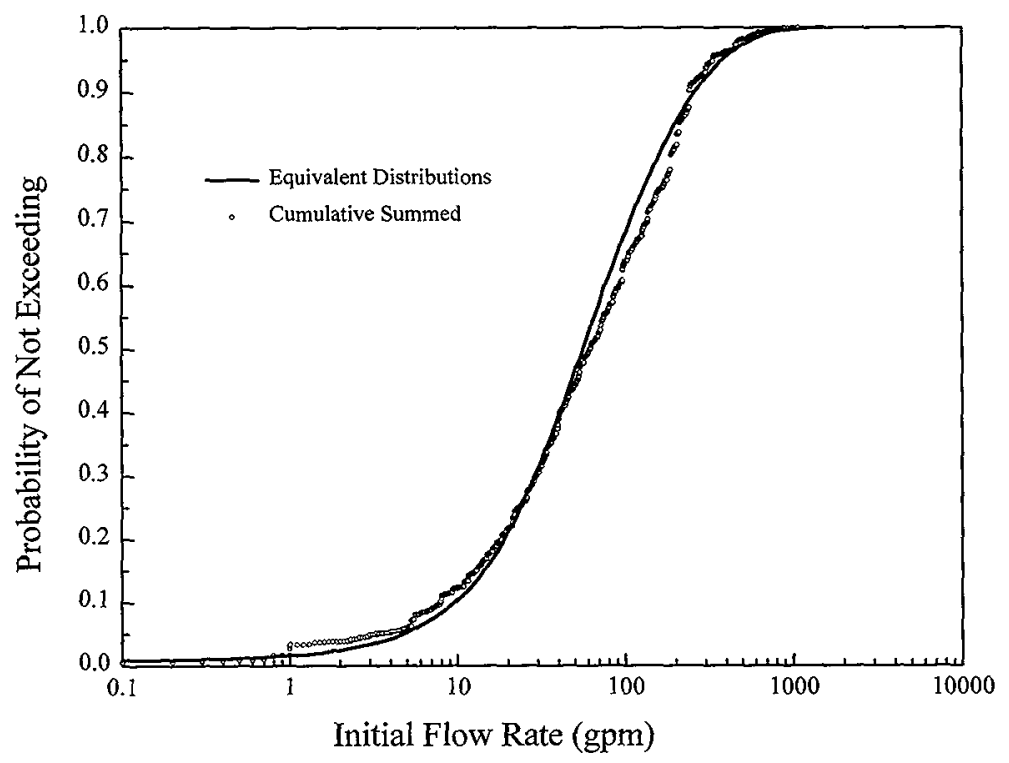

Figure E-6. Cumulative Distribution Functions for the Consequences of the Initial Flow Rate From Two Perspectives. 


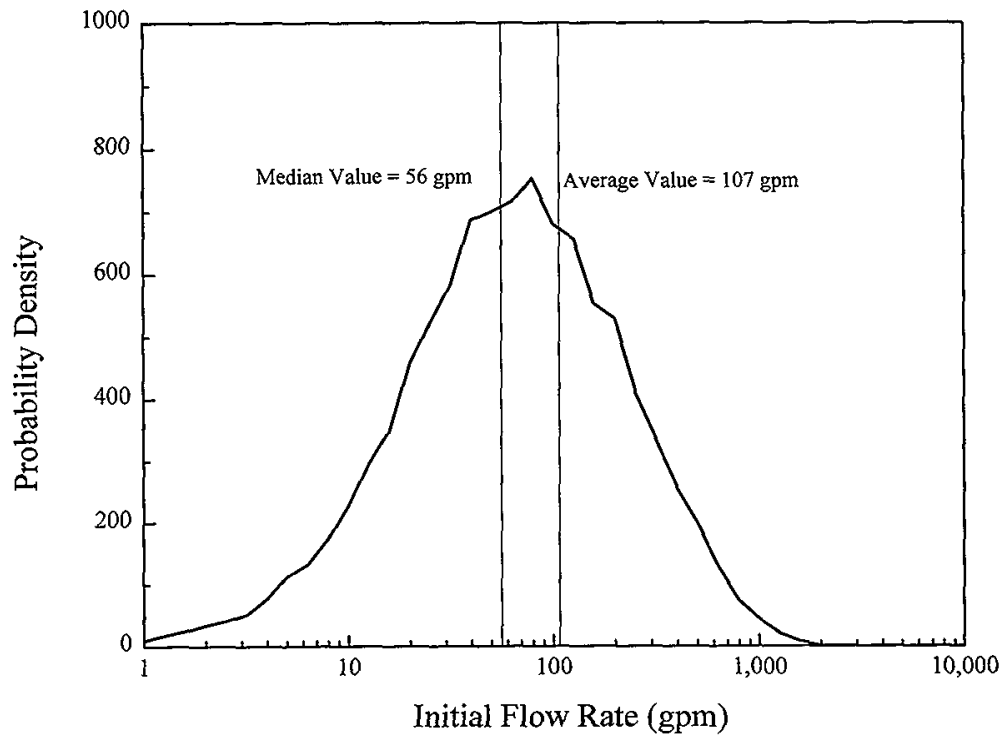

Figure E-7. Probability Density Functions for the Consequences of the Initial Flow Rate.

The results in Figures E-5 and E- 6 are summarized in Table E-4 for both distributions; the likelihood that the drain valve may be damaged by a seismic event, and given that the drain valve may be damaged, the likely leak rate. Table E- 4 provides the median value, expected or average value, and the 95 th percentile for the distribution that represents the likelihood that the drain valve may be damaged by a seismic event (in terms of the 5th, 50 th, and 95 th percentiles). Table E-4 also provides the median value, expected or average value, and the 95th percentile of the initial leak rate given that the drain valve is damaged. For example, the expected value of the 50 th percentile of the valve damage frequency is $2 \times 10^{-6}$ per year. The expected value of the initial flow rate is $107 \mathrm{gpm}$. Table $\mathrm{E}-4$ also provides the 95 th percentiles for the valve damage 
frequency and the initial flow rate. This value is interpreted, for example, that there is a probability of 0.95 that the 50 th percentile of the valve damage frequency is less than $7 \times 10^{-6}$ per year; and there is a probability of 0.95 that the initial flow rate is less than $390 \mathrm{gpm}$.

Table E-4. Summary of the Results for the Two Distributions.

\begin{tabular}{|l|c|c|c||c|}
\hline \multirow{2}{*}{} & \multicolumn{2}{|c|}{$\begin{array}{l}\text { Likelihood That The Drain Valve May } \\
\text { Be Damaged By A Seismic Event }\end{array}$} & $\begin{array}{c}\text { Given That The Drain Valve } \\
\text { May Be Damaged, } \\
\end{array}$ \\
\cline { 2 - 4 } & \multicolumn{2}{|c|}{ Frequency of Valve Damage per Year } & the Likely Flow Rate (gpm) is: \\
\cline { 2 - 4 } & 5 th & 50 th & 95 th & \\
\hline Median & $2 \times 10^{-8}$ & $2 \times 10^{-7}$ & $2 \times 10^{-5}$ & 56 \\
\hline $\begin{array}{l}\text { Expected Value } \\
\text { or Average }\end{array}$ & $3 \times 10^{-7}$ & $2 \times 10^{-6}$ & $1 \times 10^{-4}$ & 107 \\
\hline 95th & $9 \times 10^{-7}$ & $7 \times 10^{-6}$ & $4 \times 10^{-4}$ & 390 \\
\hline
\end{tabular}

From the results in Table E-4 one concludes that for a twelve-inch single drain valve, the likelihood that the drain valve may be damaged by a seismic event is reasonably small; most likely $2 \times 10^{-6}$ per year, and certainly less than $7 \times 10^{-6}$ per year. Given that a twelve-inch drain valve is damaged, the corresponding consequences, in terms of an initial flow rate, are also reasonably small; most likely $107 \mathrm{gpm}$, and certainly less than $400 \mathrm{gpm}$. One further concludes from Figure E-4 that the frequency of drain valve damage as a result of a seismic event is smaller than the frequency of $\mathrm{K}$ Basin concrete damage which may also result from a seismic event.

One may combine the results of the two distributions; the likelihood that the drain valve may be damaged by a seismic event, and given that the drain valve may be damaged, the likely leaks rate. That is, the frequency per year of valve damage (Table E-3) may be combined with the results for the probability of exceeding an initial flow rate. This is best accomplished by combining the expected values or averages for the 5th, 50th, and 95 th percentiles of the frequency of valve damage with each probability of exceeding an initial flow rate. That is, the expected values in Table E-3 for the 5th, 50th, and 95th percentiles of the frequency of valve damage are combined with the probability of exceeding a specific initial flow rate. The results are the expected frequency per year of exceeding an initial flow rate in gallons per minute. The results are presented in Table E-5. 
RISK ASSESSMENT OF K BASIN TWELVE-INCH DRAIN VALVE FAILURE

From A Postulated SEISMIC INITIATING EVENT

Report No. 984519-001, Rev.2

Table E-5. Expected Frequency of Exceeding an Initial Leak Rate for a Single Damaged Drain Valve.

\begin{tabular}{|c|c|c|c|}
\hline \multicolumn{2}{|c|}{ Distribution of the Frequency per Year } & \multirow{2}{*}{$\begin{array}{c}\text { Initial Flow Rate of: } \\
\text { (gpm) }\end{array}$} \\
\hline 5 th & 50 th & 95 th & Flow Rate $\geq 50$ \\
\hline $2 \times 10^{-7}$ & $1 \times 10^{-6}$ & $5 \times 10^{-5}$ & Flow Rate $\geq 100$ \\
\hline $1 \times 10^{-7}$ & $6 \times 10^{-7}$ & $3 \times 10^{-5}$ & Flow Rate $\geq 200$ \\
\hline $5 \times 10^{-8}$ & $3 \times 10^{-7}$ & $1 \times 10^{-5}$ & Flow Rate $\geq 300$ \\
\hline $3 \times 10^{-8}$ & $2 \times 10^{-7}$ & $8 \times 10^{-6}$ & Flow Rate $\geq 400$ \\
\hline $1 \times 10^{-8}$ & $9 \times 10^{-8}$ & $5 \times 10^{-6}$ & Flow Rate $\geq 800$ \\
\hline $2 \times 10^{-9}$ & $1 \times 10^{-8}$ & $7 \times 10^{-7}$ & Flo \\
\hline
\end{tabular}

For example, from Table E-5 one identifies that there is a 95 percent confidence that the frequency of exceeding an initial flow rate greater than $400 \mathrm{gpm}$ is less than $5 \times 10^{-6}$ per year. That is, using the information provided in Table E-4 for the 95 th percentile, one can multiply the frequency of $1 \times 10^{-4}$ per year times the probability of 0.05 (1-0.95) of exceeding an initial flow rate of $390 \mathrm{gpm}\left(1 \times 10^{-4} /\right.$ year $\times 0.05=5 \times 10^{-6} /$ year of exceeding an initial flow rate of 390 gpm, rounded to $400 \mathrm{gpm}$ ).

\section{E.5 SENSITIVITY ANALYSIS}

A sensitivity analysis was completed as part of the solution to the sequence event tree (Figure E2) to determine those variables (initiating events or branch-point probabilities) that provide the largest contribution to the uncertainty in the frequency of drain valve damage. The results are provided in Figure E-8. The largest contribution comes from the initiating event frequency for the failure of the $\mathrm{K}$ Basin super structures (54 percent). The next largest contribution to the uncertainty comes from the branch-point probability used for the failed grating and debris lying in the convergence zone ( 23 percent). The initiating event frequency for movement of the canister racks, the branch-point probability for the canister racks impacting the valve, and the branch-point probability for debris being released in the convergence zone and striking the valve contribute 8,7 and 5 percent, respectively, to the uncertainty in the frequency of drain valve damage. 
Debris Released in Convergence Zone Strike Valve

Failed Super Structure Members Fail Grating

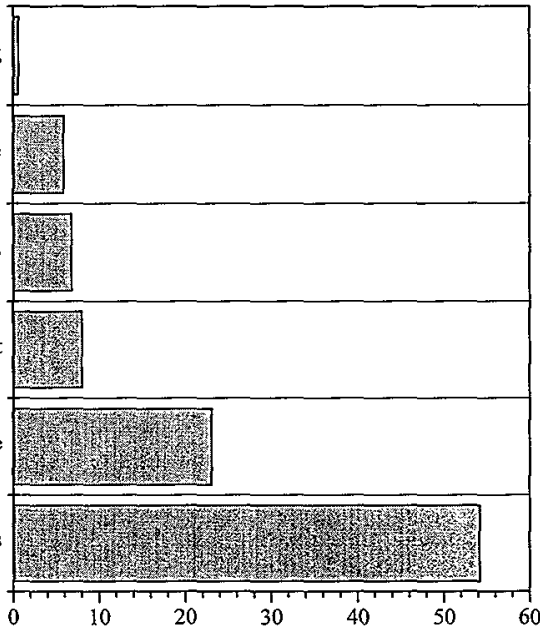

Percent Contribution

\section{Figure E-8. Contributions to the Uncertainty in the Frequency of Drain Valve Damage.}

The results provided in Figures E-6 and E-7, and in Table E-4 were for the cumulative distribution function for the equivalent circular hydraulic area (Figure D-4) that best fit all of the data (see Appendix D). However, in Appendix D two variations for the cumulative distribution function for the equivalent circular hydraulic area were also developed; one which provides a reasonable fit to the data for larger equivalent circular hydraulic area and one which only fits the minimum and upper bounds of the data. These two additional cumulative distribution functions for the equivalent circular hydraulic area were also used to evaluate the sensitivity of the initial flow rate. The results are summarized in Table E- 6 in terms of a 95 percent confidence in the frequency of exceeding the same initial flow rates provided in Table E-5. 
Table E-6. Summary of the Sensitivity of the Probability of Exceeding an Initial Flow Rate to the Distribution for the Equivalent Circular Hydraulic Area.

\begin{tabular}{|c|c|}
\hline $\begin{array}{c}\text { Distribution for Equivalent Circular } \\
\text { Hydraulic Area (Appendix D) }\end{array}$ & $\begin{array}{c}\text { Probability of Exceeding an Initial Flow Rate of } \\
400 \mathrm{gpm} .\end{array}$ \\
\hline 1 & 0.05 \\
\hline 2 & 0.11 \\
\hline 3 & 0.25 \\
\hline
\end{tabular}

For the two distributions of the equivalent circular hydraulic area identified in Table E- 6 (distribution 1 and 2) that best represent the valve damage state information (see Appendix D), there is an increase of approximately a factor of two in the probability of exceeding an initial flow rate of $400 \mathrm{gpm}$. For example, using the information in Table E- 6 and the 95th percentile for the expected frequency per year of drain valve damage in Table E-4 $\left(1 \times 10^{-4} /\right.$ year $)$ the following comparison is provided. For the cumulative distribution function for the equivalent circular hydraulic area that best fit all of the data there is a 95 percent confidence that the frequency of exceeding an initial flow rate greater than 400 gpm is less than $5 \times 10^{-6}$ per year. For the cumulative distribution function for the equivalent circular hydraulic area which provides a reasonable fit to the data for larger equivalent circular hydraulic area there is a 95 percent confidence that the frequency of exceeding an initial flow rate greater than $400 \mathrm{gpm}$ is less than $1 \times 10^{-5}$ per year (a factor of two different). This information suggests that although the initial flow rate is sensitive to the distribution used to represent the equivalent circular hydraulic area, the sensitivity is not significant (a factor of two).

\section{E.6 MULTIPLE DRAIN VALVE FAILURES}

The results in Table $\mathrm{E}-5$ are for the damage to a single twelve-inch drain valve due to a postulated seismic event. However, since there is a total of three twelve-inch drain valves located in the main basin bays along the north wall, a discussion of the potential failure of more than one drain valve needs to be addressed. The failure of each of the $K$ Basins three drain valves is treated as if the drain valves were independent, but damage was initiated by the same initiating event. 
The initiating event for drain valve damage is the same for each drain valve, namely a seismic event. However, since these drain valves are physically separated by a distance of approximately 42 to 43 feet, there is no common mode failure identified short of a catastrophic failure of the entire K Basin super structure (j.e., the sequence of events that may lead to damage of one drain valve will not be the same sequence of events that may lead to damage of another drain valve, nor are the sequences related). Furthermore, the extent of valve damage, corresponding equivalent circular area, and initial flow rate will be different and independent for each drain valve. Consequently, one can think of three distinct and independent event trees, one for each drain valve.

There are three states that represent the possibilities of drain valve damage. The first state has a single damaged and leaking drain valve; either drain valve $A$, drain valve $B$, or drain valve $C$ is damaged. The second state consists of two drain valves damaged and leaking, such as $\mathrm{A}$ and $\mathrm{B}$, $A$ and $C$, or $B$ and $C$. The third state is drain valves $A$ and $B$ and $C$ are damaged and leaking.

The corresponding results for each state are considered in terms of the Boolean "or" or "and" operator. For example for drain valve $A$ or drain valve $B$ or drain valve $C$ being damaged and leaking the Boolean "or" operator is used for the frequency of drain valve damage and the consequence is the initial flow rate for one valve being damaged. The "or" operator for the frequency of drain valve damage is computed by summing the frequencies and subtracting the cross products. Because the frequencies are small, the Boolean "or" operator can be approximated by a linear sum of the frequencies $\left(f_{A}+f_{B}+f_{C}\right)$.

For drain valve $\mathrm{A}$ and drain valve $\mathrm{B}$ damaged and leaking, the Boolean "and" operator is used for the frequency of drain valve damage by multiplying the frequencies. Because there are three possible combinations of two drain valves that may be damaged, the product of the frequencies is multiplied by three $\left(3 * \mathrm{f}_{\mathrm{A}} * \mathrm{f}_{\mathrm{B}}\right)$. The consequence is the sum of the initial flow rate for two valves being damaged. Similarly, for three drain valves being damaged the frequency of drain valve damage is the product of the three frequencies $\left(f_{A} * f_{B} * f_{C}\right)$, and the consequence is the sum of the initial flow rate for three valves being damaged. Table E-7 provides a summary of the combination for the frequency of drain valve damage and the consequence (initial flow rate). In Table E-7, the frequencies of drain valve damage are equal (i.e., $f_{A}=f_{B}=f_{C}$ ) because the damage of the drain valves is independent even though they have the same initiating event. Also, the consequences are equal (i.e., $\mathrm{C}_{\mathrm{A}}=\mathrm{C}_{\mathrm{B}}=\mathrm{C}_{\mathrm{C}}$ ) because the way each drain valve may be damaged is also independent. 
Table E-7. Different Drain Valve Damage States and Corresponding Results.

\begin{tabular}{|c|l|c|c|}
\hline States & Drain Valves Damaged and Leaking & Frequency & Consequence \\
\hline 1 & Valve $A$, or Valve $B$, or Valve $C$ & $\mathrm{f}_{A}+\mathrm{f}_{B}+\mathrm{f}_{C}$ & $\mathrm{C}_{\mathrm{A}}$ or $\mathrm{C}_{\mathrm{B}}$ or $\mathrm{C}_{C}$ \\
\hline 2 & $\begin{array}{l}\text { Valve } \mathrm{A} \text { and Valve } \mathrm{B} \text {, or Valve } \mathrm{A} \text { and Valve } \mathrm{C} \text {, or } \\
\text { Valve } \mathrm{B} \text { and Valve } \mathrm{C}\end{array}$ & $3 * \mathrm{f}_{\mathrm{A}} * \mathrm{f}_{\mathrm{B}}$ & $\mathrm{C}_{\mathrm{A}}+\mathrm{C}_{\mathrm{B}}$ \\
\hline 3 & Valve $\mathrm{A}$ and Valve $\mathrm{B}$ and Valve $\mathrm{C}$ & $\mathrm{f}_{\mathrm{A}} * \mathrm{f}_{\mathrm{B}} * \mathrm{f}_{\mathrm{C}}$ & $\mathrm{C}_{\mathrm{A}}+\mathrm{C}_{\mathrm{B}}+\mathrm{C}_{\mathrm{C}}$ \\
\hline
\end{tabular}

Using the analysis presented in Table E-7 for multiple drain valves being damaged, the expected frequency of exceeding an initial flow rate is calculated using the data in Table E-5. The $5^{\text {th }}, 50^{\text {th }}$, and 95th percentile of the expected frequency of exceeding an initial flow rate for the damage of one, two, and three twelve-inch drain valves is presented in Table E-8. Note that since the frequency for more than one drain valve being damaged is multiplied, and the consequences are added, the expected frequencies of exceeding a specific leak rate for multiple drain valve failures are several orders of magnitude less than for a single drain valve being damaged while the consequences for this condition are increased by a factor of three or less. There is a very small expectation that a common cause failure from a seismic event could potentially be cause a section of the super structure or a section of grating to fall on more than one of the three drain valves. Therefore the expected frequencies of exceeding the initial leak rate from two or three damaged valves could be greater than frequencies calculated using the products defined in Table E-7. However, the expected frequency of multiple drain valve failures would remain much less than the expected frequency of failure of a single drain valve with only a factor of three increase in the initial flow rate. In the limit there is a very small expected frequency that the initial flow rate would exceed 1980 gallons per minute (the very conservative initial flow rate shown in Appendix D). 
Table E-8. Expected Frequency of Exceeding an Initial Flow Rate for One, Two and Three Damaged Drain Valves.

\begin{tabular}{|c|c|c|c|c|}
\hline \multirow[t]{2}{*}{$\begin{array}{l}\text { Number of Drain Valves } \\
\text { Damaged }\end{array}$} & \multicolumn{3}{|c|}{$\begin{array}{c}\text { 95th Percentile of the Expected Frequency } \\
\text { (1/year) }\end{array}$} & \multirow[t]{2}{*}{$\begin{array}{l}\text { Initial Flow Rate of } \\
\text { (gpm) }\end{array}$} \\
\hline & 5 th & 50 th & 95th & \\
\hline \multirow[t]{6}{*}{1} & $6 \times 10^{-7}$ & $3 \times 10^{-6}$ & $2 \times 10^{-4}$ & Flow Rate $\geq 50$ \\
\hline & $3 \times 10^{-7}$ & $2 \times 10^{-6}$ & $9 \times 10^{-5}$ & Flow Rate $\geq 100$ \\
\hline & $2 \times 10^{-7}$ & $9 \times 10^{-7}$ & $3 \times 10^{-5}$ & Flow Rate $\geq 200$ \\
\hline & $9 \times 10^{-8}$ & $6 \times 10^{-7}$ & $2 \times 10^{-5}$ & Flow Rate $\geq 300$ \\
\hline & $3 \times 10^{-8}$ & $3 \times 10^{-7}$ & $2 \times 10^{-5}$ & Flow Rate $\geq 400$ \\
\hline & $6 \times 10^{-9}$ & $3 \times 10^{-8}$ & $2 \times 10^{-6}$ & Flow Rate $\geq 800$ \\
\hline 2 & $<1 \times 10^{-6}$ & $<1 \times 10^{-6}$ & $<1 \times 10^{-6}$ & All Flow Rates \\
\hline 3 & $<1 \times 10^{-6}$ & $<1 \times 10^{-6}$ & $<1 \times 10^{-6}$ & All Flow Rates \\
\hline
\end{tabular}


RISK ASSESSMENT OF K BASIN TWELVE-INCH DRAIN VALVE FAILURE

FROM A POSTULATED SEISMIC INITIATING EVENT
Report No. 984519-001, Rev. 2 SNF-3205, Rev, 0 August 10, 1998

\section{Appendix F}

Validation of Analysis Models 


\section{F.1 INTRODUCTION}

This appendix provides the documentation for the independent peer review and specific hand calculations to demonstrate that the model analysis is correct.

\section{F.2 INDEPENDENT REVIEW}

The report was peer reviewed by two senior ARES Corporation employees who had not participated in the analysis. One individual provided an overall technical review of the process and conclusions, while the second individual reviewed specific aspects of the models to ascertain that the models and calculations were correct and error free. A peer review checklist was used to coordinate the efforts of these individuals. Comments resulting from the overall independent technical review are documented using a Review Comment Record. Where appropriate, the report was modified in light of the review comments. Documentation of this process is attached and consists of: 1) a signed the Peer Review Checklist (Attachment F-1), and 2) the Review Comment Record denoting the disposition of the review findings (Attachment F-2).

\section{F.3 VALIDATION OF MODELS}

The calculations used in developing Appendix C and Appendix D were each checked for appropriateness and accuracy. The calculation for each equation was checked as attested by the note in the Peer Review Checklist.

The event tree model was hand checked for both the point value solutions and for one random iteration. The results of these calculations are presented in Attachment F-3.

\section{F.4 SECOND INDEPENDENT REVIEW}

The report also was peer reviewed by Dr. Michael Golay of Lexington, MA. Dr. Golay provided a short narrative that summarized his review. The narrative is provided as Attachment F-4, and is annotated with the authors' responses to some of Dr. Golay's more specific comments. 
RISK ASSESSMENT OF K BASIN TWELVE-INCH DRAIN VALVE FAILURE

From A Postulated SEISMIC INITIATING EVENT
Report No. 984519-001, Rev. 2 SNF-3205, Rev. 0 August 10, 1998

\section{Attachment F-1}

\section{Peer Review Checklist}


Document Reviewed:

Scope of Review:

\section{CHECKLIST FOR PEER REVIEW}

ARES Report No. 984519-001 DRAFT "Risk Assessment of K-Basin Twelve-Inch Drain Valve Failure from a Postulated Seismic Initiating Event” June 30,1998.

Report Sections 1.0 through 7.0, Appendices A through E. Items below indicated by $[--]$ were not in scope of review.

Previous reviews complete and cover analysis, up to scope of this review, with no gaps.

Problem completely defined.

Accident scenarios developed in a clear and logical manner.

Necessary assumptions explicitly stated and supported.

Computer codes, verification and validation, and data files documented.

Data used in calculations explicitly stated in document.

Data checked for consistency with original source information as applicable.

Mathematical derivations checked including dimensional consistency of results.

Models appropriate and used within range of validity or use outside range of established validity justified.

Hand calculations checked for errors. Spreadsheet results should be treated exactly the same as hand calculations.

Software input correct and consistent with document reviewed.

Software output consistent with input and with results reported in document reviewed.

Limits/criteria/guidelines applied to analysis results are appropriate and referenced. Limits/criteria/guidelines checked against references. Safety margins consistent with good engineering practices.

Conclusions consistent with analytical results and applicable limits. Results and conclusions address all points required in the problem statement.

Format consistent with appropriate NRC Regulatory Guide or other standards.

Review caiculations, comments, and/or notes are attached.

(See attached RCR Form)

\section{Document approved.}

[X] [ ] [ ]

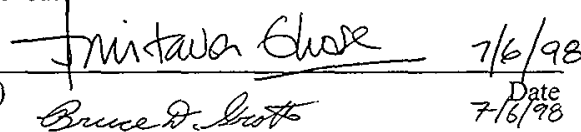

* Any calculations, comments, or notes generated as part of this review should be signed, dated, and attached to this checklist. Such material should be labeled and recorded in such a manner as to be 
RISK ASSESSMENT OF K BASIN TWELVE-INCH DRAIN VALVE FAILURE

From A POSTULATED SEISMIC INITIATING EVENT
Report No. 984519-001, Rev. 2

SNF-3205, Rev. 0 August 10, 1998

Attachment F-2

Review Comment Record 


\section{REVIEW COMMENT RECORD (RCR)}

ARES Report No. 984519.001 QRAFT "Risk Assessment of $K$-8asin Tweive-Inch Orain Valve Failure from a Postulated Seismic Initiating Event" June 30,1998.

17. Coment Sulxittal Ajproval:

\begin{tabular}{l|l}
$\begin{array}{l}\text { 6. Program/Project/ Building } \\
\text { Number }\end{array}$ & $\begin{array}{l}\text { 7. Reviewer } \\
\text { A. Ghose }\end{array}$ \\
\hline
\end{tabular}

8. Organization/Group

ARES Corporation
9. Location/Prone

(509) $946 \cdot 3300$

12.

Organization Manager (OMtional)

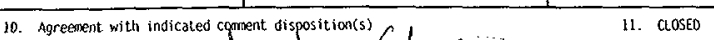

$2 / 6 / 98$

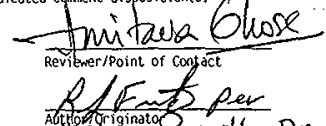
Reviewer/point of $\operatorname{cog} j$ act

Afton

13. Comment(s)/Discrepancy(s) (Provide technical justification for the corment and detailed recomendation of the action required to correct/ resolve the discrepancy/problem indicated.)

The overall risk assessment as described in the reviewed report is. in genera? comprehensive. clearly and logically presented. with appropriate assumptions. references, etc documented. This overall appraisal of the report is reflected in the attached ARES Checkl ist for Peer Review.

2 In the Executive Sumary. the likelinood of damaging a valve following a seismic event is quantified at $1 \times 10^{*}$ per year. However. there does not

14. Hold Point

(

\section{Mohlestern}

$$
7 / 6 / 98
$$

$+$

1

15. Disposition (Provide justification if nor accepted.)

Coment Accepted. No change to the document is required.

Corment Accepted. The basis is in fact Figure 6 , however, the number comes from Table E-2 and Table E-3. In these tables the number is given as $4 \times 10^{-5}$ /year for the expected value. The number was rounded in the Executive Sumary to $1 \times 10^{-5} /$ year. The Executive Summary was changed to (approximately $1 \times 10^{-5} /$ year) to denote that the number is only to one significant figure.

Coment accepted. Table 5 and Table E-8 were changed as requested.

Corment accepted. No change to the document is required.

Coment accepted. The change was made to Equation B-5 in Appendix B.

\footnotetext{
appear to be any discussion of the basis for this number, either in Section 5.0 Results, or in Appendix E. The only related results appear to be in Figure 6. from which it can be determined that there is a probability of 0.2 of exceeding the above quantified frequency of valve damage. Please provide a discussion of the basis for the valve damage frequency. as appropriate.

3 In Table 5 (Page Mumber 14) the highest leak rate is $1.980 \mathrm{gpm}$. which is the initial leak rate for Damage State 9 (worst case damage) for a sinole valve. as discussed in Appendix 0 . However. since Table 5 is providing the expected frequencies for exceeding various leak rates. for three damaged valves. compared to corresponding leak rates for one damaged valve provided in Table 3 it appears that each leak rate entry in Table 5 should be three times the corresponding leak entry in Table 3 . Thus it appears that 1.980 gom should be replaced by $2.250 \mathrm{gpm}$, and the corresponding expected frequency in the bottom row of Table 5. Please modify the table or clarify as appropriate. This coment also applies to Table E-8.

$4 \quad$ In Appendix B. the median peak ground accelerations for failure of the superstructure, the bas in concrete structure. and the piping systems. have been selected appropriately on a well documented basis, and the corresponding risk curves (Figures B.6. 8-8, and B-10. respectively) display a consistent trend i.e. decreasing risk of failure with increasing resilience to seismic load.

5 In Appendix B.6. the evaluation of seismic response of Cannister Racks on the basis of comparing the seismic lateral force to the frictional resistive force. is a rational approach. A minor correction to Equation $8-5$ is noted: the right

hand side denominator should be 'mg' and not 'mbg'

1

,

.

Per telece 16. Status 


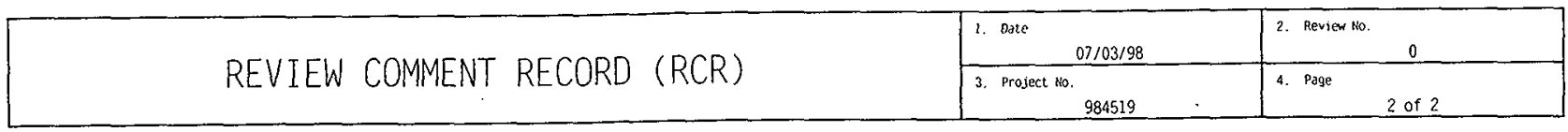

12. 13. Comment(s)/Discrepancy(s) (Provide technical justification for the comment 12. and detailed recomendation of the action required to correct/ resolve the discrepancy/problem indicated.)

14.

Hold

In Section E.2. page E-4, the label for items near the ceiling in Figure E-1

should probably be "Pieces of Sunerstructure". The statement near the bottom

of this page: "... it is very unlikeiy that damaged concrete around the valve

will damage the valve". does not appear to be self-evident. and therefore a

one-sentence elaboration. if appropriate. is needed.

\begin{tabular}{|l|l}
\hline 15. Disposition (Provide justification if NOT accepted.) & $\begin{array}{l}16 . \\
\text { Status }\end{array}$ \\
\hline Corment accepted. The change is made to Figure E-1 on Page E-4. & \\
\hline
\end{tabular}


RisK ASSESSMENT OF K Basn Twelve-INCh Drain Valve FaIlure

Report No. 984519-001, Rev. 2 FROM A POSTULATED SEISMIC INITIATING EVENT SNF-3205, Rev. 0 August 10, 1998

\section{Attachment F-3}

Calculation Notes

\begin{tabular}{ll|llll} 
ARES & PAGE NUMBER & F-8 \\
\hline CoRPATION
\end{tabular}




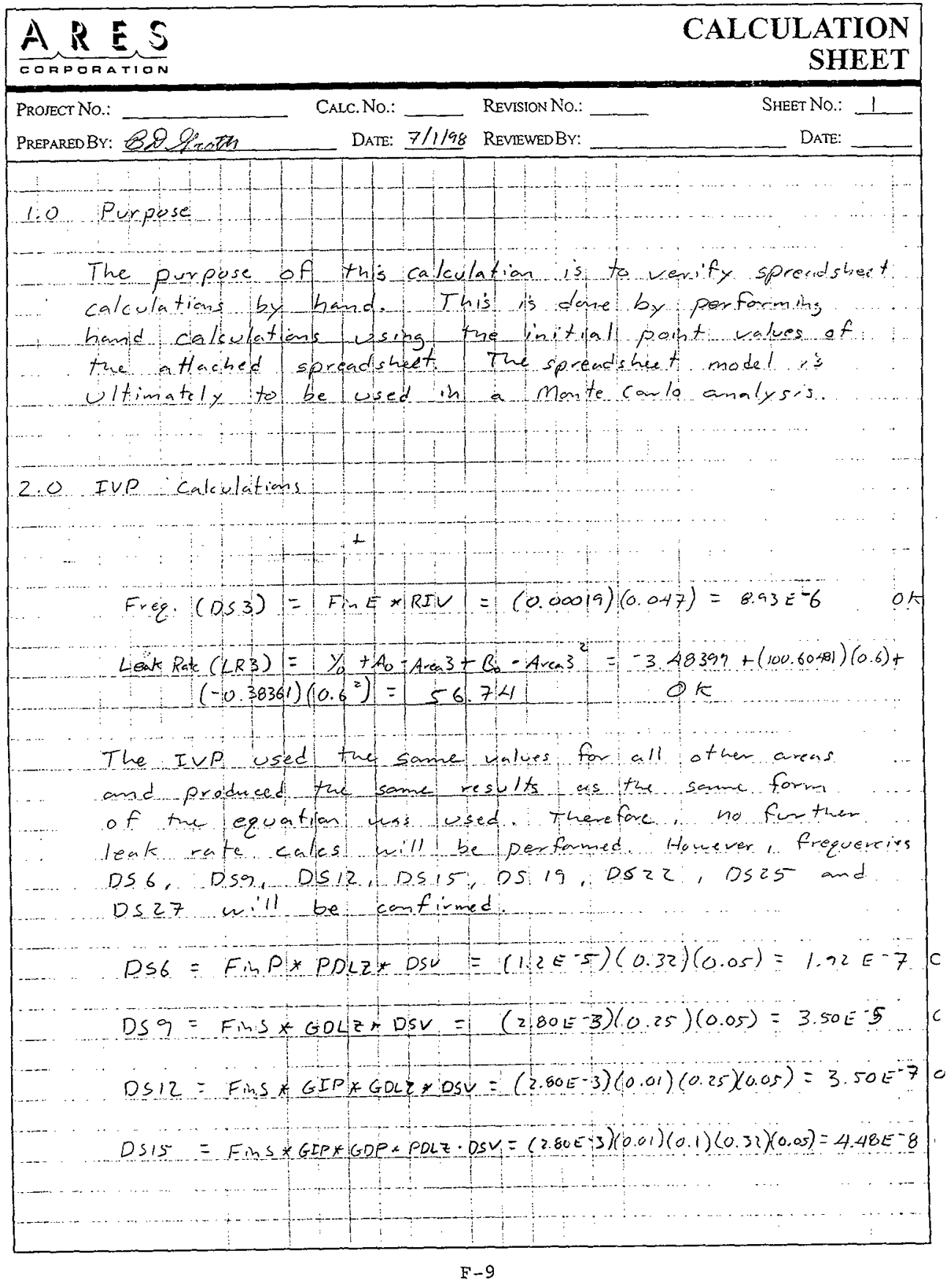




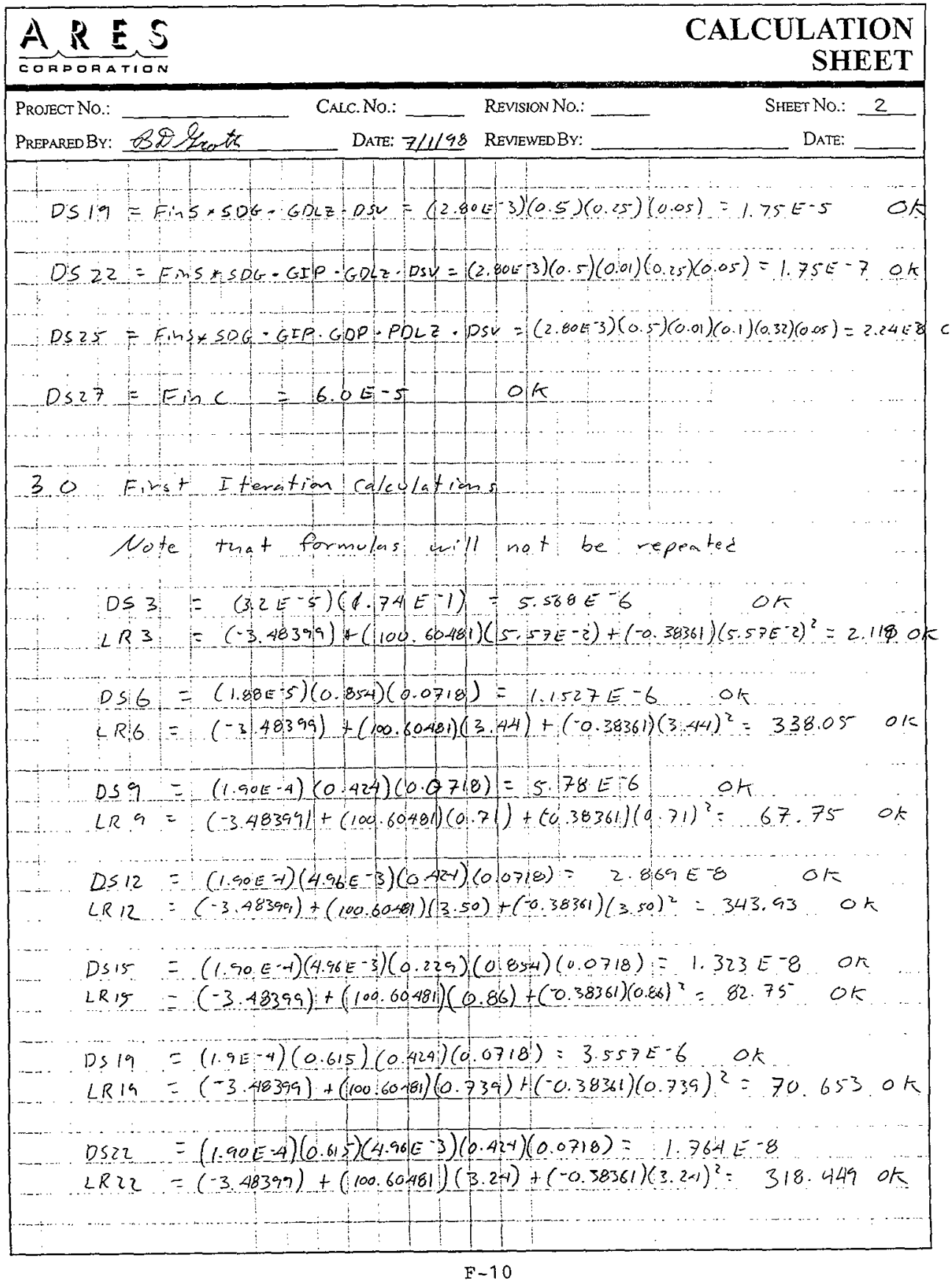




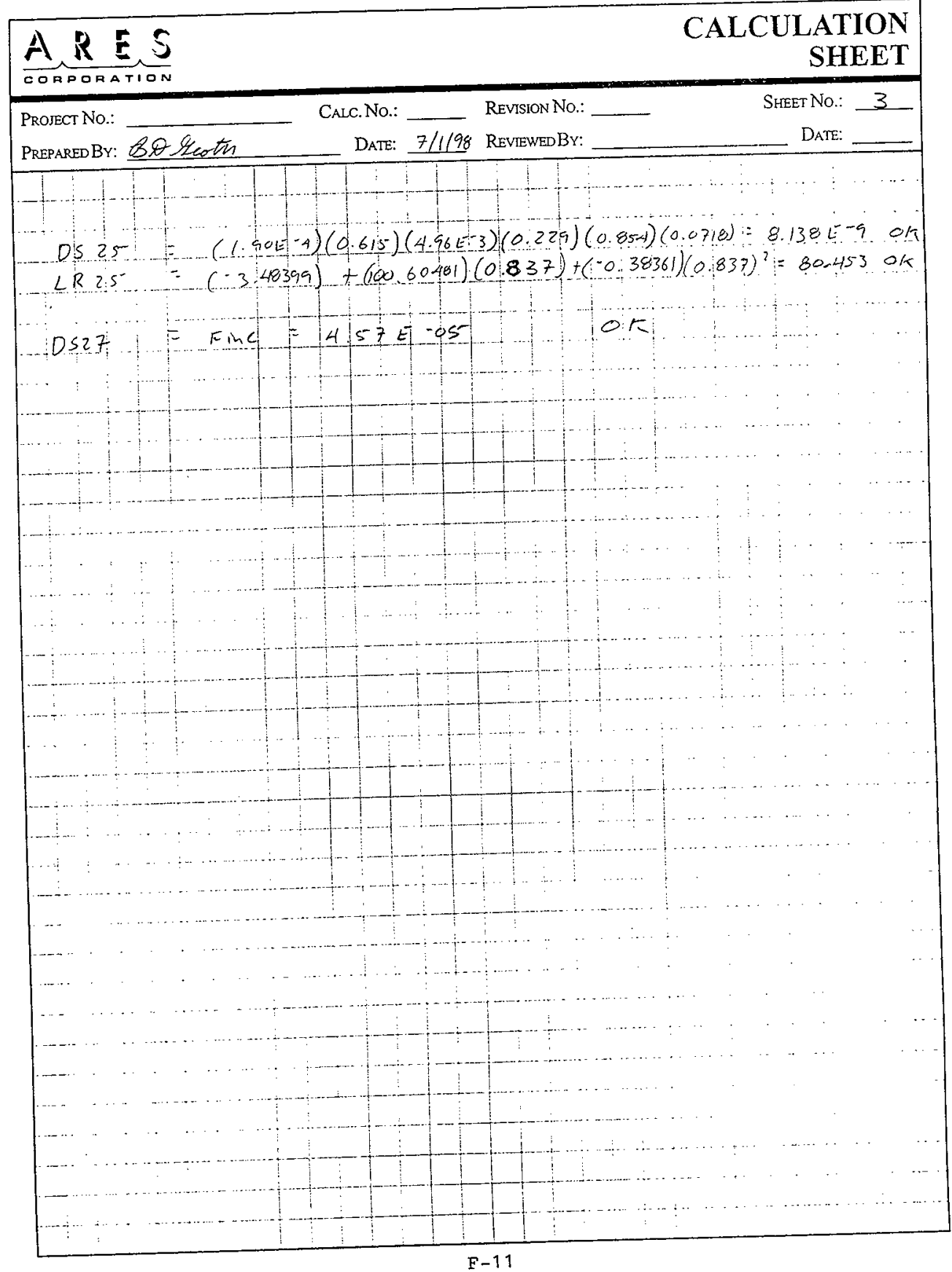




\section{(1) Initial Point Values}

Seismic Initiating Event Model for Twelve-Inch Drain Valves

Initiating Event Frequency for Super Structures

Initiating Event Frequency for Piping

Initiating Event Frequency for Concrete Structure

Initiating Event Frequency for Rack Movement

Debris Released in Convergence Zone Strike Valve

Failed Piping Debris Lies in Convergence Zone

Failed Grating Debris Lies in Convergence Zone

Failed Grating Damages Piping

Grating \& Debris Impact Piping

Failed Super Structure Members Fail Grating

Canister Racks Impact Valves

Parameters to Calculate Initial Leak Rate

Cannister Rack Impact Event

Piping Impact Event

Grating Impact Event

Grating Impact Event

Piping \& Grating Impact Event

Grating \& Super Structure Impact Event

Grating \& Super Structure Impact Event

Grating, Super Structure \& Piping Impact Event

$\mathrm{K}$ Basin Concrete Structure Damaged

\begin{tabular}{lrrrlllll} 
& \multicolumn{2}{c}{$\ln (\mathrm{mu})$} & \multicolumn{2}{c}{$\ln (\mathrm{sigma})$} & \multicolumn{1}{l}{ Min } & Max & & \\
FinS & $2.80 \mathrm{E}-03$ & -5.88 & 1.45 & $1.00 \mathrm{E}-06$ & 1 & $2.80 \mathrm{E}-03$ & -5.878136 \\
FinP & $1.20 \mathrm{E}-05$ & -11.33 & 1.6 & $1.00 \mathrm{E}-08$ & 1 & $1.20 \mathrm{E}-05$ & -11.3306 \\
FinC & $6.00 \mathrm{E}-05$ & -9.72 & 1.6 & $1.00 \mathrm{E}-08$ & 1 & $6.00 \mathrm{E}-05$ & -9.721166 \\
FinE & $1.90 \mathrm{E}-04$ & -8.57 & 1.2 & $1.00 \mathrm{E}-07$ & 1 & $1.90 \mathrm{E}-04$ & -8.568486 \\
DSV & $5.00 \mathrm{E}-02$ & -3.00 & 0.5 & $1.00 \mathrm{E}-06$ & & 1 & $5.00 \mathrm{E}-02$ & -2.995732 \\
PDLZ & $3.20 \mathrm{E}-01$ & -1.12 & 1.2 & $1.00 \mathrm{E}-06$ & 1 & $3.20 \mathrm{E}-01$ & -1.139434 \\
GDLZ & $2.50 \mathrm{E}-01$ & -1.38 & 1.2 & $1.00 \mathrm{E}-06$ & 1 & $2.50 \mathrm{E}-01$ & -1.386294 \\
GDP & $1.00 \mathrm{E}-01$ & -2.3 & 1.2 & $1.00 \mathrm{E}-06$ & 1 & $1.00 \mathrm{E}-01$ & -2.302585 \\
GIP & $1.00 \mathrm{E}-02$ & -4.6 & 1.2 & $1.00 \mathrm{E}-06$ & & 1 & $1.00 \mathrm{E}-02$ & -4.60517 \\
SDG & $5.00 \mathrm{E}-01$ & -0.693 & 1.0 & $1.00 \mathrm{E}-06$ & & 1 & $5.00 \mathrm{E}-01$ & -0.693147 \\
RIV & $4.70 \mathrm{E}-02$ & -3.057 & 1.1 & $1.00 \mathrm{E}-06$ & & 1 & $4.70 \mathrm{E}-02$ & -3.057608
\end{tabular}

$\begin{array}{lr}\text { Yo } & -3.48399 \\ \text { Ao } & 100.60481 \\ \text { Bo } & -0.38361\end{array}$

Frequency

DS3 $8.93 \mathrm{E}-06$

DS6 1.92E-07

DS9 3.50E-05

DS12 3.50E-07

DS15 4.48E-08

DS19 1.75E-05

DS22 1.75E-07

DS25 2.24E-08

DS27 6.00E-05

\begin{tabular}{|c|c|c|c|c|c|c|}
\hline \multicolumn{2}{|c|}{ Leak Rate } & \multicolumn{2}{|c|}{ Area } & & & \\
\hline LR3 & 56.7 & Area3 & $6.00 \mathrm{E}-01$ & -0.5 & 1.2 & $1.00 \mathrm{E}-02$ \\
\hline LR6 & 56.7 & Area6 & $6.00 \mathrm{E}-01$ & -0.5 & 1.2 & $1.00 \mathrm{E}-02$ \\
\hline LR9 & 56.7 & Area9 & $6.00 \mathrm{E}-01$ & -0.5 & 1.2 & $1.00 \mathrm{E}-02$ \\
\hline LR12 & 56.7 & Areal2 & $6.00 \mathrm{E}-01$ & -0.5 & 1.2 & $1.00 \mathrm{E}-02$ \\
\hline LR15 & 56.7 & Areal5 & $6.00 \mathrm{E}-01$ & -0.5 & 1.2 & $1.00 \mathrm{E}-02$ \\
\hline LRI9 & 56.7 & Areal9 & $6.00 \mathrm{E}-01$ & -0.5 & 1.2 & $1.00 \mathrm{E}-02$ \\
\hline LR22 & 56.7 & Area 22 & $6.00 \mathrm{E}-01$ & -0.5 & 1.2 & $1.00 \mathrm{E}-02$ \\
\hline LR25 & 56.7 & Area25 & $6.00 \mathrm{E}-01$ & -0.5 & 1.2 & $1.00 \mathrm{E}-02$ \\
\hline
\end{tabular}




\section{(2) One Iteration of Values}

Seismic Initiating Event Model for Twelve-Inch Drain Valves

Initiating Event Frequency for Super Structures

Initiating Event Frequency for Piping

Initiating Event Frequency for Concrete Structure

Initiating Event Frequency for Rack Movement

Debris Released in Convergence Zone Strike Valve

Failed Piping Debris Lies in Convergence Zone

Failed Grating Debris Lies in Convergence Zone

Failed Grating Damages Piping

Grating \& Debris Impact Piping

Failed Super Structure Members Fail Grating

Canister Racks Impact Valves

Parameters to Calculate Initial Leak Rate

Cannister Rack Impact Event

Piping Impact Event

Grating Impact Event

Grating Impact Event

Piping \& Grating Impact Event

Grating \& Super Structure Impact Event

Grating \& Super Structure Impact Event

Grating, Super Structure \& Piping Impact Event

$\mathrm{K}$ Basin Concrete Structure Damaged

\begin{tabular}{|c|c|c|c|c|c|}
\hline & & nu) & $\ln ($ sigma $)$ & Min & $\operatorname{Max}$ \\
\hline Fins & $1.90 \mathrm{E}-04$ & -5.88 & 1.45 & $1.00 \mathrm{E}-06$ & \\
\hline Fin $P$ & $1.88 \mathrm{E}-05$ & -11.33 & 1.6 & $1.00 \mathrm{E}-08$ & \\
\hline FinC & $4.57 \mathrm{E}-05$ & -9.72 & 1.6 & $1.00 \mathrm{E}-08$ & \\
\hline FinE & $3.20 \mathrm{E}-05$ & -8.57 & 1.2 & $1.00 \mathrm{E}-07$ & \\
\hline DSV & $7.18 \mathrm{E}-02$ & -3.00 & 0.5 & $1.00 \mathrm{E}-06$ & \\
\hline PDLZ & $8.54 \mathrm{E}-01$ & -1.12 & 1.2 & $1.00 \mathrm{E}-06$ & \\
\hline GDLZ & $4.24 \mathrm{E}-01$ & -1.38 & 1.2 & $1.00 \mathrm{E}-06$ & \\
\hline GDP & $2.29 \mathrm{E}-01$ & -2.3 & 1.2 & $1.00 \mathrm{E}-06$ & \\
\hline GIP & $4.96 \mathrm{E}-03$ & -4.6 & 1.2 & $1.00 \mathrm{E}-06$ & \\
\hline SDG & $6.15 \mathrm{E}-01$ & -0.693 & 1.0 & $1.00 \mathrm{E}-06$ & \\
\hline RIV & $1.74 \mathrm{E}-01$ & -3.057 & 1.1 & $1.00 \mathrm{E}-06$ & \\
\hline Yo & -3.48399 & & & & \\
\hline Ao & 100.60481 & & & & \\
\hline
\end{tabular}

$1 \quad 2.80 \mathrm{E}-03 \quad-5.878136$

$1 \quad 1.20 \mathrm{E}-05 \quad-11.3306$

$1 \quad 6.00 \mathrm{E}-05 \quad-9.721166$

$\begin{array}{llll}1 & 1.90 \mathrm{E}-04 & -8.568486\end{array}$

I $5.00 \mathrm{E}-02 \quad-2.995732$

$1 \quad 3.20 \mathrm{E}-01-1.139434$

$1 \quad 2.50 \mathrm{E}-01-1.386294$

$1 \quad 1.00 \mathrm{E}-01 \quad-2.302585$

$\begin{array}{lll}1 & 1.00 \mathrm{E}-02 & -4.60517\end{array}$

I $5.00 \mathrm{E}-01 \quad-0.693147$

$\begin{array}{lll}1 & 4.70 \mathrm{E}-02 & -3.057608\end{array}$

\begin{tabular}{rrrrrrrrr}
\multicolumn{2}{c}{ Frequency } & \multicolumn{2}{c}{ Leak Rate } & \multicolumn{2}{c}{ Area } \\
DS3 & $5.56 \mathrm{E}-06$ & LR3 & 2.1 & Area3 & $5.57 \mathrm{E}-02$ & -0.5 & 1.2 & $1.00 \mathrm{E}-02$ \\
DS6 & $1.15 \mathrm{E}-06$ & LR6 & 338.0 & Area6 & $3.44 \mathrm{E}+00$ & -0.5 & 1.2 & $1.00 \mathrm{E}-02$ \\
DS9 & $5.77 \mathrm{E}-06$ & LR9 & 67.8 & Area9 & $7.10 \mathrm{E}-01$ & -0.5 & 1.2 & $1.00 \mathrm{E}-02$ \\
DS12 & $2.86 \mathrm{E}-08$ & LR12 & 344.2 & Area12 & $3.50 \mathrm{E}+00$ & -0.5 & 1.2 & $1.00 \mathrm{E}-02$ \\
DS15 & $1.32 \mathrm{E}-08$ & LR15 & 82.8 & Area15 & $8.60 \mathrm{E}-01$ & -0.5 & 1.2 & $1.00 \mathrm{E}-02$ \\
DS19 & $3.55 \mathrm{E}-06$ & LR19 & 70.7 & Area19 & $7.39 \mathrm{E}-01$ & -0.5 & 1.2 & $1.00 \mathrm{E}-02$ \\
DS22 & $1.76 \mathrm{E}-08$ & LR22 & 318.2 & Area22 & $3.24 \mathrm{E}+00$ & -0.5 & 1.2 & $1.00 \mathrm{E}-02$ \\
DS25 & $8.15 \mathrm{E}-09$ & LR25 & 80.4 & Area25 & $8.37 \mathrm{E}-01$ & -0.5 & 1.2 & $1.00 \mathrm{E}-02$ \\
DS27 & $4.57 \mathrm{E}-05$ & & & & & & &
\end{tabular}


RISK AsSESSMENT OF K BASIN TwelVE-INCH DRAIN VALVE FaILURE

From A Postulated SEISMIC INITIATING EVENT

Report No. 984519-001, Rev. 2

SNF-3205, Rev. 0

August 10, 1998

Attachment F-4

Review Narrative of Dr. Michael Golay 
Review of the Report

"RISK ASSESSMENT OF K BASIN TWELVE-INCH DRAIN VALVE FAILURE FROM A POSTULATED SEISMIC INITIATING EVENT"

\author{
from \\ ARES CORPORATION \\ for \\ DE\&S Hanford, Inc. \\ Richland WA \\ performed by \\ Michael W. Golay, Consultant \\ Lexington MA
}

7 July 1998 
Summary: I have reviewed the report, "RISK ASSESSMENT OF K BASIN TWELVEINCH DRAIN VALVE FAILURE FROM A POSTULATED SEISMIC INITIATING EVENT" from ARES CORPORATION. My overall comments and subsequently my detailed comments concerning the report are reported below.

In summary I believe that the method used in the report is sound and can be used for assessing the $\mathrm{K}$ basin seismic risks. The method used has been applied in a straightforward way following the available literature, and thus, the results can be defended as having been obtained in a conventional fashion.

However, the report is not yet ready for submission as a definitive assessment of the $\mathrm{K}$ basin risks. Rather, if it were to be submitted now it could be used to describe a method for assessing these risks, but where the actual application requires further work. The most important of such requirement areas are discussed as follows.

Chain of Logic: The most important area needing further work concerns an apparent omission in the logical chain leading from the initiating earthquake to the consequent estimation of the rate of water flow from the $\mathrm{K}$ basin tank. The chain described in the report goes from the earthquake to resulting damage to structures within the tank hall, to their descent onto the three gate valves of interest.

The gap in the logic of the report occurs at this point, where one requires an estimation of the damage caused to a valve as a function of the momentum vector of each impinging object. No such estimate is apparent in the report that I have reviewed. Rather, this gap is bridged, by the authors defining a set of valve damage states, with each state having a postulated frequency of occurrence. It is unclear what role is played in the risk estimate by the report's work concerning events prior to valye damage, as these portions are not needed when one postulates respective occurrence frequencies for the valve damage states.

Subsequent to occurrence of valve damage the report describes the resulting equivalent flow area created within the valve, and the corresponding tank leakage flowrates of coolant leaving the fuel storage tank.

For the events described above the authors estimate probability density functions, and utilize versions of the Monte Carlo technique for combining the events and propagating the probability uncertainties in order to obtain the probability density function for the resulting leakage flowrate. From this result the probability of exceeding a defined maximum allowable flowrate is obtained.

Authors' Response: An effort has been made to revise the document such that the authors better explain their logic. A flow diagram was added to the main report to assist the reader in understanding what steps were followed in the analysis. Appendix D has been substantially rewritten to clarify the apparent gap in logic. To estimate "the damage caused to a valve as a function of the momentum vector" as identified by the reviewer is one approach to analyzing the problem; the authors are attempting to present another approach. The discussion of Appendix $D$ has been rewritten to explain both of these approaches and to explain why the authors pursued the second approach as opposed to that purposed by the reviewer. 
Subjective Probability Data: The probability density functions used in the risk estimates are formulated subjectively by the authors, and arguments are offered to justify their choices. This is done in order to permit utilizing rather than ignoring current, imperfect understanding of important factors in the analysis. In some instances these arguments are plausible and in others not. Overall the authors have made reasonable attempts to provide subjective probability estimates for portions of the problem where needed physical data are unavailable. Given their likely resources their efforts appear to be as good as one would reasonably demand.

However, this is an area of the report that needs to be strengthened before the report can be considered to be definitive, as the probability inputs to the analysis determine the resulting risk estimates. In order to do this it would be desirable to utilize a more formal elicitation process, capturing the knowledge of a set of qualified experts wherever a subjective expert elicitation is required by the analysis.

Authors' Response: Although a formal elicitation process was not utilized, a group of qualified and informed engineers was used in formulating the risk estimates. This information was obtained via conversations with the Spent Nuclear Fuel Program personnel versed in the valve design, operation and failure mechanisms and the basin configuration. The SNF engineers have discussed with the valve manufacturer, Crane, the failure mechanisms of the valve. The discussion of damage states in Appendix D is based on the interpretation of this information. Furthermore, the use of the uncertainty based analysis allowed the developed estimates to vary within the model. Doing so de-emphasized the impact of less than perfect estimates on the final results.

Conservative? Assumptions: The report contains various areas of risk bias that are conservative (i.e., risk-increasing) and risk reducing. Most of the observable bias used is conservative, leading to the suspicion that the report over-estimates the risks of the facility. However, one cannot demonstrate that this is the case.

Authors' Response: One of the purposes of this report was to apply risk analysis techniques to reduce the necessity of introducing additional conservatism into the analyses to compensate for uncertainty. Best engineering judgement was used to develop the risk estimates. In the opinion of the authors, the level of bias is reasonably conservative as it should be and is not excessive. But, it is indeed difficult to quantify or demonstrate that this is the case. This response required no change to document.

Sensitivity Analyses: Many of the inputs to this risk analysis are highly uncertain. The approach taken in this work utilizes an approach that permits one to use all of the available relevant information to the extent feasible, rather than the more cautious but less valuable traditional approach of ignoring any factors that cannot be quantified objectively at an acceptable level of accuracy. However, any analyses utilizing uncertain data will benefit from a sensitivity analysis (i.e., varying the parameters of the analysis in order to identify those upon which the results are most sensitive). Such an analysis is typically is performed in order to identify the portions of the work where uncertainty can be most important in influencing the analytical results. One may object that what is called for here is already being done by means of presenting the results at different confidence levels. However, that presentation does not permit one to identify the most important events or parameters in the analysis. The quality of the report would be strengthened if this were done. 
Authors' Response: Appendix $E$ has been modified to include a discussion of the sensitivity analysis the authors' performed. This analysis included analyzing the individual variables in the event tree sequences. The analysis also considered the form (type and shape) of distribution chosen for the valve damage and leak rate.

Hazards That Compete with Valve Damage in Causing Harmful Consequences: In Figs. E-2 and E-3 event trees are developed for valve damage and pool concrete damage cases, respectively. However, the analysis presented does not consider how these alternatives compete in dominating the risks of pool drainage. At some point it is plausible that the pool can become emptied regardless of the state of the valves, and that coincident pool damage events can limit the ultimate consequences that can be caused by valve damage. It would appear to be worthwhile to consider the intersection of these two classes of events in assessing the risks that can be contributed by the valves. As far as I can tell from the report that has not been done.

Authors' Response: The failure of the basin structure leading to pool drainage is considered in the K Basin Safety Analysis Report. The current design leakrate from the basin for this accident is 3,000 gallons per hour. This equates to seven days of recovery time to refill the basin before the radiation dose level begins to limit recovery activities. Comparison of the current design leakrate with predictions from the valve damage scenario does provide a measure of the intersection of the valve damage and pool concrete damage cases. However, the assessment of the relative risks from the different design basis accidents is more properly being addressed in the next revision of the SAR and is beyond the scope of this document. This response required no change to document.

Manual Recovery Actions: Finally, should the $\mathrm{K}$ basin facility become damaged and be losing water it is conceivable that manual recovery actions would be possible to mitigate or prevent harmful consequences (e.g., providing make-up water). In order to inform fully the concerned decision makers it would be valuable to take these into account in the risk analysis. Often such actions are simple and easy, with high success probabilities.

Authors' Response: Again, the failure of the basin structure leading to pool drainage is addressed in the K Basin Safety Analysis. The same emergency planning procedures and recovery actions identified for this accident are applicable to a leak from a damaged valve. However, this is considered to be outside the scope of this report and is not addressed. This response required no change to document.

Comments: In the remainder of this report I present my detailed comments concerning the report. They are divided into Major and Minor Comments, and are presented in order of occurrence in the report. The following discussion is necessarily negative, as its purpose is to identify areas of weakness and for improvement. I do not wish this tone to lead to the conclusion that the report does not deserve praise as I believe that the authors have done a good job in the first iteration of analyzing the risks of the basin-valve system.

\section{Major Comments}

Lack of Clarity: In several areas the discussion of the report is not clear, to the extent that a reader cannot be sure of the ideas being presented. Such sections need to be rewritten. Important examples include the following: pp. 8, para. 4; 9,10 (required 
legends and connection to the Appendixes are absent), p. B-7, para. 1; p. B-9; p. E-2, para. 1 and 4 ; p. E-7, para. 3 .

Authors' Response: The specific sections have been revised to clarify the meaning. In addition, an effort has been made to generally revise the document such that the authors better explain their logic. A flow diagram was added to the main report to assist the reader in understanding what steps were followed in the analysis. Text has been added to individually explain the various steps. Appendix D and E has been substantially rewritten to clarify the overall approach of the analysis.

Common Cause Failures and Combined Independent Failures: In the discussion of pp. 12 and 13, and E-15 to 17 the authors state that no common cause (i.e., dependent) failures are taken into account in the analysis (presumably because none could be identified plausibly). This treatment may arouse criticism as earthquakes are among the most important common causes of failures encountered with safety critical systems. If the earthquake were to be treated as a common failure cause one would analyze the system with each valve having the same end state (albeit governed by the probability distributions developed in the reported work). If the failures are treated as being independent a broader range of final valve system states (e.g., two failures and one success) would be considered. The authors appear to have followed the latter path.

The authors appear (from the text it is not clear what was truly done) to combine the failures of each of the tank's three valves as if they were independent, but stimulated by the same initiating event. With this formulation in a single sampling of the probability distributions each valve could either fail or succeed without regard for the fates of the others. However, it is not clear how at the end of a converged Monte Carlo analysis each valve would have substantially different consequence distribution. In actuality the discussion of the report is sufficiently unclear that it is impossible to know what the authors really did concerning coincident valve failures in their analyses.

This topic is difficult because the uncertainty distributions used in the report are used to treat both epistimic (knowledge-related) and aleatory (random) uncertainties. With the former the phenomenological reality (e.g., the set of missile momenta sufficient to cause damage of specified sort) affecting each valve should be the same, even through it is unknown by us within some range of values. The reality becomes known at the end of an event, but is treated as being governed probabilistically prior to the event.

With the latter (e.g., as in throwing dice) the process outcomes are randomly determined and will vary with every trial. If the uncertainties used in the analysis were purely epistimic one could describe the trials of the valves as having a common cause, the earthquake, with each valve then having the same damage outcome, i.e., total consequences would be thrice those of a single valve trial, and that of each valve would be the same.

If the uncertainties were purely aleatory the apparent treatment of the report would apply and some valves might fail independently during an earthquake and others might survive. However, for components involving low individual failure probabilities in the limit of many trials involving combined independent failures the two treatments will converge to approximately the same result. The discussion of the report would be clearer is it would note the points presented here and discuss how they have been treated.

Authors' Response: The failures of each of the tank's three valves are treated as if they are independent, but cased by the same initiating event. The text in Appendix $\mathrm{E}$ was modified to incorporate this comment. 
Ground Motion During Earthquakes: Earthquakes can involved destructive ground motion in all three dimensions. However, the report (pp. B-15,-16) considers only horizontal accelerations. The reasons for omitting vertical accelerations are not explained. As these can also contribute to serious damage and risks they should either be taken into account, or their omission should be justified.

Authors' Response: The text in Appendix B was modified to reflect both horizontal and vertical accelerations that can originate during a seismic event. The equations describing the movement of the canister racks have been revised to also reflect the multi-dimensional aspect of the acceleration field.

Hydrostatic and Hydrodynamic Forces: In Appendix $\mathrm{C}$ the report explicitly ignores pool-related buoyancy and hydrodynamic drag forces in evaluating the trajectories and potential impacts of objects striking the valves. For objects falling into the pool these approximations will typically result in the number of objects able to strike the valves and their momenta being overestimated. For the canisters it will cause the acceleration needed both to move a canister and the resulting displacement to be overestimated. Some of the results are not conservative. Also, the role of pool water sloshing in association with an earthquake is ignored, yet could conceivably add to risks. In the next iteration of work on seismic risks these topics would be worth addressing.

Authors' Response: The authors did not model the effects of drag and buoyancy for falling objects because it is conservative to ignore their combined effect (as pointed out by the reviewer). The authors agree that these two forces are worthy of investigation in subsequent iterations of the analysis work. In the case of the canisters, the authors did not intend to ignore these effects. Rather, these effects were accounted for by varying the coefficient of friction over a wide range. The authors have revised the text of Section B.6 to better explain this. As for the role of pool water sloshing, the authors also agree that this phenomena would be worth consideration in future analyses.

Trajectories of Objects Potentially Capable of Striking a Valve: Free missiles: A frictionless ballistic analysis is used in the report to identify the loci of objects that might strike one of the valves of interest. It likely overestimates the set of objects having this potential. However, this point is apparently moot as the momenta of these objects and the damage that they might cause to the valves upon impact are not used in the report in evaluating the outcomes of subsequent events. If this portion of the report were to be completed it would be necessary to evaluate these quantities and to link these results to their effects upon subsequent valve damage and flow states.

Authors' Response: As identified in introductory section of Appendix C, the intent of the trajectory analysis was to determine the probability of a falling object hitting the valve. Because of this, the momentum of objects at impact and the ensuing damage of the valve were not of importance to the analysis. Because the section determines (at least conservatively) the likelihood of object trajectories reaching the valve, the authors consider this portion of the document complete in its objective of determining the probability of a falling object hitting the valve.

Further, the analysis of the missiles striking the valves could be improved by taking into account, via dynamic trajectory analysis, the effects of buoyancy and drag as the objects pass through the water of the pool. Finally, when one considers the oscillatory nature of earthquake motions it would be possible also to evaluate the probability that an object at 
a particular locus would have sufficient initial momentum to strike a valve (because the acceleration on an object will oscillate not all objects at an eligible location will actually be launched so as to strike a valve).

Authors' Response: The authors feel the analysis as developed is conservative in regards to drag, buoyancy and the oscillatory nature of the initial acceleration field. The authors do feel, however, that it may be worth analyzing these effects in future analyses to determine if this conservatism could be removed.

Large connected objects: The most important omission from the trajectory analysis of objects capable of striking a valve is that the possibility is ignored of objects (e.g., an Ibeam, pipe or joist) initially outside of the "zone of convergence" participating in such impacts by virtue of being connected to objects within the "zone." Such objects are important because they could have much more momenta, and thus, greater damage potential, than those originating only from within the "zone." The reasons for these omissions are discussed in Section E.2, but not convincingly as far as I could tell.

Authors' Response: An object outside the zone striking an object inside the zone was considered in the analysis. The main document and Section E.2 have been revised to better indicate that such objects were considered.

Valve Damage States: The postulated valve damage states are plausible. However, their population is skewed toward severe damage cases. Those where a valve component is merely displaced rather than removed appear to be given too little emphasis. This treatment should be reconsidered, as the paucity of slightly damaged states may have influenced the authors to underestimate the livelihoods of low-damage states.

Authors' Response: Admittedly the analysis may underestimate the likelihood of damage in the low damage range. However, this is conservative as it implies an overall overestimation of the amount of likely damage. Unfortunately little information exists to distinguish between events leading to little damage and events leading to somewhat moderate damage. Given the lack of information, the authors chose the conservative approach. As discussed in Appendix D, variations in the cumulative distribution function of the hydraulic area were considered. These variations considered different probabilities for low-damage events.

Probabilities Corresponding to the Various Valve Damage States: The data of p. D11 are central to the ultimate risk estimates developed in the report. However, their bases are not well justified in the report. The authors may have done as much as their knowledge and resources would permit, but given the importance of these data it would be worth considering engaging a broader set of experts to refine them.

Authors' Response: Again, this information was obtained via conversations with the Spent Nuclear Fuel Program personnel versed in both the valve design, operation and failure mechanisms and the basin configuration. The SNF engineers discussed with the valve manufacturer, Crane, the failure mechanisms of the valve. The discussion of damage states in Appendix D is based on the interpretation of this information.

Valve-Basin System Event Trees: The event trees shown in Figs. E-2 and E-3 potentially involve substantially more branches than are shown. Usually a branch will be excluded from consideration in refining an event tree because of as low mean likelihood. However, this rule appears to have been used in some cases but not others (e.g., branch 
25). The rationale for what was done is not clearly explained, and should be developed more thoroughly.

Authors' Response: The sequence event tree includes branches for the direct interaction of the piping, grating, and racks with the valve. There are also branches for the interaction of the superstructure with these three components. All branches excluded from consideration in the sequence event tree are considered to have a low mean likelihood since they would involve multiple interactions of the components. Event sequence 25 is an example of this situation. It involves the combined interaction of the super structure, the piping, and grating. On Figure E4 , it can be seen to have essentially the lowest frequency of valve damage per year of the sequences calculated.

\section{Minor Comments}

Expected Number of Initiating Events: It has been reported that the intended future service life of the $\mathrm{K}$ basin facility is short (i.e., three years). Should this be the case it is unlikely that the facility will experience exactly the expected number of earthquakes during the remaining service life. Rather, the uncertainty associated with the number of earthquakes that may occur during the remaining service life should also be taken into account in assessing the seismic-related risk of the facility. The report states that the frequency distribution of peak ground acceleration is normalized to the expected number of seismic events during a year. Doing this eliminates the randomness due to earthquake occurrence from the analysis. Rather, it would be more useful to take into account the excepted service life of the $K$ basin facilities and the variability of the number of earthquakes which could occur.

Authors' Response: Currently, the prescribed methodology for evaluating the seismic risk to a facility is based on an annual basis and is independent of the facility lifetime. While it might be more useful to take into account the excepted service life of the $K$ basin facilities and the variability of the number of earthquakes which could occur, this type of analysis is outside the scope of this document.

Flow Friction: Section D.4 and D.5 discusses the flowrates associated with the valve damage states. This discussion appears to lay too much emphasis upon whether the flow is turbulent or laminar, when in reality the point may be moot. Rather, the flow path is likely to labyrinthine, and not characterized by a single regime. Also, the correlation's used for regime classification in Table D-3 appear to be for fully developed flow, and really do not apply as used. Finally, the effects upon the flow of (uncertainly configured) structures downstream of the valves are not taken into account, and may play at least as large a role in determining the actual flowrates as do the valves themselves.

Authors' Response: The work presented in Parsons (1998) considered the effects of the downstream piping. Appendix $\mathrm{D}$ has also been revised to include a summary of this document to aid the reader in understanding the extrapolated data. Appendix $\mathrm{D}$ also has been revised to deemphasis the flow regime of the individual states.

Event Probabilities: The results displayed in Table E-1 list a point "value" for the probability of each of the events used in the event tree. This appears to be the mean used in the corresponding lognormal distribution. The report does not explain how it and the corresponding standard deviation value were obtained, presumably from the results of Fig. B-5 and B-6 for the event "Members of Super Structure Fall," with similar treatments for other events. 
Authors' Response: The values in Table E-1 were derived in Appendix B, C and E. Values involving the super structure, the piping, the basin concrete, and the canister racks were developed in Appendix B. The parameter involving the probability of debris being in the convergence zone was developed in Appendix C. The probability of failed piping debris and failed grating debris lying in the zone was developed in Appendix $\mathrm{E}$. The standard deviations were developed based also on engineering judgement. After fitting a lognormal function through each mean value, the standard deviation was adjusted until the function spanned the physical range of the parameter.

Support of Gratings: From the discussion of p. E-8, para. 1 it appears that the gratings are not supported laterally. Considering their importance in providing protection for the valves from (the most energetic) falling objects, including themselves, including such support might be a case worth analyzing in the risk analysis. Should the results indicate a high risk reduction value for such support it is a modification that might be considered as a low cost way to reduce the risks that exist.

Authors' Response: The authors agree that such modification to the basin grating would be worth considering. The authors suggest this case be included in future analyses.

Clarity of Presentation: Even though the information needed to identify the event sequences discussed in Fig. E-4 are available elsewhere, a simple legend for that purpose as well as a clearer graphics would be useful with this display.

Authors' Response: Text was added to Section E-2 of Appendix E to describe the event sequences in Figure E-4 leading to a damage state. 
DISTRIBUTION SHEET

\begin{tabular}{|c|c|c|c|c|c|}
\hline \multirow{2}{*}{$\begin{array}{l}\text { To } \\
\text { Distribution }\end{array}$} & \multirow{2}{*}{\multicolumn{3}{|c|}{$\begin{array}{l}\text { From } \\
\text { Nuclear Safety }\end{array}$}} & \multicolumn{2}{|l|}{ Page 1 of 1} \\
\hline & & & & \multicolumn{2}{|c|}{ Date $9 / 24 / 98$} \\
\hline \multirow{2}{*}{\multicolumn{4}{|c|}{$\begin{array}{l}\text { Project Title/Work Order } \\
\text { SNF-3205, Rev. O } \\
\text { Risk Assessment of K Basin Twelve-Inch Drain Valve Failure From } \\
\text { a Postulated Seismic Initiating Event }\end{array}$}} & \multirow{2}{*}{\multicolumn{2}{|c|}{$\begin{array}{ll}\text { EDT No. } & 624287 \\
\text { ECN No. } & \text { N/A }\end{array}$}} \\
\hline & & & & & \\
\hline Name & MSIN & $\begin{array}{c}\text { Text } \\
\text { With All } \\
\text { Attach. }\end{array}$ & Text Only & $\begin{array}{l}\text { Attach./ } \\
\text { Appendix } \\
\text { Only }\end{array}$ & $\begin{array}{c}\text { EDT/ECN } \\
\text { Only }\end{array}$ \\
\hline $\begin{array}{l}\text { C.J. Alderman } \\
\text { S.B. Harrington } \\
\text { H.L. Johnson } \\
\text { R.G. Morgan } \\
\text { D.L. Schifferl } \\
\text { J.E. Turnbaugh } \\
\text { M.J. Wiemers } \\
\text { SNF Project Fi]es }\end{array}$ & $\begin{array}{l}\text { X3-74 } \\
\text { R3-26 } \\
\text { X3-78 } \\
\text { R3-26 } \\
\text { X3-74 } \\
\text { X3-79 } \\
\text { R3-11 } \\
\text { R3-11 } \\
\end{array}$ & $\begin{array}{l}X \\
X \\
X \\
X \\
X \\
X \\
X \\
X \\
\end{array}$ & & & \\
\hline KBASIN Project Files & $\times 3-8$ & $x$ & & & \\
\hline
\end{tabular}

